\title{
The Glasgow-Maastricht foot model
}

Citation for published version (APA):

Oosterwaal, M. (2016). The Glasgow-Maastricht foot model: development, repeatability and sources of error of a 26 segment multi-body foot model. [Doctoral Thesis, Maastricht University]. Maastricht University. https://doi.org/10.26481/dis.20161123mo

Document status and date:

Published: 01/01/2016

DOI:

10.26481/dis.20161123mo

Document Version:

Publisher's PDF, also known as Version of record

\section{Please check the document version of this publication:}

- A submitted manuscript is the version of the article upon submission and before peer-review. There can be important differences between the submitted version and the official published version of record.

People interested in the research are advised to contact the author for the final version of the publication, or visit the DOI to the publisher's website.

- The final author version and the galley proof are versions of the publication after peer review.

- The final published version features the final layout of the paper including the volume, issue and page numbers.

Link to publication

\footnotetext{
General rights Owners
rights.

- You may freely distribute the URL identifying the publication in the public portal. please follow below link for the End User Agreement:

www.umlib.nl/taverne-license

Take down policy

If you believe that this document breaches copyright please contact us at:

repository@maastrichtuniversity.nl

providing details and we will investigate your claim.
}

Copyright and moral rights for the publications made accessible in the public portal are retained by the authors and/or other copyright owners and it is a condition of accessing publications that users recognise and abide by the legal requirements associated with these

- Users may download and print one copy of any publication from the public portal for the purpose of private study or research.

- You may not further distribute the material or use it for any profit-making activity or commercial gain

If the publication is distributed under the terms of Article $25 \mathrm{fa}$ of the Dutch Copyright Act, indicated by the "Taverne" license above, 


\section{THE GLASGOW-MAASTRICHT FOOT MODEL}

Development, repeatability and sources of error of a 26 segment multi-body foot model

Michiel Oosterwaal 


\section{Colofon}

(C) Michiel Oosterwaal, Utrecht 2016. All rights reserved

\section{Cover design Douwe Hoendervanger}

Layout Michiel Oosterwaal

Printing Ridderprint B.V.

ISBN 978-94-6299-459-1 


\title{
THE GLASGOW-MAASTRICHT FOOT MODEL
}

\author{
Development, repeatability and sources of error of a 26 \\ segment multi-body foot model
}

\section{PROEFSCHRIFT}

ter verkrijging van de graad van doctor aan de Universiteit Maastricht, op gezag van de Rector Magnificus, Prof. dr. Rianne M. Letschert volgens het besluit van het College van Decanen, in het openbaar te verdedigen op woensdag 23 november 2016 om 14:00 uur.

door

\section{Michiel Oosterwaal}

Geboren op 14 maart 1983 te Rozenburg, Nederland 


\section{Promotor}

Prof. dr. L.W. van Rhijn

\section{Copromotores}

Dr. K. Meijer

Dr. M.A. Witlox

\section{Beoordelingscommissie}

Prof. dr. H.H.C.M. Savelberg (voorzitter)

Dr. R. Dubbeldam (Roessingh Research and Development)

Dr. M. Poeze

Prof. dr. N.C. Schaper

Prof. dr. ir. N. Verdonschot (Radboudumc) 


\section{Contents}

$\begin{array}{llr}\text { Chapter } 1 & \text { General introduction } & \text { Page } \\ \text { Chapter } 2 & \text { Generation of subject-specific, dynamic, multi-segment ankle and foot } \\ & \text { models to improve orthotic design: a feasibility study } & 23 \\ \text { Chapter } 3 & \text { The Glasgow-Maastricht foot model, evaluation of a } 26 & 41 \\ & \text { kinematic model of the foot } & 65 \\ \text { Chapter } 4 & \text { Test-retest repeatability of the Glasgow-Maastricht foot model } \\ \text { Chapter 5 } & \text { Non-invasive assessment of the effect of soft tissue artefacts on marker } \\ & \text { positions of kinematic foot models } & 87 \\ \text { Chapter } 6 & \text { General discussion } & 101 \\ & \text { Valorisation } & 115 \\ & \text { Summary } & 121 \\ & \text { Samenvatting } & 133\end{array}$



General introduction

CHAPTER 1

GENERAL INTRODUCTION 


\section{Chapter 1}

\section{The use of foot orthoses in reduction of foot and ankle}

\section{pain}

A quarter of the middle and old aged population suffers of foot and ankle pain on a daily basis ${ }^{1}$. A conservative treatment to reduce foot and ankle pain is the use of foot orthoses (FO's). FO's lead to reduction of foot and ankle pain, e.g. by plantar pressure reduction for metatarsalgia ${ }^{2}$ or by manipulation of the alignment in for example flatfeet ${ }^{3}$.

Finding the correct material and shape of FO's for a specific patient is not trivial. This is amongst others caused by the complexity of the foot, which consists of 26 bones and over 100 ligaments and muscles, all interacting with each other. Hence, a small difference in the plantar surface (created by the FO) can result in changed forces ${ }^{4}$ and angles in all joints of the foot and more proximal in the kinematic chain. Furthermore, the prescribed FO's should work for all types of activities (e.g. standing, walking, running, and biking). Finally, prescription is complicated by the fact that FO's are worn inside different types of shoes, while orthotic therapy mainly is based on barefoot measurements.

These aforementioned difficulties in prescribing FO's have resulted in a large variety of prescription methods. These include different theoretical principles on which the orthosis is based, different diagnostic tools and different methods to define the shape and material of the orthotic device. This could lead to different practitioners prescribing different FO's to the same patient, as shown by Guldemond et al. ${ }^{5}$ in diabetic patients. This variance can be caused by two effects: the effect of the orthotic device is depending on the prescriber, or no patient specific device is needed to achieve a therapeutic effect of orthoses. The latter effect has been disproven, since custom made FO's have a better outcome than offthe shelf alternatives ${ }^{6,7}$. It is therefore concluded that standardization in customization in prescription of FO's is needed.

Two major factors are impeding the standardisation in the prescription and design of FO's. Firstly and most importantly, it is required to improve understanding of foot biomechanics in general as well as to improve understanding of the biomechanical effect foot orthoses have on foot function. Secondly, standardization and improved protocols for the design of FO's are needed for improving the clinical decision making of the FO by the prescriber. To this end, this thesis utilises biomechanical models to improve knowledge of foot biomechanics. Foot biomechanics can for instance provide insight in how the 26 bones interact and how this complex interplay can be affected by manipulation from the outside. Understanding this mechanism furthermore helps to predict the effect of foot orthoses on reduction of foot and ankle pain. 


\section{Using computational models to improve knowledge of orthotic therapy}

Computational models have already shown to be of large benefit in the field of clinical biomechanics ${ }^{8}$. From designing a patient specific acetabular cup ${ }^{9,10}$ to determination of the time point when to use botulinum toxine in children with cerebral palsy ${ }^{11}$. All these models work on the same principle: they are mathematical descriptions of physical laws governing human locomotion. All models need an input (e.g. forces, torques, and displacements) and produce an output (pressure, motion, etc.) by performing calculations (e.g. based on Newton's laws of motion).

In the field of FO's, various kinematic models have been used to measure the effect of the orthoses, by looking at the altered gait pattern ${ }^{12,}{ }^{13}$. Validation of the effect of FO is clinically highly relevant. Nevertheless these kinematic models lack the capability in predicting the effect of the FO on foot function.

On the other hand various researchers have investigated finite element (FE) models to predict the effect of the FO in a computer simulation. Some researchers used 2D FE simulations to determine the effect of an orthosis or shoe insole on the foot. Starting 35 years ago with a static simulation of the complete foot ${ }^{14}$, via a detailed $2 \mathrm{D}$ analysis of the plantar pressure below the metatarsal heads ${ }^{15}$ or the heel ${ }^{16}$, towards a dynamic 2D simulation of the stance phase during normal gait ${ }^{17}$. Several 3D models, in which designs were based on CT-scans or MRI scans, have been developed to test the effect of total contact insoles on the full plantar surface ${ }^{18}$, or to test the effect of different FO materials 19. FE-models of the foot have also been used to test design rules for FO's, e.g. multi-plugs in pressure reducing FO ${ }^{20}$ or positioning elevations in the FO ${ }^{21}$. In conclusion FE simulations provided insights of foot biomechanics that were not known before ${ }^{22-24}$. However, none of these FE models have been used in daily clinical practice to design patient specific FO's. Although these FE-models can be of great use to investigate on a detailed level in a (quasi-) static situation. However, the high computational complexity of these models impedes the use of these highly detailed models for dynamic use. As mentioned earlier, FO's are designed for all types of activities, including walking, which require simulations of the dynamic locomotion. These simulations come at the cost of a reduced level of detail, e.g. choosing a 2D FE approach in modelling the foot and FO ${ }^{17}$. Spirka et al. ${ }^{25}$ used a highly simplified 3D model of the foot to predict a reduction in plantar peak pressures on the forefoot with a FO. By this method they overcame the 2D problem. However, due to the simplifications of this model, the correcting effects of foot orthoses could not be simulated.

On the other hand two properties of FE are of great interest in the prediction of the effect of FO's. Firstly, the predictive nature of FE-simulations, as proven in e.g. the field of hip 


\section{Chapter 1}

prosthesis is the possibility to predict the effect of an alteration on the patients functional capabilities. Secondly, the high level of detail of the plantar surface can simulate the correct plantar surface / FO interaction.

This thesis presents a modelling approach to design patient specific FO's that meets the criteria described above. The model should be dynamic to simulate dynamic roll off of the foot. On the other hand the model should be able to model a high level of detail of the plantar surface, since this is contact with the FO. Furthermore it should be able to perform patient specific simulations.

\section{Using a forward dynamic model of the foot and ankle to calculate an optimal FO}

Previous work used a forward dynamic model of the foot and ankle in an iterative loop to calculate a theoretical optimal FO ${ }^{26}$. A forward dynamic model calculates the motion of bones (segments) caused by muscle forces (boundary conditions). This specific model uses a combination of the dynamic capabilities of multibody (MB) models with the high level of detail of FE. The FO is optimised for plantar pressure distribution, so lowering the peak pressures by better distribution of the forces; see Figure 1.1 for a schematic overview of the optimisation method.

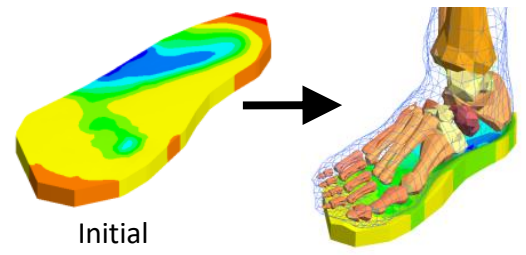

configuration

\begin{abstract}
Biomechanical
\end{abstract} simulation

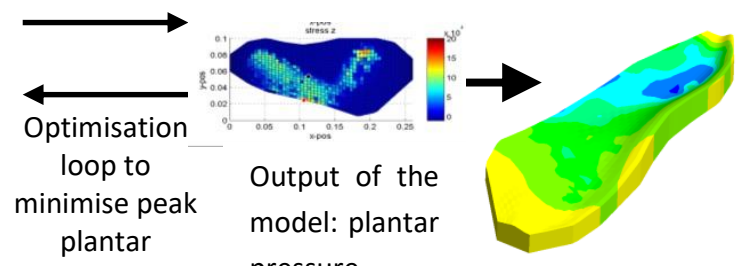

pressure distribution
Optimal configuration

Figure 1.1 Schematic overview of the method to use the forward dynamic model to calculate an optimal FO

Starting with a flat digital FO below the forward dynamic model of the foot, this digital FO is automatically adapted in several iterative steps to decrease the peak plantar pressure. Figure 1.2 shows the shape of the FO and the plantar pressure distribution at the start of the process, after step 10 and at the end of the process (step 20). 


\section{General introduction}
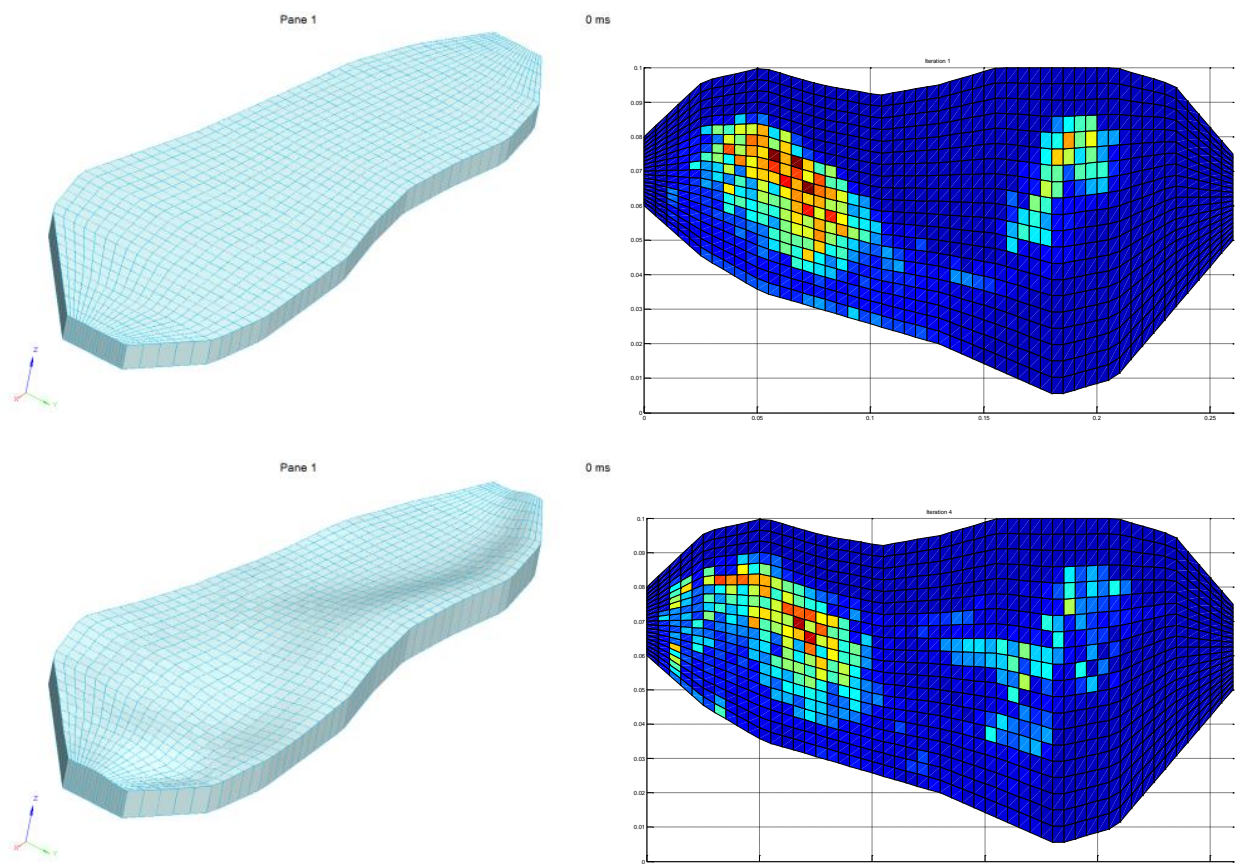

oms
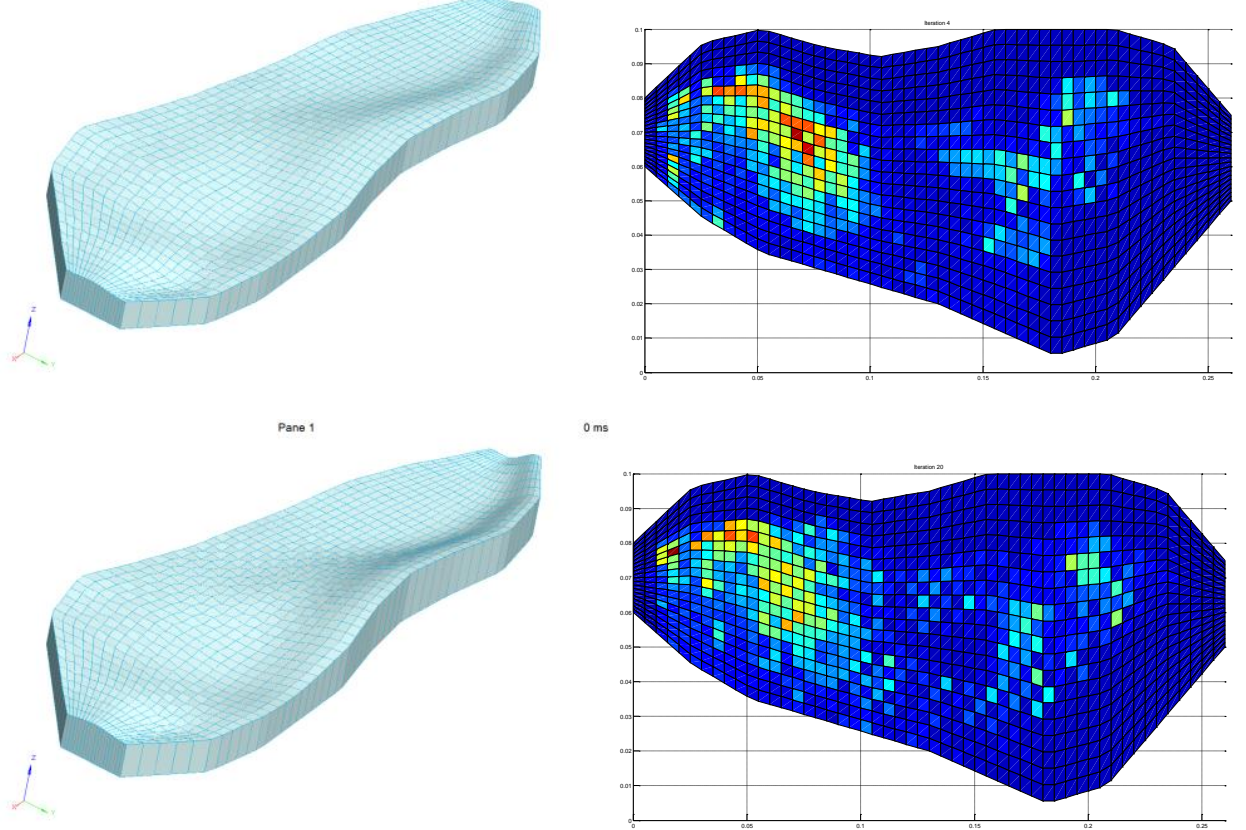

Figure 1.2 Results of the automated computation of orthotic. Left the new design; right the plantar pressure distribution. For iteration step 1, 10 and 20

This forward dynamic approach showed the ability to use computational models in the field of foot orthoses. However the approach had three major drawbacks that impeded implementation in daily clinical practice.

1) The simulated dynamic motion is a drop of the foot. This motion is a unnatural movement and clinically irrelevant, since maximum peak pressures won't occur during a semi-static loading. Dynamic motion causes higher pressures caused by the acceleration and deceleration of the foot. Simulating physiological relevant 


\section{Chapter 1}

motions with the ankle and foot model is currently not possible, the required input parameters, muscle forces or joint torques, are unknown.

2) The model of the foot and ankle is based on an average (cadaver) foot ${ }^{27}$. Validation of the output of the simulations and testing of the optimised FO is therefore not possible.

3) The geometry and mechanical properties of the forward dynamic model of the foot and ankle is based on the anatomy of a healthy subject. However, the FO with optimal plantar pressure distribution is clinically used for pathological feet. E.g. for diabetic patients, whose feet are different in many anatomical structures. It is therefore necessary to develop a model of the foot and ankle describing a subject with a clinically relevant pathology.

In conclusion, the previous presented forward dynamic model showed a method to automatically calculate optimal FO design. However, before the model could be used in daily clinical practice the model should be able to simulate dynamic motion. In addition a patient specific configuration is required for validation purposes and patient specific simulations.

\section{Improving the input parameters by coupling with a kinematic and inverse dynamic model}

Simulation of a clinically relevant motion requires realistic forces or joint torques as a boundary condition for the forward dynamic model. Currently, no non-invasive method is available to measure these forces ${ }^{28}$. An alternative method that calculates joint torques is the use of an inverse dynamic model ${ }^{29}$. Such a model uses motion as an input and predicts the muscle forces to generate this motion. The motion that this inverse dynamic model uses as an input can be measured using a kinematic model. By tracking markers attached to the skin, this kinematic model calculates the motion of the bones that are generating the motion of the skin-based markers. A visual representation of this chain of models is given in Figure 1.3.

Using this chain of models also solves the second problem of the approach, the validation problem. Since the model will use human experiments as an input, validation with on actual subjects is possible. The problem on the generalizability, i.e. the differences in anatomy between pathological and healthy feet, which affect the outcome, can be solved by using a model that is capable of modelling variations in anatomy. This commonly is solved by scaling a general model into patient specific models, via predefined rules. These rules are mathematical equations that are dependent on demographic variables, such as length, height and mass, gender, age ${ }^{30}$ and geometry of body parts ${ }^{31}$. More specific 
scaling can be driven by medical imaging of the subject via e.g. MRI ${ }^{32}$. Since anatomical variations can be in all joints, ligaments and muscles, input on a very high level of detail is necessary. More specifically, the forces required to move the joints between all 26 bones of the foot are required, these forces can be for example torques or muscle forces.

All in all using the output of kinematic and inverse dynamic models as input for the forward dynamic model is a solution for the validation, scalability of the forward dynamic model. Most importantly the chain of kinematic, inverse and forward dynamic models leads to valid dynamic motion of the forward dynamic model.

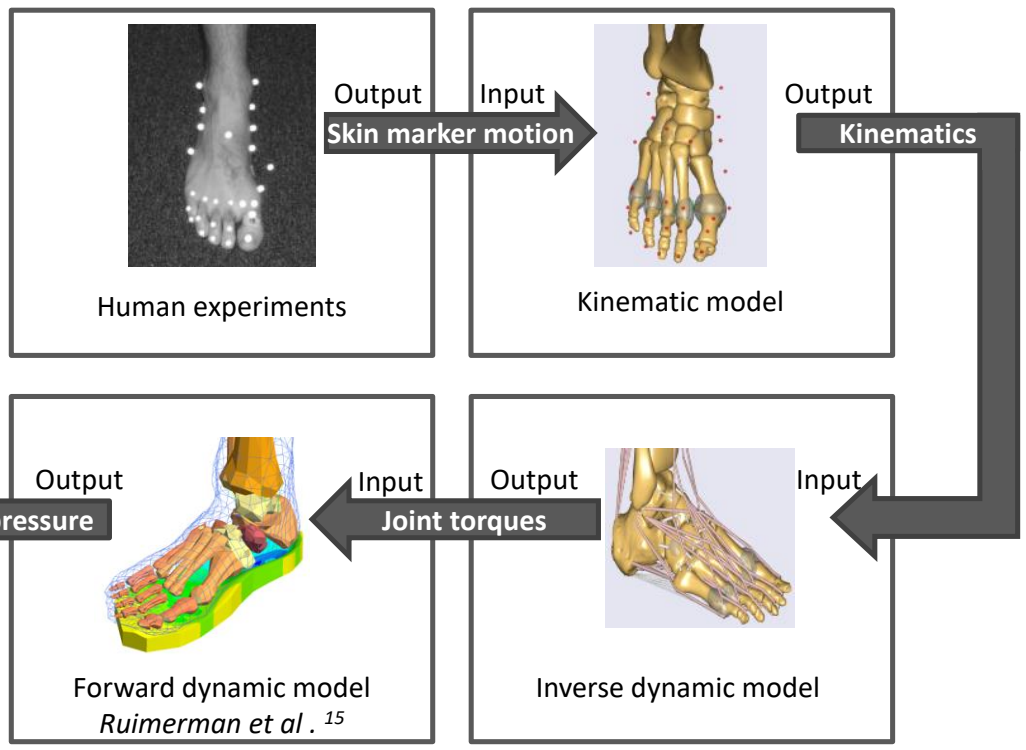

Figure 1.3 Chain of models to come from a patient specific measurement to the prediction of the effect of an orthotic device on (e.g.) plantar pressure distribution

\section{Existing kinematic foot models do not have sufficient segments to use as an input for the forward dynamic model}

From the previous paragraphs it is clear that the essential step towards an applicable forward dynamic model is the definition of a suitable kinematic foot model.

Kinematic foot models have been developed over the past years from one single rigid segment to more complex models. More precisely, three dimensional (3D) foot modelling started with a single rigid segment foot model. An example is the 'Helen Hayes foot model' ${ }^{33}$, which is used to asses ankle motion during gait ${ }^{34}$. Although this model is 


\section{Chapter 1}

relatively easy to use and analyse, it does not provide information about intrinsic foot motion during gait. Furthermore, since this model only allows motion in the ankle joint, motion of other joints is wrongly allocated to the ankle. Hence, this oversimplified model may lead to biased results. Less simplified model of the foot might resolve these problems by dividing the foot into multiple segments these models allow motion within the foot ${ }^{35}$, 36 .

\section{Existing multi-segment foot models and their applications in foot biomechanics and clinical research}

To date over 15 multi-segment foot models ${ }^{37,38}$ have been developed. The difference between these models is the location of the markers on the foot and in what way the foot is divided in the different segments. This variance in segments is in the number of segments, ranging from two ${ }^{39-41}$ to eight segments in the foot ${ }^{42}$, and in the composition of these segments. These multi-segment foot models have provided insight in biomechanics of several foot pathologies.

A commonly used model is the Milwaukee foot model ${ }^{43,44}$, in which the foot is divided into three segments: hindfoot (talus, navicular and calcaneus), forefoot (cuboid, cuneiforms and metatarsals) and hallux ${ }^{45}$. With the Milwaukee foot model, Khazzam et al. ${ }^{44}$ found decreased range of motion in the ankle joint for patients with ankle arthrosis.

Woodburn et al. ${ }^{46}$ showed reduced range of motion in the foot for patients with rheumatoid arthritis, using the Oxford foot model. The Oxford foot model ${ }^{47}$ also is a three segment foot model, however it divides the foot in different segments compared to the Milwaukee foot model: hindfoot (talus, calcaneus), forefoot (metatarsals), and hallux ${ }^{48}$. With the Oxford foot model, van Hoeve et al. ${ }^{49}$ showed a relation between a commonly used parameter from CT images and range of motion after calcaneal fractures.

The Leardini foot model is developed with a particular clinical focus on the frontal plane alignment of the hindfoot and the transverse and sagittal plane alignment of the forefoot 46. The included segments are hindfoot (calcaneus), midfoot (navicular, cuneiforms, cuboid) and forefoot (metatarsals) ${ }^{36,48}$. It has been used to study biomechanical parameters for numerous clinical purposes, e.g. the effect of the rotational axis of a hinged ankle foot orthosis 50 and the effect of surgical treatment on improving foot kinematics in children with idiopathic flatfeet ${ }^{51}$.

In conclusion, many kinematic models of the foot and ankle have been developed. The use of these models in further understanding of foot biomechanics is increasing. Furthermore these models have shown their ability to be used in investigating specific joints and pathologies. 


\section{Sources of errors in kinematic models of the foot}

As all models, kinematic models of the foot are a simplified representation of reality and are therefore sensitive to errors. For kinematic foot models an important source of error is the effect of the assumptions made to calculate joint kinematics from the motion of markers on the skin ${ }^{52}$, i.e. soft tissue artefacts (STA) ${ }^{53,54}$ and the rigid body assumption ${ }^{55}$. All kinematic models are sensitive to STA ${ }^{52}$, caused by the soft tissue between marker and underlying bone. STA are the artefacts arising from the relative movement of the skin with respect to the bones. In literature many types of methods have been presented to deal with STA for different parts of the human body. These methods can be divided in two groups, STA compensation and STA quantification ${ }^{52}$. STA compensation is a method to compensate for errors and STA quantification is used to measure the size of the error. A commonly used STA compensation method is marker clustering, in which a large number of markers are positioned on one segment and this leads to a smaller effect-size of STA on the calculated kinematics ${ }^{56}$. Another compensation method is to choose skin marker positions far from joint areas, since it is shown that skin markers in the vicinity of the joint would lead to higher STA ${ }^{54}$. Furthermore, Karlsson, Tranberg ${ }^{57}$ suggested that thickness of soft tissue could be important, since more underlying soft tissue could provide a less rigid base for the markers.

Several methods have been used to quantify STA in foot and ankle models. ${ }^{58-64}$. By combining surgical applied bone pins and skin mounted markers, Nester et al. ${ }^{58}$ found a maximal effect of $10^{\circ}$ in kinematics. By indirect measurement of relative marker motion within a kinematic segment, Chen et al. ${ }^{59}$ used a motion capture system to measure STA. Alternatively, STA quantification can be measured without surgical intervention by using imaging techniques such as MRI ${ }^{60}$, fluoroscopy ${ }^{61-63}$ or x-ray ${ }^{64}$ to quantify STA.

Another source of error in kinematic foot models is caused by the rigid body assumption. All existing kinematic models used the rigid body assumption. This is the assumption that two separate bones can be modelled as one single rigid segment ${ }^{55}$. While motion between foot bones has been shown in cadaver and bone pin studies, these are studies in which healthy volunteers have been surgically equipped with pins in the foot bones with a tracking marker on top of this pin. For example, an in vitro study of Nester et al. ${ }^{65}$ has shown substantial motion in three dimensions between navicular and medial cuneiform, central cuneiform and lateral cuneiform. While current multi-segment foot models all simulate the navicular bone and medial cuneiform as a single segment.

The rigid body assumption can lead to missing information as has been shown in patients with chronic ankle instability ${ }^{66}$. De Ridder et al. ${ }^{66}$ found when comparing the six segment Ghent Foot Model ${ }^{67}$ with a single segment foot model, compensation in intrinsic foot motion could only be detected using the Ghent Foot Model. Furthermore, the rigid body 


\section{Chapter 1}

assumption may even lead to opposite results in kinematics as has been shown on ankle joint kinematics ${ }^{68}$ when comparing a single segment foot with the Oxford foot model. More specific, at heelstrike the Oxford foot model showed ankle plantar flexion and valgus, while the single segment model showed ankle dorsiflexion and varus.

In the development of kinematic foot models the aforementioned errors should be carefully taken into account. The results of all multi-segment kinematic foot models can be influenced due to the wrong translation of marker motion into joint kinematics. When presenting results of these models, the possible effect of these errors should be mentioned and quantified.

\section{Repeatability of kinematic models of the foot}

In addition to the aforementioned model errors, other imperfections can occur when performing repeated measurements. This repeated measurements can be within one trial, between two trials performed by the same researcher or different researchers and when acquiring data in multiple centres ${ }^{69,}{ }^{70}$. These errors can occur by different marker positioning or by measurement errors caused by the tracking of these markers ${ }^{71}$. For existing multi-segment models several tests have been performed to quantify the repeatability of these models.

Repeatability of the Oxford foot model has been studied by various research groups ${ }^{47,72-}$ ${ }^{74}$, in general showing good repeatability. Deschamps et al. ${ }^{75}$ found that the Leardini foot model showed moderate to good repeatability for within-day and between-day sessions. Long et al. ${ }^{70}$ found a good inter centre repeatability for the Milwaukee foot model, which supports the use of this kinematic foot model at multiple sites.

Testing and quantifying the repeatability of kinematic models is necessary before using the models in a clinical setting. For example, it is difficult to interpret pre and post intervention kinematics with a kinematic model with a low inter-trial repeatability.

\section{Developing an advanced kinematic foot model that provides insight in motion of all 26 segments}

Existing multi-segment foot models all use the rigid body assumption. This is probably because of the physical dimensions of the foot; it is therefore not possible to attach sufficient markers on each single bone in the foot. The current thesis describes the development of a kinematic foot model that decreases the number of degrees of freedom using kinematic rhythms. This novel kinematic foot model simulates the motion of all 26 segments on a highly detailed level. 


\section{General introduction}

Since this is the first kinematic model that models motion in all 26 segments, the data for model development is also new. Chapter 2 of this thesis describes the measurements performed to generate input for the model development. Subsequently the measurements are used to develop the model. Chapter 3 contains a description of the model and validates the model by comparing the results of the model with existing literature. Before using the model in a clinical setting, further validation is necessary. An import validation is the intra subject repeatability of the model ${ }^{76}$. This is measured in Chapter 4. Chapter 5 investigates the effect of STA and describes the relative motion caused by soft tissue motion of markers of the model. The last chapter of this thesis, Chapter 6, discusses the novel kinematic foot model, by describing its strengths, weaknesses, recommendations for future research and possible clinical applications. 


\section{Chapter 1}

\section{References}

1. Thomas MJ, Roddy E, Zhang W, Menz HB, Hannan MT, Peat GM. The population prevalence of foot and ankle pain in middle and old age: A systematic review. PAIN. 2011;152:28702880.

2. Poon C, Love B. Efficacy of foot orthotics for metatarsalgia. The Foot. 1997;7:202-204.

3. Noll KH. The use of orthotic devices in adult acquired flatfoot deformity. Foot and Ankle Clinics. 2001;6:25-36.

4. Takahashi KZ, Gross MT, van Werkhoven H, Piazza SJ, Sawicki GS. Adding Stiffness to the Foot Modulates Soleus Force-Velocity Behaviour during Human Walking. Scientific Reports. 2016;6:29870.

5. Guldemond NA, Leffers P, Schaper NC, Sanders AP, Nieman FH, Walenkamp GH. Comparison of foot orthoses made by podiatrists, pedorthists and orthotists regarding plantar pressure reduction in The Netherlands. BMC Musculoskeletal Disorders. 2005;6:1-9.

6. Powell M, Seid M, Szer IS. Efficacy of custom foot orthotics in improving pain and functional status in children with juvenile idiopathic arthritis: a randomized trial. The Journal of rheumatology. 2005;32:943-950.

7. Wrobel JS, Fleischer AE, Crews RT, Jarrett B, Najafi B. A Randomized Controlled Trial of Custom Foot Orthoses for the Treatment of Plantar Heel Pain. Journal of the American Podiatric Medical Association. 2015;105:281-294.

8. Taylor M, Prendergast PJ. Four decades of finite element analysis of orthopaedic devices: Where are we now and what are the opportunities? Journal of biomechanics. 2015;48:767778.

9. Baauw $M$, van Hellemondt $G$, van Hooff $M$, Spruit M. The accuracy of positioning of a custom-made implant within a large acetabular defect at revision arthroplasty of the hip. The bone \& joint journal. 2015;97:780-785.

10. Gelaude F, Clijmans T, Delport H. Quantitative computerized assessment of the degree of acetabular bone deficiency: total radial acetabular bone loss (TrABL). Advances in orthopedics. 2011;2011.

11. Bar-On L, Aertbeliën E, Molenaers G, Van Campenhout A, Vandendoorent B, Nieuwenhuys A, Jaspers $E$, Hunaerts $C$, Desloovere K. Instrumented assessment of the effect of Botulinum Toxin-A in the medial hamstrings in children with cerebral palsy. Gait \& posture. 2014;39:1722.

12. Nester C, Van Der Linden M, Bowker P. Effect of foot orthoses on the kinematics and kinetics of normal walking gait. Gait \& posture. 2003;17:180-187.

13. Gibson KS, Woodburn J, Porter D, Telfer S. Functionally Optimized Orthoses for Early Rheumatoid Arthritis Foot Disease: A Study of Mechanisms and Patient Experience. Arthritis Care \& Research. 2014;66:1456-1464.

14. Nakamura S, Crowninshield RD, Cooper RR. An analysis of soft tissue loading in the foot-a preliminary report. Bulletin of Prosthetics Research. 1981;10-35:27-34.

15. Lemmon D, Shiang TY, Hashmi A, Ulbrecht JS, Cavanagh PR. The effect of insoles in therapeutic footwear-a finite element approach. Journal of Biomechanics. 1997;30:615-620.

16. Goske S, Erdemir A, Petre M, Budhabhatti S, Cavanagh PR. Reduction of plantar heel pressures: Insole design using finite element analysis. Journal of Biomechanics. 2006;39:2363-2370. 
17. Qian Z, Ren L, Ding Y, Hutchinson JR, Ren L. A dynamic finite element analysis of human foot complex in the sagittal plane during level walking. 2013.

18. Chen WP, Ju CW, Tang FT. Effects of total contact insoles on the plantar stress redistribution: a finite element analysis. Clin Biomech (Bristol, Avon). 2003;18:S17-24.

19. Cheung JT, Zhang M. A 3-dimensional finite element model of the human foot and ankle for insole design. Archives of Physical Medicine and Rehabilitation. 2005;86:353-358.

20. Actis RL, Ventura LB, Lott DJ, Smith KE, Commean PK, Hastings MK, Mueller MJ. Multi-plug insole design to reduce peak plantar pressure on the diabetic foot during walking. Medical and Biological Engineering and Computing. 2008;46:363-371.

21. Erdemir A, Saucerman JJ, Lemmon D, Loppnow B, Turso B, Ulbrecht JS, Cavanagh PR. Local plantar pressure relief in therapeutic footwear: design guidelines from finite element models. Journal of Biomechanics. 2005;38:1798-1806.

22. Cheung JT, Nigg BM. Clinical applications of computational simulation of foot and ankle. Sportorthopädie - Sporttraumatologie. 2007;23:264-271.

23. Wang $\mathrm{Y}$, Wong DW-C, Zhang M. Computational models of the foot and ankle for pathomechanics and clinical applications: a review. Annals of biomedical engineering. 2015:1-9.

24. Telfer S, Erdemir A, Woodburn J, Cavanagh PR. What Has Finite Element Analysis Taught Us about Diabetic Foot Disease and Its Management? A Systematic Review. 2014.

25. Spirka TA, Erdemir A, Spaulding SE, Yamane A, Telfer S, Cavanagh PR. Simple finite element models for use in the design of therapeutic footwear. Journal of biomechanics. 2014;47:2948-2955.

26. Ruimerman R, Oosterwaal M, Guldemond NA. Optimalisatie van inlegzoolontwerp door gebruik van computer simulaties. NOV2009. Rosmalen, the Netherlands 2009.

27. Robin S. HUMOS: human model for safety-a joint effort towards the development of refined human-like car occupant models. 17th international technical conference on the enhanced safety vehicle 2001:297.

28. Erdemir A, McLean S, Herzog W, van den Bogert AJ. Model-based estimation of muscle forces exerted during movements. Clin Biomech (Bristol, Avon). 2007;22:131-154.

29. Otten E. Inverse and forward dynamics: models of multiâ€"body systems. Philosophical Transactions of the Royal Society of London. Series B: Biological Sciences. 2003;358:14931500.

30. D'Souza S, Rasmussen J, Schwirtz A. Multiple linear regression to develop strength scaled equations for knee and elbow joints based on age, gender and segment mass. International Journal of Human Factors Modelling and Simulation. 2012;3:32-47.

31. Oomen P, Annegarn J, Rasmussen J, Rausch J, Siebertz K, Verdijk L, Drost M, Meijer K. Development and validation of a rule-based strength scaling method for musculoskeletal modelling. International Journal of Human Factors Modelling and Simulation. 2015;5:19-32.

32. Fernandez J, Pandy M. Integrating modelling and experiments to assess dynamic musculoskeletal function in humans. Experimental physiology. 2006;91:371-382.

33. Davis III RB, Ounpuu S, Tyburski D, Gage JR. A gait analysis data collection and reduction technique. Human Movement Science. 1991;10:575-587.

34. Brodsky JW, Polo FE, Coleman SC, Bruck N. Changes in gait following the Scandinavian total ankle replacement. The Journal of Bone \& Joint Surgery. 2011;93:1890-1896. 


\section{Chapter 1}

35. Caravaggi P, Benedetti MG, Berti L, Leardini A. Repeatability of a multi-segment foot protocol in adult subjects. Gait \& posture. 2011;33:133-135.

36. Leardini A, Benedetti MG, Berti L, Bettinelli D, Nativo R, Giannini S. Rear-foot, mid-foot and fore-foot motion during the stance phase of gait. Gait \& posture. 2007;25:453-462.

37. Deschamps K, Staes F, Roosen P, Nobels F, Desloovere K, Bruyninckx H, Matricali GA. Body of evidence supporting the clinical use of 3D multisegment foot models: a systematic review. Gait \& posture. 2011;33:338-349.

38. Rankine L, Long JT, Canseco K, Harris GF. Multisegmental Foot Modeling: A Review. 2008;36:127-181.

39. Davis RB, Jameson EG, Davids JR, Christopher LM, Rogozinski BM, Anderson JP. The Design, Development and Initial Evaluation of a Multisegment Foot Model for Routine Clinical Gait Analysis. In: Harris GF, Smith PA, Marks RM, eds. Foot and Ankle Motion Analysis: CRC Press; 2008:425-444.

40. Rattanaprasert U, Smith R, Sullivan M, Gilleard W. Three-dimensional kinematics of the forefoot, rearfoot, and leg without the function of tibialis posterior in comparison with normals during stance phase of walking. Clinical Biomechanics. 1999;14:14-23.

41. Hunt AE, M. Smith R, Torode M, Keenan A-M. Inter-segment foot motion and ground reaction forces over the stance phase of walking. Clinical Biomechanics. 2001;16:592-600.

42. MacWilliams BA, Cowley M, Nicholson DE. Foot kinematics and kinetics during adolescent gait. Gait \& Posture. 2003;17:214-224.

43. Canseco K, Long J, Marks R, Khazzam M, Harris G. Quantitative characterization of gait kinematics in patients with hallux rigidus using the Milwaukee foot model. Journal of orthopaedic research : official publication of the Orthopaedic Research Society. 2008;26:419427.

44. Khazzam M, Long JT, Marks RM, Harris GF. Preoperative gait characterization of patients with ankle arthrosis. Gait \& posture. 2006;24:85-93.

45. Kidder SM, Abuzzahab FS, Harris GF, Johnson JE. A system for the analysis of foot and ankle kinematics during gait. IEEE Transactions on Rehabilitation Engineering. 1996;4:25-32.

46. Woodburn J, Nelson KM, Siegel KL, Kepple TM, Gerber LH. Multisegment foot motion during gait: proof of concept in rheumatoid arthritis. The Journal of rheumatology. 2004;31:19181927.

47. Carson MC, Harrington ME, Thompson N, O'Connor JJ, Theologis TN. Kinematic analysis of a multi-segment foot model for research and clinical applications: a repeatability analysis. Journal of Biomechanics. 2001;34:1299-1307.

48. Novak AC, Mayich DJ, Perry SD, Daniels TR, Brodsky JW. Gait analysis for foot and ankle surgeons-- topical review, part 2: approaches to multisegment modeling of the foot. Foot \& ankle international. / American Orthopaedic Foot and Ankle Society [and] Swiss Foot and Ankle Society. 2014;35:178-191.

49. van Hoeve S, de Vos J, Verbruggen JP, Willems P, Meijer K, Poeze M. Gait Analysis and Functional Outcome After Calcaneal Fracture. J Bone Joint Surg Am. 2015;97:1879-1888.

50. Leardini A, Aquila A, Caravaggi P, Ferraresi C, Giannini S. Multi-segment foot mobility in a hinged ankle-foot orthosis: the effect of rotation axis position. Gait \& Posture. 2014;40:274277. 


\section{General introduction}

51. Berti L, Lullini G, Caravaggi P, Tamarri S, Giannini S, Leardini A. Biomechanical analysis in flatfoot children: Effect of two surgical treatments by bioreabsorbable screws. Gait \& Posture. 2015;42:S21.

52. Leardini A, Chiari L, Della Croce U, Cappozzo A. Human movement analysis using stereophotogrammetry. Part 3. Soft tissue artifact assessment and compensation. Gait \& posture. 2005;21:212.

53. Peters A, Galna B, Sangeux M, Morris M, Baker R. Quantification of soft tissue artifact in lower limb human motion analysis: A systematic review. Gait \& Posture. 2010;31:1-8.

54. Cappozzo A, Catani F, Leardini A, Benedetti MG, Della Croce U. Position and orientation in space of bones during movement: experimental artefacts. Clinical Biomechanics. 1996;11:90-100.

55. Nester CJ, Liu AM, Ward E, Howard D, Cocheba J, Derrick T. Error in the description of foot kinematics due to violation of rigid body assumptions. Journal of Biomechanics. 2010;43:666-672.

56. Cappozzo A, Cappello A, Croce UD, Pensalfini F. Surface-marker cluster design criteria for 3-D bone movement reconstruction. Biomedical Engineering, IEEE Transactions on. 1997;44:1165-1174.

57. Karlsson D, Tranberg R. On skin movement artefact-resonant frequencies of skin markers attached to the leg. Human Movement Science. 1999;18:627-635.

58. Nester C, Jones RK, Liu A, Howard D, Lundberg A, Arndt A, Lundgren P, Stacoff A, Wolf P. Foot kinematics during walking measured using bone and surface mounted markers. Journal of Biomechanics. 2007;40:3412-3423.

59. Chen S-J, Mukul M, Chou L-S. Soft-Tissue Movement at the Foot During the Stance Phase of Walking. Journal of the American Podiatric Medical Association. 2011;101:25-34.

60. Sangeux M, Marin F, Charleux F, Dürselen L, Ho Ba Tho MC. Quantification of the 3D relative movement of external marker sets vs. bones based on magnetic resonance imaging. Clinical Biomechanics. 2006;21:984-991.

61. Wrbaškić $\mathrm{N}$, Dowling JJ. An investigation into the deformable characteristics of the human foot using fluoroscopic imaging. Clinical Biomechanics. 2007;22:230-238.

62. Shultz R, Kedgley AE, Jenkyn TR. Quantifying skin motion artifact error of the hindfoot and forefoot marker clusters with the optical tracking of a multi-segment foot model using single-plane fluoroscopy. Gait \& Posture. 2011;34:44-48.

63. Maslen BA, Ackland TR. Radiographic study of skin displacement errors in the foot and ankle during standing. Clinical Biomechanics. 1994;9:291-296.

64. Tranberg $R$, Karlsson $D$. The relative skin movement of the foot: a 2-D roentgen photogrammetry study. Clinical Biomechanics. 1998;13:71-76.

65. Nester CJ, Liu AM, Ward E, Howard D, Cocheba J, Derrick T, Patterson P. In vitro study of foot kinematics using a dynamic walking cadaver model. Journal of Biomechanics. 2007;40:19271937.

66. De Ridder R, Willems T, Vanrenterghem J, Robinson M, Pataky T, Roosen P. Gait kinematics of subjects with ankle instability using a multisegmented foot model. Med Sci Sports Exerc. 2013;45:2129-2136.

67. De Mits S, Segers V, Woodburn J, Elewaut D, De Clercq D, Roosen P. A clinically applicable six-segmented foot model. Journal of Orthopaedic Research. 2012;30:655-661. 


\section{Chapter 1}

68. Pothrat C, Authier G, Viehweger E, Berton E, Rao G. One-and multi-segment foot models lead to opposite results on ankle joint kinematics during gait: Implications for clinical assessment. Clinical Biomechanics. 2015;30:493-499.

69. Deschamps K, Staes F, Roosen P, Nobels F, Desloovere K, Bruyninckx H, Matricali GA. Body of evidence supporting the clinical use of $3 \mathrm{D}$ multisegment foot models: a systematic review. Gait \& posture. 2011;33:338-349.

70. Long JT, Eastwood DC, Graf AR, Smith PA, Harris GF. Repeatability and sources of variability in multi-center assessment of segmental foot kinematics in normal adults. Gait \& Posture. 2010;31:32-36.

71. Chiari L, Della Croce U, Leardini A, Cappozzo A. Human movement analysis using stereophotogrammetry: Part 2: Instrumental errors. Gait \& posture. 2005;21:197-211.

72. van Hoeve S, de Vos J, Weijers PHE, Verbruggen J, Willems P, Poeze M, Meijer K. Repeatability of the Oxford Foot Model for Kinematic Gait Analysis of the Foot and Ankle. Clinical research on foot \& ankle. 2015;3:171.

73. Curtis DJ, Bencke J, Stebbins JA, Stansfield B. Intra-rater repeatability of the Oxford foot model in healthy children in different stages of the foot roll over process during gait. Gait \& Posture. 2009;30:118-121.

74. Stebbins J, Harrington M, Thompson N, Zavatsky A, Theologis T. Repeatability of a model for measuring multi-segment foot kinematics in children. Gait \& Posture. 2006;23:401-410.

75. Deschamps K, Staes F, Bruyninckx H, Busschots E, Jaspers E, Atre A, Desloovere K. Repeatability in the assessment of multi-segment foot kinematics. Gait \& Posture. 2012;35:255-260.

76. Bishop C, Paul G, Thewlis D. Recommendations for the reporting of foot and ankle models. Journal of biomechanics. 2012;45:2185-2194. 


\section{CHAPTER 2}

\section{GENERATION OF SUBJECT- SPECIFIC, DYNAMIC, MULTI- SEGMENT ANKLE AND FOOT MODELS TO IMPROVE ORTHOTIC DESIGN: A FEASIBILITY STUDY}

Michiel Oosterwaal, Scott Telfer, Søren Tørholm, Sylvain Carbes, Lodewijk van Rhijn, Ross Macduff, Kenneth Meijer, Jim Woodburn BMC Musculoskeletal Disorders 2011; 12:256 


\section{Chapter 2}

\section{Abstract}

State of the art (ankle-) foot orthosis design is based on traditional techniques, which restricts the design space. The use of biomechanical foot models can give further insight in the effect of (ankle-) foot orthosis. Current ankle and foot models are too complex or too simplified, while the design of orthotic devices needs highly detailed but dynamic models. To develop these models a subject specific dataset needs to be generated.

This dataset will be collected in 2 centres; participants will be 10 healthy subjects and 15 patients requiring orthotic devices. Three groups of patients with ankle and foot problems are included: 7 metatarsalgia, 7 flexible flat foot and 1 stroke patient.

The protocol exists of 4 sections. 1) A clinical foot function assessment by a clinician, followed by two questionnaires to measure foot-related impairments.2) A 3D surface scan to digitally measure foot shape in different loading positions. 3) Extended gait analysis will be undertaken, including kinematics, kinetic, EMG and plantar pressure measurements. This analysis will be for barefoot and shod trials. 4) The foot and ankle complex will be imaged by $\mathrm{CT}$ and a subgroup will be imaged by MRI. Four CT scans will be undertaken in various loading positions, while the plantar pressure is measured by an instrumented insole.

Image data will be segmented to derive the size of bones and orientation of the joint axis. Insertion and origins of muscles and ligaments are determined from the MRI and CT-scans. Soft tissue material properties are computed by the loaded CT data in combination with the plantar pressure measurements. Clinical assessment and 3D surface scan are used for extra input on biomechanical properties of the model. Gait analysis parameters are used to drive the models and for validation purposed.

This study will lead to a unique dataset, which will be used to develop biomechanical foot models. These foot models will be used to predict the effect of orthotic devices. 


\section{Background}

It has been estimated that almost 200 million people in Europe have disabling foot or ankle pain and that this figure will rise with aging societies and the associated increase in prevalence of chronic long term conditions ${ }^{1-5}$. Foot pain can cause loss of function, discomfort, and a general lowering of the patient's quality of life. Custom ankle-foot and foot orthoses are a popularly prescribed conservative treatment intended to alleviate this pain, via a number of purported mechanisms. Currently the design of these devices is largely based on foot shape captured using traditional techniques such as plaster casting and foot function based on clinical orthopaedic/podiatry examination, observational and quantitative (limited) gait analysis and plantar pressure distribution analysis. However these approaches restrict design choice and personalised function to simple parameters such as cushioning, support and range of motion control.

Computational modelling of the human body - ranging from the force interactions of joints to the way cells communicate with each other - has advanced significantly in the past few decades and it is now an important and useful tool for researchers and clinicians. These models provide a method of simulating and assessing interventions that are being developed; reducing the time and risk involved with trialling in humans. This approach is particularly appealing for studying foot biomechanics due to the challenging nature of investigating the internal loading and movements of the complex structure of bones and soft tissues of the foot that occur during gait.

A small but growing body of research, primarily based around finite element analysis (FEA), has studied the foot using models based on different combinations of gait analysis, pressure distribution measurements, computed tomography (CT) and magnetic resonance (MR) imaging of the foot. This has provided insights into inflammation of the plantar fascia 6,7 , pressure assessment of the diabetic foot ${ }^{8}$ and therapeutic footwear ${ }^{9}$.

Lower limb musculoskeletal biomechanics is an area where extensive modelling work has been successfully carried out, supporting the development and assessment of a range of treatments and interventions ${ }^{10-13}$. In terms of the foot however, musculoskeletal models have tended to represent it as a single rigid segment, and it is only recently that progress has been made in starting to incorporate the intrinsic joints of the foot ${ }^{14}$.

With these factors in mind, it is therefore suggested that there is a great deal of potential for highly detailed biomechanical foot models to be used in the process of designing orthotic interventions for the foot and ankle. These could lead to the development of devices and prescription paradigms which could improve the efficacy of these devices and benefit the patient as well as reducing long term treatment costs for the healthcare provider. 


\section{Chapter 2}

\section{Models}

This article describes a protocol that has been developed to generate the biomechanical and anatomical data required to produce two linked foot models: a forward dynamic model that combines a multibody approach with a FEA; and an inverse dynamic model which describes the musculoskeletal interactions of the system. The forward dynamic model will be developed using the Madymo software platform (TASS, Rijswijk), and the inverse dynamic model in the AnyBody modelling system (AnyBody Technology, Aalborg). Generally, forward dynamic models need joint torques and/or muscle forces as an input to compute kinematics, and for a complex structure like the foot this information can be generated from inverse dynamic models driven by motion capture data. Using the same dataset to construct both models leads to the possibility of a combination of both models in a final application.

\section{Inverse dynamic model}

Standard gait analysis and inverse dynamic models of the lower extremity consider the foot as a single rigid segment. Some models have been developed describing the foot in more detail, however to the authors' knowledge no kinematic model has attempted to describe all 26 bones. The proposed kinematic model ${ }^{15}$ is scalable and parametric and will integrate into the existing AnyBody whole body musculoskeletal model (Figure 2.1a). The model will contain all of the ligaments and muscles of the foot and ankle. By combing the inverse dynamic modelling with an optimisation algorithm the model will provide insight in function of the foot and leg muscles during gait.

\section{Forward dynamic model}

The forward dynamic model is a combined multibody finite element approach. Bones, joints, ligaments and muscles are all multibody elements. This multibody model is surrounded by a two dimensional finite element mesh, representing the soft tissue. This combination leads to a computational less complex model compared to a full finite element model of the foot and ankle. This reduction could be improved by a full multibody representation of the ankle-foot complex, however in this model computation of the plantar pressure would be impossible. In the proposed model this is solved by a finite element mesh representing the plantar surface, leading to the possibility of performing a dynamic simulation to compute the deforming plantar surface.

An existing model (Figure 2.1b) has previously been developed which is partly constructed from a dataset of a post-mortem human subject with other model properties based on data available in the literature. ${ }^{16}$ The generation of one, complete, dataset leads to a consistent model. Additionally, the generation of datasets from several subjects creates 


\section{Study protocol}

the possibility of scaling the model. This scaling will be extended for patients requiring (ankle) foot ortheses.

The primary aim of this study is to collect data for the development of two biomechanical foot models
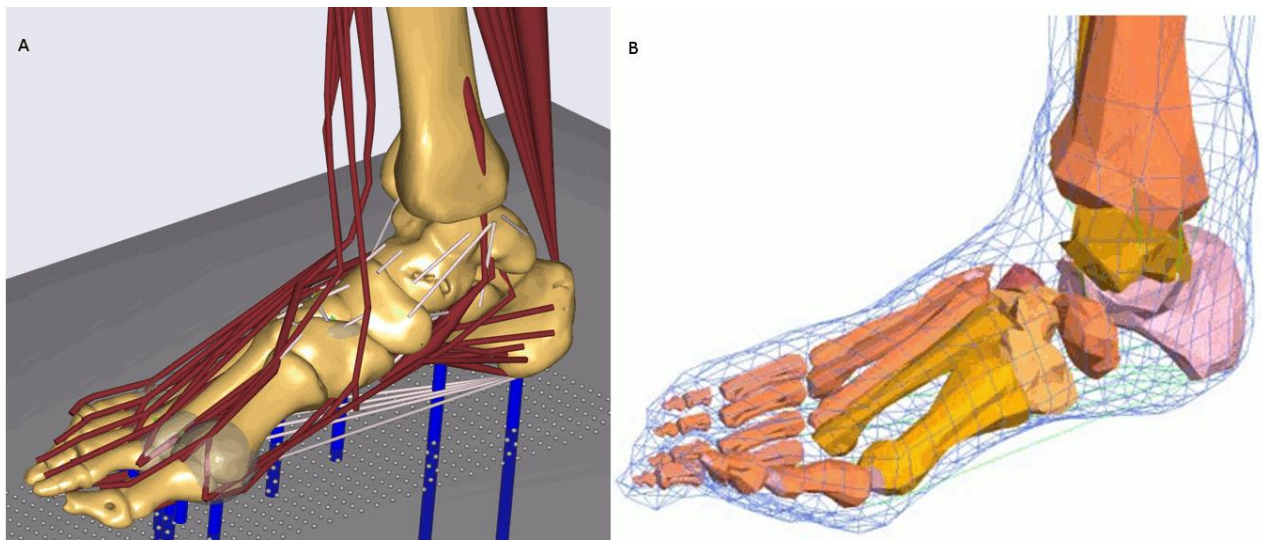

Figure 2.1 Foot models - Graphical representation of a) Current inverse dynamic model , b) Current forward dynamic model

\section{Methods/Design}

\section{Study Design}

This study is a feasibility/pilot study to generate data, which will be used for the development of biomechanical foot models. It is a multicentre-study, between Glasgow Caledonian University (GCU), and Maastricht University Medical Centre (MUMC+). The data acquisition will be independent, after acquisition the data will be pooled. This data pool will be used to develop both models.

The data collection will take a period of 6 months for each centre. Each subject will be measured once; this will take 4 hours in total. The measurements will take place in the motion capture lab of the GCU and Radiology Department of Glasgow Royal Infirmary, and in the motion capture lab of MUMC+ and Department of Radiology of the MUMC+.

\section{Ethical Consideration}

This study was conducted in accordance to the Declaration of Helsinki.Ethical approval for this study has been provided by the West of Scotland Research Ethics Committee (application reference 10/S1001/24) and National Health Service Greater Glasgow and Clyde Research and Development Committee (reference GN10RH187) for the UK site. In 


\section{Chapter 2}

the Dutch centre, the study was granted approval by the Medical Ethical Committee azM/UM (reference number NL31656.068.10 / MEC 08-2-028).

\section{Participants}

Two groups of participants will be investigated, healthy volunteers and patients. Healthy volunteers will be recruited by flyers. Participants with pathological foot problems will be informed about the study by their orthopaedic surgeon (Maastricht) or podiatrist (Glasgow).

The total population will be recruited in two centres (GCU and MUMC+), Table 2.1 gives an overview of the study population. Participants will be selected if they meet the inclusion and exclusion criteria.

Table 2.1 Study population

\begin{tabular}{|l|c|c|c|}
\hline & Total & Maastricht & Glasgow \\
\hline Healthy subjects & $\mathbf{1 0}$ & 5 & 5 \\
\hline Patients requiring: & $\mathbf{1 5}$ & 7 & 8 \\
\hline Pressure releasing orthotics & $\mathbf{7}$ & 3 & 4 \\
\hline Alignment improving orthotics & $\mathbf{7}$ & 4 & 3 \\
\hline Ankle foot orthosis for motion control & $\mathbf{1}$ & 0 & 1 \\
\hline
\end{tabular}

\section{Inclusion criteria}

Inclusion criteria for both groups, healthy feet and group pathological feet, are:

1. Physically able to perform testing (able to walk at least 20 meters barefoot and unaided)

2. $38<$ Shoe size $<44$ (EUR), $5.5<$ Shoe size $<9.5$ (UK)

3. $18<$ age $<50$

4. Fully competent and able to give informed consent

In addition to this general inclusion criteria, participants within the group of pathological must fall into one of the following categories:

5. Patients with metatarsalgia on their right foot, who would be prescribed pressure relieving foot orthoses

6. Patients with flexible flat foot deformities on their right foot,who would be prescribed foot orthoses to improve alignment

7. Hemiplegic stroke patients who would be prescribed an ankle foot orthosis on their right foot, for motion control.

\section{Exclusion criteria}

Participants in both groups will be excluded if: 


\section{Study protocol}

1. They have other lower extremity problems, causing gait variation

2. Pregnant and lactating women

3. To be part of the healthy patient group, participants will be excluded if they :

4. Are currently receiving health professional treatment or advice for a foot conditions

5. Have a diagnosable disease with known involvement of the lower limb and foot including, for example diabetes mellitus, peripheral vascular disease and have rheumatoid arthritis

6. Have a significant history of foot or ankle trauma, injury, fracture or dislocation

7. Clarification of sample size

The exploratory nature of this study makes it difficult to calculate power requirements for statistical purposes. Therefore, a pragmatic approach has been taken with the number of subjects chosen by the opinion of experts to cover a broad scope of variation of foot problems. A broad range of subjects in terms of foot size, age, BMI, will be included for development of scaling methods and to test the validity of the models. For each subgroup of pathological subjects varying severities of the pathology will be included.

\section{Study procedure}

The participants will initially be asked to attend to the movement laboratory of the site they are applying at. From here the protocol can be split into four sections:

1. Clinical foot assessment

2. 3-D surface geometry

3. Gait analysis, with a high detail of foot kinematics

4. Medical imaging of the foot

\section{Clinical foot assessment}

Subjects will first have an extended foot function assessment. For this study a customised foot function form is developed to capture range of joint motion, muscle strength, posture and impairments such as pain, stiffness and deformity. A qualified clinician will take general demographic details and perform a foot exam. Subject will be requested to complete two short ( $<5$ minutes to complete both) questionnaires which measure footrelated impairments and disability. These validated questionnaires are the Manchester Foot Pain and Disability Questionnaire ${ }^{17}$ and the foot-function index ${ }^{18,19}$. 


\section{Chapter 2}

\section{3-D surface geometry}

Participants will be asked to stand with their right foot in a 3D foot surface scanner (Easy Foot Scan; OrthoBaltic, Kaunas, Lithuania) and scans will be taken with: minimal weight on the foot ( $<5 \%$ body weight); $50 \%$ body weight on the foot; and $>95 \%$ body weight on the foot. The participant will be asked before each scan if they are comfortable maintaining the related level of weight bearing on the foot and the scan will only be carried out if they are able to maintain this load. These scans will take approximately one minute each. Supports will be provided and a researcher will stay close by the participant to reduce the risk of falls.

\section{Gait analysis}

After the general foot assessments have been completed, the participant will undergo a comprehensive assessment of their gait, in both barefoot and shod conditions. During gait analysis, kinematic, kinetic, electromyographic (EMG) and plantar pressure measurements will be collected simultaneously from the participant's right foot and leg during stance phase.

\section{i) Kinematic measurements}

Kinematic data will be collected using a 12 camera Qualisys system (Glasgow) and an eight camera Vicon system (Maastricht). Residual errors of $<1 \mathrm{~mm}$ are deemed acceptable for both systems.

Bony and tracking landmarks (see Table 2.2) will be identified through physical palpation of the relevant areas on the foot and leg by trained researchers. Once identified, these points are indicated on the skin with non-permanent marker. Passive, reflective markers (Qualisys AB, Gothenburg, Sweden) will be attached at these points using double sided tape. The marker model used is an adapted version of that used in the multi-segment foot model described in Hyslop et al. (2010) ${ }^{20}$. The model has been extended with additional markers on the thigh, hips, lesser toes and the lateral cuneiform. The full marker list is given in Table 2.2.

For the shod trials, the participants are provided with standardised footwear (Flextop Diabetic Black shoes, Reed Medical, Blackburn, UK). A number of the foot mounted markers used in the barefoot trials will be removed for the shod trials (see Table 2.2 for details), and holes are cut into the shoes to allow the remaining markers to be visualised by the motions capture system and to move during walking without interference. 
Table 2.2 Kinematics - Overview of the kinematic marker set

\begin{tabular}{|c|c|c|c|c|}
\hline & Landmark/Location & $\begin{array}{l}\text { Label } \\
\text { Name }\end{array}$ & $\begin{array}{l}\text { Marker Size } \\
\quad(\mathrm{mm})\end{array}$ & $\begin{array}{l}\text { Barefoot trials } \\
\text { only (B) or shod } \\
\text { and barefoot (S) }\end{array}$ \\
\hline 1 & Right iliac crest & RAIC & 19 & $S$ \\
\hline 2 & Left iliac crest & LAIC & 19 & $S$ \\
\hline 3 & Right posterior superior iliac spine & RPSI & 19 & $\mathrm{~S}$ \\
\hline 4 & Left posterior superior iliac spine & LPSI & 19 & $\mathrm{~S}$ \\
\hline 5 & Right greater trochanter & RGT & 12 & $\mathrm{~S}$ \\
\hline 6 & Left greater trochanter & LGT & 12 & $S$ \\
\hline 7 & Thigh $1^{\text {st }}$ & THI1 & 19 & $\mathrm{~S}$ \\
\hline 8 & Thigh $2^{\text {nd }}$ & THI2 & 19 & $S$ \\
\hline 9 & Lateral knee & LKNE & 12 & $S$ \\
\hline 10 & Tibial tuberosity & TTUB & 7 & $\mathrm{~S}$ \\
\hline 11 & Head of fibula & HFIB & 7 & $S$ \\
\hline 12 & Shin $1^{\text {st }}$ & SHN1 & 19 & $S$ \\
\hline 13 & Shin $2^{\text {nd }}$ & SHN2 & 19 & $\mathrm{~S}$ \\
\hline 14 & Superior calcaneum & SCAL & 7 & $\mathrm{~S}$ \\
\hline 15 & Inferior calcaneum & ICAL & 7 & $S$ \\
\hline 16 & Medial malleolus & MMAL & 7 & $S$ \\
\hline 17 & Medial calcaneum & MCAL & 7 & $S$ \\
\hline 18 & Tuberosity navicular & NAV & 7 & $S$ \\
\hline 19 & Proximal $1^{\text {st }}$ met head & P1MT & 7 & $B$ \\
\hline 20 & Central $1^{\text {st }}$ met & C1MT & $\begin{array}{c}7 \text { (on } 20 \mathrm{~mm} \\
\text { wand) }\end{array}$ & B \\
\hline 21 & Medial $1^{\text {st }}$ met head & M1MT & 7 & $\mathrm{~S}$ \\
\hline 22 & Lateral $1^{\text {st }}$ met head & L1MH & 7 & $B$ \\
\hline 23 & Hallux $1^{\text {st }}$ & HLX1 & 7 & $B$ \\
\hline 24 & Hallux $2^{\text {nd }}$ & HLX2 & 7 & B \\
\hline 25 & Hallux $3^{\text {rd }}$ & HLX3 & 7 & B \\
\hline 26 & Lateral malleolus & LMAL & 7 & $\mathrm{~S}$ \\
\hline 27 & Lateral calcaneum & LCAL & 7 & $S$ \\
\hline 28 & Cuboid & CUB & 7 & $B$ \\
\hline 29 & Proximal 5 $5^{\text {th }}$ met & P5MT & 7 & $\mathrm{~S}$ \\
\hline 30 & Distal $5^{\text {th }}$ met & D5MT & 4 & $S$ \\
\hline 31 & Intermediate cuneiform & ICUN & 7 & $B$ \\
\hline 32 & Lateral cuneiform & LCUN & 7 & $\mathrm{~B}$ \\
\hline 33 & $2^{\text {nd }}$ met head & D2MT & 4 & $B$ \\
\hline 34 & $3^{\text {rd }}$ met head & D3MT & 4 & $B$ \\
\hline 35 & $4^{\text {th }}$ met head & D4MT & 4 & $B$ \\
\hline
\end{tabular}




\section{Chapter 2}

\begin{tabular}{|l|l|l|c|c|}
\hline 36 & $2^{\text {nd }}$ proximal phalanx & D2PP & 4 & B \\
\hline 37 & $3^{\text {rd }}$ proximal phalanx & D3PP & 4 & B \\
\hline 38 & $4^{\text {th }}$ proximal phalanx & D4PP & 4 & B \\
\hline 39 & $5^{\text {th }}$ proximal phalanx & D5PP & 4 & B \\
\hline 40 & $2^{\text {nd }}$ distal phalanx (on nail) & D2DP & 4 & B \\
\hline 41 & $3^{\text {rd }}$ distal phalanx (on nail) & D3DP & 4 & B \\
\hline 42 & $4^{\text {th }}$ distal phalanx (on nail) & D4DP & 4 & B \\
\hline 43 & $5^{\text {th }}$ distal phalanx (on nail) & D5DP & 4 & B \\
\hline
\end{tabular}

\section{ii) Kinetic measurements}

Kinetic measurements will be taken at both centres using Kistler force plates (Kistler Instrument Corp., Amherst, NY) synchronised with and recorded through the QTM software (Glasgow) or Nexus software (Maastricht), sampled with a frequency of $2400 \mathrm{~Hz}$.

\section{iii) Electromyographic measurements}

All parts of the protocol relating to surface EMG measurement will be carried out in accordance with the guidelines produced by the Surface Electromyography for the NonInvasive Assessment of Muscles (SENIAM) project ${ }^{21}$. These guidelines cover the location and orientation of electrode placement, skin preparation and signal tests for each muscle. Trigno wireless EMG systems (Delsys Inc, Boston, MA) will be used to collect the EMG measurements at both centres. The electrode units will be attached to the following muscles: tibialis anterior, gastrocnemius medialis, gastrocnemius lateralis, soleus, peroneus longus, vastus lateralis, rectus femoris, and biceps femoris. Signals from each muscle will be checked in real time using EMGworks software (Delsys Inc, Boston, MA) while performing the exercises described in the SENIAM guidelines.

Reference measurements will be taken for each muscle in the form of maximal voluntary isometric contractions (MVICs). Measurements will be recorded for five seconds in total with the participant being asked to gradually build up the force they apply over the first two seconds, and maintain their maximum effort for the remainder of the contraction. Each contraction is repeated three times in a non-consecutive randomised order with at least one minute recovery time between exercises.

For the MVIC and gait components of the testing, EMG signals from the Trigno sensors will be recorded through the analogue channels of QTM or VICON software.

\section{iv) Plantar pressure measurements}

For barefoot trials, plantar pressure measurements will be collected using a $0.5 \mathrm{~m}$ Footscan ${ }^{\circledR}$ plate (RSscan International, Lammerdries, Belgium) recording at $500 \mathrm{~Hz}$. The plate is mounted directly on top of the force plate and secured in place using double sided tape. The effect of this setup on the accuracy of the force plate was assessed using the 


\section{Study protocol}

CalTester ${ }^{\circledast}$ quality assurance tool and errors were found to be within acceptable limits. To ensure high levels of accuracy in the pressure measurements, the pressure plate is dynamically calibrated with the vertical force signals from the force plate.

In-shoe plantar pressure measurements will be made using the Pedar ${ }^{\circledR}$ system (Novel, $\mathrm{GmbH}$, Munich, Germany) at $50 \mathrm{~Hz}$. In addition, pressure under the sole of the shoe will be recorded using the Footscan ${ }^{\circledR}$ plate.

\section{v) Testing}

A static trial will be recorded with the participant in a relaxed standing pose in the motion capture area. The participant will then be asked to walk barefoot at a self-selected speed along the motion capture area such that their right foot strikes the centre of the pressure plate. Five successful walking trials will be recorded. This is then repeated for the shod trials.

\section{Imaging}

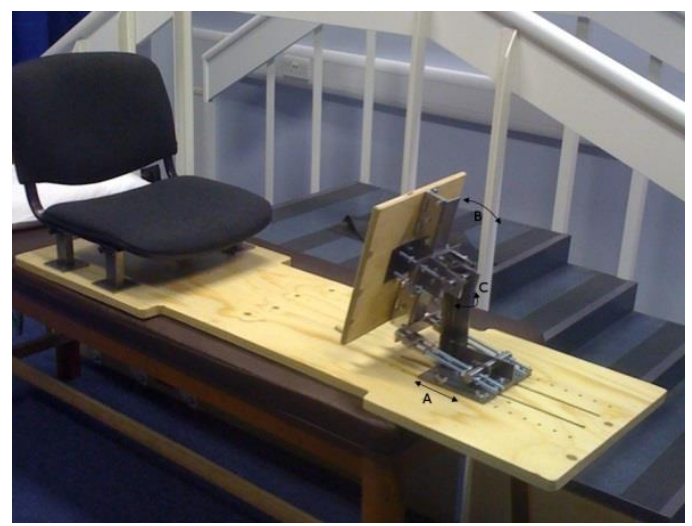

Figure 2.2 Loading rig A: loading plate can be moved linearly to accommodate different leg lengths; B: plate can be tilted to give plantar/dorsi flexion of the foot; C: plate can be tilted to invert/evert the foot.

\section{i) Computed tomography (CT)}

CT scans of the leg and foot will be undertaken in hospital radiology centres. Four scans will be carried out under a variety of different conditions. These scans are: knee, shank and foot, unloaded and with the foot in a neutral position (90 degrees flexion); foot loaded to $50 \%$ body weight in the neutral position; $50 \%$ body weight with 25 degrees plantar flexion; $50 \%$ body weight with 10 degrees dorsal flexion. With the exception of the first, unloaded scan, the order of the scans is randomised.

To allow the participant to apply force on the foot while being scanned, a novel loading rig was developed and fabricated. Previously, several investigators have developed similar 


\section{Chapter 2}

systems (14) but to the authors' knowledge this is the first device that allows the position of the foot in relation to the lower leg to be easily and quickly manipulated.

The loading rig (Figure 2.2) takes the form of a chair fixed on to a plywood base plate. At the opposite end to the chair, a plate. The nature of CT means that metallic objects can cause interference in the image, an effect known as scattering. To avoid this, the steel components which allow the loading plate to be repositioned are kept behind the scan plane. The loading plate can be easily moved closer to or further from the chair at fixed $20 \mathrm{~mm}$ intervals to suit the participant's leg length. A standard bathroom scale with a large LED display is mounted on the loading plate and is used to provide feedback to the participant on the level of loading they are applying.

The relatively short time frame of the CT scan (5-10 seconds) allows medium level loads to be applied and maintained over its duration.

During the scans, a Pedar pressure insole (Novel, GmbH, Munich, Germany) is placed between the foot and the loading plate. In addition, using the pen marks made on the foot to guide placement, radiopaque markers $\left(4 \mathrm{~mm}\right.$ diameter Beekley Spots ${ }^{\circledR}$, Oncology Imaging Systems, East Hoathly, UK) are attached at the same points as the motion capture markers during gait analysis.

The following parameters were used to acquire the four scans on a Toshiba Aquilion 64 slice scanner (Glasgow) or a Philips Brilliance 64 slices (Maastricht): 120kVp, 100mAs, $1.0 \mathrm{~mm}$ collimination, $1.0 \mathrm{~mm}$ effective slice thickness, pitch factor 41 , rotation time 0.5 seconds, B30S medium smooth reconstruction kernel, 512x512 matrix.

\section{ii) $M R$}

Due to the limitations of soft tissue information that can be inferred from CT imaging, a subset of five participants will also have MR scans taken of their right foot. This will take place on a different day to the rest of the testing, but within six weeks of the initial assessment.

For the MR scans the foot is placed in a suitable imaging coil and foam padding is placed around the foot to prevent movement during the scan. Images will be acquired using a 3T system (Siemens Verio; Erlangen, Germany). Three scans will be taken in total, a T2weighted scan covering the full foot and ankle, and two T1-weighted scans, one of the rearfoot/midfoot complex and one of the forefoot/midfoot complex.

Scanning parameters for the T2 scan (trueFISP 3D volume) are: repetition time, 9.8ms; echo time, $4.92 \mathrm{~ms}$; flip angle, $35^{\circ}$; field of view, $290 \mathrm{~mm}$; slice thickness, $0.6 \mathrm{~mm}$ (no slice gap); slices per slab, 144; matrix, 256×216 (interpolated); phase encoding, anterior to posterior; number of averages, 2.

Scanning parameters for the T1 scan (Space 3D volume) are: repetition time $700 \mathrm{~ms}$; echo time $22 \mathrm{~ms}$; flip angle $105^{\circ}$; field of view, $150 \mathrm{~mm}$; slice thickness $0.8 \mathrm{~mm}$ (no slice gap); 


\section{Study protocol}

slices per slab, 94; matrix 320×290 (interpolated); phase encoding anterior to posterior; averages, 2.4 .

\section{Data Analysis}

The data will be used to create parameters for the biomechanical foot models.

\section{i) Gait analysis data}

The kinematic data, the kinetic data and the plantar pressure will be processed by using Nexus (Vicon, Oxford, UK) software (Maastricht) or Qualisys Track Manager (Qualisys, Gothenburg, Sweden) software (Glasgow) and saved in the C3D-format.

Kinematic and kinetic measurements will be used as an input for the inverse dynamic model and to validate the forward dynamic model. The dataset of one healthy subject is used to develop the first model. Afterwards the datasets of the other healthy subjects are used to refine the initial model, develop kinematic and kinetic rules and a morphing-based scaling facility so the models become personalised. After the development of the morphing algorithm the combination of this algorithm and the two models can be used to predict the effect of insoles. This will be validated in a later study.

Data from the foot assessments in combination with the 3D surface scans will be processed to develop an algorithm for personalisation of the models with a non-invasive, low-end method. An extra algorithm will be developed to correlate plantar pressure measurements with kinematic parameters of the lower extremities.

\section{ii) Imaging data}

CT data will be segmented into the individual bones of the foot using Mimics (Materialise, Leuven, Belgium) image processing software. The CT-data will be used to compute the joint axis of the foot, by correlating the positions of the bones in the various positions. The loaded CT-data in combination with the pressure measurement, will gain insight in the soft tissue characteristics of the foot. Insertion and via points will be identified from partial segmentation of the MRI data and described as co-ordinates on the bones segmented from the CT data. Insertion points will be defined as the centre of the area of insertion.

\section{Discussion}

The primary aim of this study is to collect data for the development of two biomechanical foot models. One dataset, including foot assessment, gait analysis data and imaging data has not been combined previously for the generation of biomechanical foot models ${ }^{22}$. Geometry of existing FE models are mainly based on an MRI-dataset ${ }^{23}$ or $\mathrm{CT}^{24}$ for one 


\section{Chapter 2}

subject ${ }^{23}$, while material properties are obtained from literature of larger groups of subjects. Cheung et al. ${ }^{25}$ have used an existing FE model to simulate several phases of the gait cycle. Boundary conditions for these static simulations are derived from EMG and ground reaction force measurements.

To the authors' knowledge, multibody models of the foot describing the level of detail proposed here have not previously been attempted. An inverse dynamic model with three segments has been developed by Saraswat et al. ${ }^{14}$, anatomical information is however derived from literature, which makes it impossible to derive a personalised model.

Various FE models have been used in combination with insole models ${ }^{26-33}$. These models have been developed in varying complexity, from 2D FE simulations of the second ray ${ }^{27}$ till nonlinear material properties. These studies are mainly parametric studies in which several properties of the insole are simulated in a static simulation of the mid-stance phase. Variations can be made in geometry ${ }^{28}$ or material properties ${ }^{26}$, or a combination 29. The computational complexity of highly detailed FE models forces a static simulation.

A driving input of the models is the kinematic data. This data is acquired by a new developed set of skin markers. Markers are positioned on bony-landmarks, taking into account, the influence of muscles, tendons and ligaments on skin motion. Previously performed bone pin studies show the distinction between the movements of the skin markers and the bones ${ }^{34}$. This difference has two causes: soft tissue movement ${ }^{35}$ and the rigid body violation ${ }^{36}$. The last point is solved by introducing a 26 segment model. The problem of soft tissue movement is addressed by performing loaded CT with radio-opaque markers and having the option to include directional dependent weight factors in the AnyBody model. A bone pin study involving all bones is not possible due to the small size of the bones. In addition, the confounding effect of this invasive method on the motion pattern in the feet is not known.

Validation of the models is partly performed by comparison of the muscle activity of the large muscles generated by the inverse dynamic model to those recorded during gait. EMG can be acquired by surface electrodes or by intramuscular measurements. Both methods have advantages and disadvantages, in this study we've chosen for surface EMG to keep the influence of the measurements on normal gait as small as possible since EMG is not used as an input for the model, but will be used only as a validation tool.

Weight bearing CT-scans are performed with approximately $50 \%$ body weight. By this standardised loading normal stance is simulated, Commean et al. ${ }^{8}$ have proven the reliability of weight-bearing $\mathrm{CT}$ in a sitting position. The full foot and ankle can be scanned using this method making it preferred to the standing on the CT-table as has been performed by Weijers et al. ${ }^{37}$. 


\section{Study protocol}

During the motion analysis force measurements are performed in three dimensions by a force plate and in one dimension by the plantar pressure plate. The force plate measures a global force vector of the ground reaction force, averaged in space. A pressure plate measures the vertical component of the ground reaction force on a high resolution. Ideally these measurements would be combined, yielding a high resolution measurement of three dimensional force vectors. Attempts have been performed in the development of this measurement device; however no fully validated device is available. During the series of loaded CT-scans it is impossible to measure loading with a force plate and pressure plate because of scattering. This problem is solved by using a plantar pressure insole to measure plantar pressure during scanning.

Despite previous mentioned shortcomings of the measurements, this protocol will lead to a unique dataset involving highly detailed anatomical data and a dynamic biomechanical dataset. This dataset will be used to develop scalable biomechanical foot models for deeper knowledge of the foot function and an endeavour to predict the effect of (ankle) foot orthotic design. The next step will be a trial for clinical evidence for the use of the model for the development of ankle and foot orthoses, which may lead to improved efficacy. 


\section{Chapter 2}

\section{References}

1. Garrow AP, Silman AJ, Macfarlane GJ. The Cheshire Foot Pain and Disability Survey: a population survey assessing prevalence and associations. Pain. 2004;110:378-384.

2. Barr EL, Browning C, Lord SR, Menz HB, Kendig H. Foot and leg problems are important determinants of functional status in community dwelling older people. Disability and Rehabilitation. 2005;27:917-923.

3. Spahn G, Schiele R, Hell AK, Klinger HM, Jung R, Langlotz A. The prevalence of pain and deformities in the feet of adolescents. Results of a cross-sectional study. Zeitschrift fur Orthopadie und Ihre Grenzgebiete. 2004;142:389-396.

4. Brem H, Sheehan P, Rosenberg HJ, Schneider JS, Boulton AJ. Evidence-based protocol for diabetic foot ulcers. Plastic and Reconstructive Surgery. 2006;117:193S-209S; discussion 210S-211S.

5. Michelson J, Easley M, Wigley FM, Hellmann D. Foot and ankle problems in rheumatoid arthritis. Foot and Ankle International. 1994;15:608-613.

6. Cheng HY, Lin CL, Wang HW, Chou SW. Finite element analysis of plantar fascia under stretch-the relative contribution of windlass mechanism and Achilles tendon force. Journal of Biomechanics. 2008;41:1937-1944.

7. Cheng HY, Lin CL, Chou SW, Wang HW. Nonlinear finite element analysis of the plantar fascia due to the windlass mechanism. Foot and Ankle International. 2008;29:845-851.

8. Commean PK, Mueller MJ, Smith KE, Hastings M, Klaesner J, Pilgram T, Robertson DD. Reliability and validity of combined imaging and pressures assessment methods for diabetic feet. Arch Phys Med Rehabil. 2002;83:497-505.

9. Erdemir A, Saucerman JJ, Lemmon D, Loppnow B, Turso B, Ulbrecht JS, Cavanagh PR. Local plantar pressure relief in therapeutic footwear: design guidelines from finite element models. Journal of Biomechanics. 2005;38:1798-1806.

10. Chao EY, Armiger RS, Yoshida H, Lim J, Haraguchi N. Virtual Interactive Musculoskeletal System (VIMS) in orthopaedic research, education and clinical patient care. J Orthop Surg Res. 2007;2:2.

11. Fang L, Jia X, Wang R. Modeling and simulation of muscle forces of trans-tibial amputee to study effect of prosthetic alignment. Clin Biomech (Bristol, Avon). 2007;22:1125-1131.

12. Blana D, Hincapie JG, Chadwick EK, Kirsch RF. A musculoskeletal model of the upper extremity for use in the development of neuroprosthetic systems. Journal of Biomechanics. 2008;41:1714-1721.

13. Be'ery-Lipperman M, Gefen A. A method of quantification of stress shielding in the proximal femur using hierarchical computational modeling. Comput Methods Biomech Biomed Engin. 2006;9:35-44.

14. Saraswat P, Andersen MS, Macwilliams BA. A musculoskeletal foot model for clinical gait analysis. Journal of Biomechanics. 2010;43:1645-1652.

15. Carbes S, Tørholm S, Telfer S, Woodburn J, Oosterwaal M, Rasmussen J. A new multisegmental foot model and marker protocol for accurate simulation of the foot biomechanics during walking. ISB2011. Brussels 2011.

16. Ruimerman R, Oosterwaal M, Guldemond NA. Optimalisatie van inlegzoolontwerp door gebruik van computer simulaties. NOV2009. Rosmalen, the Netherlands 2009.

17. Garrow AP, Papageorgiou AC, Silman AJ, Thomas E, Jayson MI, Macfarlane GJ. Development and validation of a questionnaire to assess disabling foot pain. Pain. 2000;85:107-113. 
18. Budiman-Mak E, Conrad KJ, Roach KE. The Foot Function Index: a measure of foot pain and disability. Journal of Clinical Epidemiology. 1991;44:561-570.

19. Kuyvenhoven MM, Gorter KJ, Zuithoff P, Budiman-Mak E, Conrad KJ, Post MW. The foot function index with verbal rating scales (FFI-5pt): A clinimetric evaluation and comparison with the original FFI. Journal of Rheumatology. 2002;29:1023-1028.

20. Hyslop E, Woodburn J, McInnes IB, Semple R, Newcombe L, Hendry G, Rafferty D, De Mits S, Turner DE. A reliability study of biomechanical foot function in psoriatic arthritis based on a novel multi-segmented foot model. Gait and Posture. 2010;32:619-626.

21. Hermens HJ, Freriks B, Merletti R, Stegeman D, Blok J, Rau G, Disselhorst-Klug C, Hägg G. European Recommendations for Surface ElectroMyoGraphy, Results of the SENIAM project Enschede, the Netherlands: Roessingh Research and Development; 1999.

22. Klein Horsman MD, Koopman HFJM, van der Helm FCT, Prosé LP, Veeger HEJ. Morphological muscle and joint parameters for musculoskeletal modelling of the lower extremity. Clinical Biomechanics. 2007;22:239-247.

23. Cheung JT, Zhang M, An KN. Effects of plantar fascia stiffness on the biomechanical responses of the ankle-foot complex. Clinical Biomechanics. 2004;19:839-846.

24. Chen WP, Tang FT, Ju CW. Stress distribution of the foot during mid-stance to push-off in barefoot gait: a 3-D finite element analysis. Clinical Biomechanics. 2001;16:614-620.

25. Cheung JTM, Vries G, de, Nigg BM. Biomechanical effects of midfoot fusion - a finite element study. Journal of Biomechanics. 2007;40:S326.

26. Cheung JT, Zhang M. A 3-dimensional finite element model of the human foot and ankle for insole design. Archives of Physical Medicine and Rehabilitation. 2005;86:353-358.

27. Lemmon D, Shiang TY, Hashmi A, Ulbrecht JS, Cavanagh PR. The effect of insoles in therapeutic footwear-a finite element approach. Journal of Biomechanics. 1997;30:615-620.

28. Chen WP, Ju CW, Tang FT. Effects of total contact insoles on the plantar stress redistribution: a finite element analysis. Clin Biomech (Bristol, Avon). 2003;18:S17-24.

29. Actis RL, Ventura LB, Lott DJ, Smith KE, Commean PK, Hastings MK, Mueller MJ. Multi-plug insole design to reduce peak plantar pressure on the diabetic foot during walking. Medical and Biological Engineering and Computing. 2008;46:363-371.

30. Cheung JTM, Zhang M. Parametric design of pressure-relieving foot orthosis using statisticsbased finite element method. Medical Engineering and Physics. 2008;30:269-277.

31. Goske S, Erdemir A, Petre M, Budhabhatti S, Cavanagh PR. Reduction of plantar heel pressures: Insole design using finite element analysis. Journal of Biomechanics. 2006;39:2363-2370.

32. Barani Z, Haghpanahi M, Katoozian $\mathrm{H}$. Three dimensional stress analysis of diabetic insole: a finite element approach. Technology and Health Care. 2005;13:185-192.

33. Hsu YC, Gung YW, Shih SL, Feng CK, Wei SH, Yu CH, Chen CS. Using an optimization approach to design an insole for lowering plantar fascia stress--a finite element study. Annals of Biomedical Engineering. 2008;36:1345-1352.

34. Nester C, Jones RK, Liu A, Howard D, Lundberg A, Arndt A, Lundgren P, Stacoff A, Wolf P. Foot kinematics during walking measured using bone and surface mounted markers. Journal of Biomechanics. 2007;40:3412-3423.

35. Chen S-J, Mukul M, Chou L-S. Soft-Tissue Movement at the Foot During the Stance Phase of Walking. Journal of the American Podiatric Medical Association. 2011;101:25-34. 


\section{Chapter 2}

36. Nester CJ, Liu AM, Ward E, Howard D, Cocheba J, Derrick T. Error in the description of foot kinematics due to violation of rigid body assumptions. Journal of Biomechanics. 2010;43:666-672.

37. Weijers R, Walenkamp G, van Mameren H, van den Hout JAAM. Changes of the soft tissue of the forefoot during loading: a volumetric study. The Foot. 2003;13:70-75. 


\section{CHAPTER 3}

\section{THE GLASGOW-MAASTRICHT FOOT MODEL, EVALUATION OF A 26 SEGMENT KINEMATIC MODEL OF THE FOOT}

Michiel Oosterwaal, Sylvain Carbes, Scott Telfer, James Woodburn, Søren Tørholm, Amir Al-Munajjed, Lodewijk van Rhijn, Kenneth Meijer Journal of foot and ankle research 2016; 9:1-10 


\section{Chapter 3}

\section{Abstract}

Accurately measuring of intrinsic foot kinematics using skin mounted markers is difficult, limited in part by the physical dimensions of the foot. Existing kinematic foot models solve this problem by combining multiple bones into idealized rigid segments. This study presents a novel foot model that allows the motion of the 26 bones to be individually estimated via a combination of partial joint constraints and coupling the motion of separate joints using kinematic rhythms.

Segmented CT data from one healthy subject was used to create a template GlasgowMaastricht foot model (GM-model). Following this, the template was scaled to produce subject-specific models for five additional healthy participants using a surface scan of the foot and ankle. Forty-three skin mounted markers, mainly positioned around the foot and ankle, were used to capture the stance phase of the right foot of the six healthy participants during walking. The GM-model was then applied to calculate the intrinsic foot kinematics.

Distinct motion patterns were found for all joints. The variability in outcome depended on the location of the joint, with reasonable results for sagittal plane motions and poor results for transverse plane motions.

The results of the GM-model were comparable with existing literature, including bone pin studies, with respect to the range of motion, motion pattern and timing of the motion in the studied joints. This novel model is the most complete kinematic model to date. Further evaluation of the model is warranted. 


\section{Background}

The foot is comprised of 26 bones, excluding the sesamoids. Standard gait analysis considers the foot as one rigid segment connected to the shank with a ball joint ${ }^{1}$. Multisegmented kinematic foot models have been developed to model intrinsic foot bone motion ${ }^{2-12}$. These models differ in the number of segments, ranging from two ${ }^{6,8,11}$ to eight segments in the foot ${ }^{5}$, and in the composition of these segments. The hindfoot, for example, has been modelled in at least four different ways, varying in level of detail. These include modelling the calcaneus alone ${ }^{9-11}$, the calcaneus and talus in one segment ${ }^{2,3,6-8}$, including the talus as part of the mid foot ${ }^{5}$, or as two separate segments ${ }^{12}$. Furthermore, for all existing kinematic foot models the navicular bone and the three cuneiforms are modelled as a single rigid segment, an assumption that has been shown to be incorrect. For example, an in vitro study of Nester et al. ${ }^{13}$ has shown substantial motion in three dimensions between navicular and medial cuneiform, central cuneiform and lateral cuneiform of $4.5^{\circ}-11.4^{\circ}, 5.4^{\circ}-9.8^{\circ}$ and $11.2^{\circ}-14.3^{\circ}$ respectively. Current multi-segment kinematic foot models, using standard gait analysis techniques, all use a rigid body assumption to combine individual bones in one segment, based on fixing joints that have been shown to be non-rigid.

Although using rigid bodies leads to the possibility to measure foot kinematics of the nonrigid joints of the chosen kinematic model, motion of joints that are modelled rigidly is neglected. When using kinematic models as an input for musculoskeletal models, these rigid bodies can be of large influence. Since a small change in muscle length can have a large influence on the strength of this muscle. Goal of this research is to generate a kinematic model that is able to capture motion in each joint, so it can be used as an input for a musculoskeletal model of the foot. No kinematic foot model has been presented to measure kinematics of all bones, largely due to the physical dimensions of the foot bones and thus available space to attach markers; it has not been possible to capture the individual motion of all bones using standard gait analysis techniques. Current standard to capture intrinsic foot motion, uses skin mounted markers and the total number of degrees of freedom (DoF) is decreased by combining bones into segments. Another solution to decrease the number of DoF might be the use of kinematic rhythms, described by Wolf et al. ${ }^{14}$ as functional units. These rhythms are based on functional synergies in foot motion, caused by ligamental structures overcrossing multiple joints, e.g. the transverse metatarsal ligaments couple the metatarsal motion. In general, these rhythms represent coupled motion of two or more joints.

The objective of this study was to develop a 26 segment kinematic model of the foot and ankle that used a combination of skin markers and kinematic rhythms to help reduce the 


\section{Chapter 3}

number of DoF. The model was tested on healthy participants and results compared with existing data from literature.

\section{Methods}

Detailed information on the data capturing of the measurements in this chapter has been described in Chapter 2. This section gives a brief overview of the measurements performed to acquire input data for the kinematic model.

\section{Participants}

Ten healthy participants were measured divided over two sites: Glasgow Caledonian University, UK, and Maastricht University Medical Center, the Netherlands. For both sites the local medical ethical committee approved the research. Data from four participants was not used, due to malfunction (one participant) of the measurement devices or incorrect marker capturing (three participants). Incorrect marker capturing was caused by overlapping marker tracks and missing markers that were obscured by the other leg. The demographics of the participants whose data has been used are shown in Table 3.1. Data from one healthy participant was used to create a 'template' kinematic foot model using the AnyBody Modeling System (AnyBody Technology, Aalborg, Denmark). Data from the remaining participants was analysed using subject-specific, scaled versions of the template.

Table 3.1 Anthropometrics of participants - GCU participants were measured at the site in Glasgow, United Kingdom, MAS participants were measured at the site in Maastricht, the Netherlands

\begin{tabular}{|l|l|l|l|}
\hline Participant & Gender & Body Mass & Foot Length \\
\hline GCUC01 & M & $76 \mathrm{~kg}$ & $23.5 \mathrm{~cm}$ \\
\hline GCUC02 & M & $74 \mathrm{~kg}$ & $25.7 \mathrm{~cm}$ \\
\hline GCUC03 & $\mathrm{F}$ & $85 \mathrm{~kg}$ & $23 \mathrm{~cm}$ \\
\hline GCUC05 & M & $76 \mathrm{~kg}$ & $26.2 \mathrm{~cm}$ \\
\hline MAS1 & M & $78 \mathrm{~kg}$ & $27.5 \mathrm{~cm}$ \\
\hline MAS2 & $\mathrm{F}$ & $58 \mathrm{~kg}$ & $23.5 \mathrm{~cm}$ \\
\hline
\end{tabular}

\section{Data capturing}

For all participants static foot surface scans (Easy Foot Scan, Orthobaltic) and motion capture data from at least three successful normal walking trials were recorded. Motion capture data included skin mounted markers (8 cameras Vicon Nexus in Maastricht, 12 
cameras Qualisys in Glasgow) and ground reaction force (GRF) (Kistler 9821A SN in Maastricht, Kistler 9286B in Glasgow).

For one participant $\mathrm{CT}$ data of foot and ankle was acquired during an unloaded situation to provide a template foot model. The CT data was segmented using Mimics software (Materialise NV) to create 26 individual geometrical segments of representing all bones of the human foot, with the exception of the sesamoid bones.

\section{Model implementation}

\section{Bones and Joints}

The basis for the model has been the segmented CT data. This data was used to define the geometry of the bones and position of the bones with respect to each other. The kinematic model has been implemented in the AnyBody Modeling System (AnyBody Technology, Aalborg, Denmark). The joints or kinematic links between the bones of the foot were simulated using a combination of revolute (one rotation allowed), universal (two rotations allowed) and spherical (three rotations allowed) joints, and these are detailed in Table 3.2. Rotation in three directions was possible for the joints in the rearfoot. For segments closer to the forefoot choices had to be made in which direction a motion is allowed, this was mainly due to the lack of space to attach markers for capturing all degrees of freedom. Previous kinematic models showed larger range of motion in the sagittal and transverse plane measurements. De Mits et al. ${ }^{3}$ for example showed smallest range of motion in inversion/eversion for midfoot vs rearfoot and medial forefoot vs midfoot.

Table 3.2 Foot joints modelled in the GM-model

\begin{tabular}{|l|l|}
\hline Joint & Type \\
\hline Ankle & $\begin{array}{l}\text { Revolute (from default human model in AnyBody } \\
\text { Modeling System) }\end{array}$ \\
\hline Subtalar & $\begin{array}{l}\text { Revolute (from default human model in AnyBody } \\
\text { Modeling System) }\end{array}$ \\
\hline talonavicular & spherical \\
\hline calcaneocuboid & spherical \\
\hline $1-3$ cuneonavicular & universal \\
\hline $1-5$ tarsometatarsal(TMT1-5) & universal \\
\hline $1-5$ metatarsophalangeal (MTP1-5) & universal \\
\hline $1-5$ interphalangeal (IP1-5) & revolute \\
\hline
\end{tabular}




\section{Chapter 3}

\section{Rhythms}

Due to the size of the foot not all of the remaining DoF of every segment could be tracked separately. Previous studies have used the rigid body assumption to reduce the number of DoF, in the present model functional units or rhythms were used to constrain the number of DoF in the model and allow the kinematics of all bones to be estimated with a reduced marker set. These rhythms, used in this version of the model, are given in Table 3.3, with additional details given in the appendix.

Table 3.3 Rhytms used and short description of the rythm. A full description can be found in the appendix

\begin{tabular}{|l|l|}
\hline Name of the rythm & Coupled joints \\
\hline IP plantar flexion & For each phalanx inter phalangeal joints \\
\hline MTP plantar flexion1-5 & Flexion of all MTP joints is coupled \\
\hline Metatarsal tranverse arch 1-5 & $\begin{array}{l}\text { An arch is constructed, that couples the height of the } \\
\text { metatarsal heads }\end{array}$ \\
\hline Tarsal tranverse arch 1-5 & Transverse arch coupling motion of all tarsals \\
\hline Longitudinal medial arch & Coupling plantar flexion of joints in the first ray \\
\hline Longitudinal lateral arch & Coupling plantar flexion of Calcaneocuboid joint and TMT5 \\
\hline
\end{tabular}

\section{Inter-tarsal contact}

Between the cuboidnavicular, cuneocuboid and the two intercuneiforms joints no idealised joints were defined. However, these joints do exist and a definition of the interaction between the bones within these joints is needed, to avoid the possibility for the algorithm to move bones within each other. These joints were modelled as gliding joints using an ellipsoid fitted to the lateral side of the tarsal bones. Interaction between these ellipsoids was modelled with a contact algorithm, which did not allow the ellipsoids to intersect.

\section{Scaling}

The model was scaled to each subject using the built in radial basis function (RBF) with a thin plate spline ${ }^{15}$. A set of 16 landmarks (see Figure 3.1) on the surface scan geometry of the participant used for the template was defined, and a corresponding set was defined on each new participant's scan. The system subsequently calculated the RBF function so that the source landmarks matched the target ones. Every point in the volume of the landmarks was scaled with this non-affine transformation. 

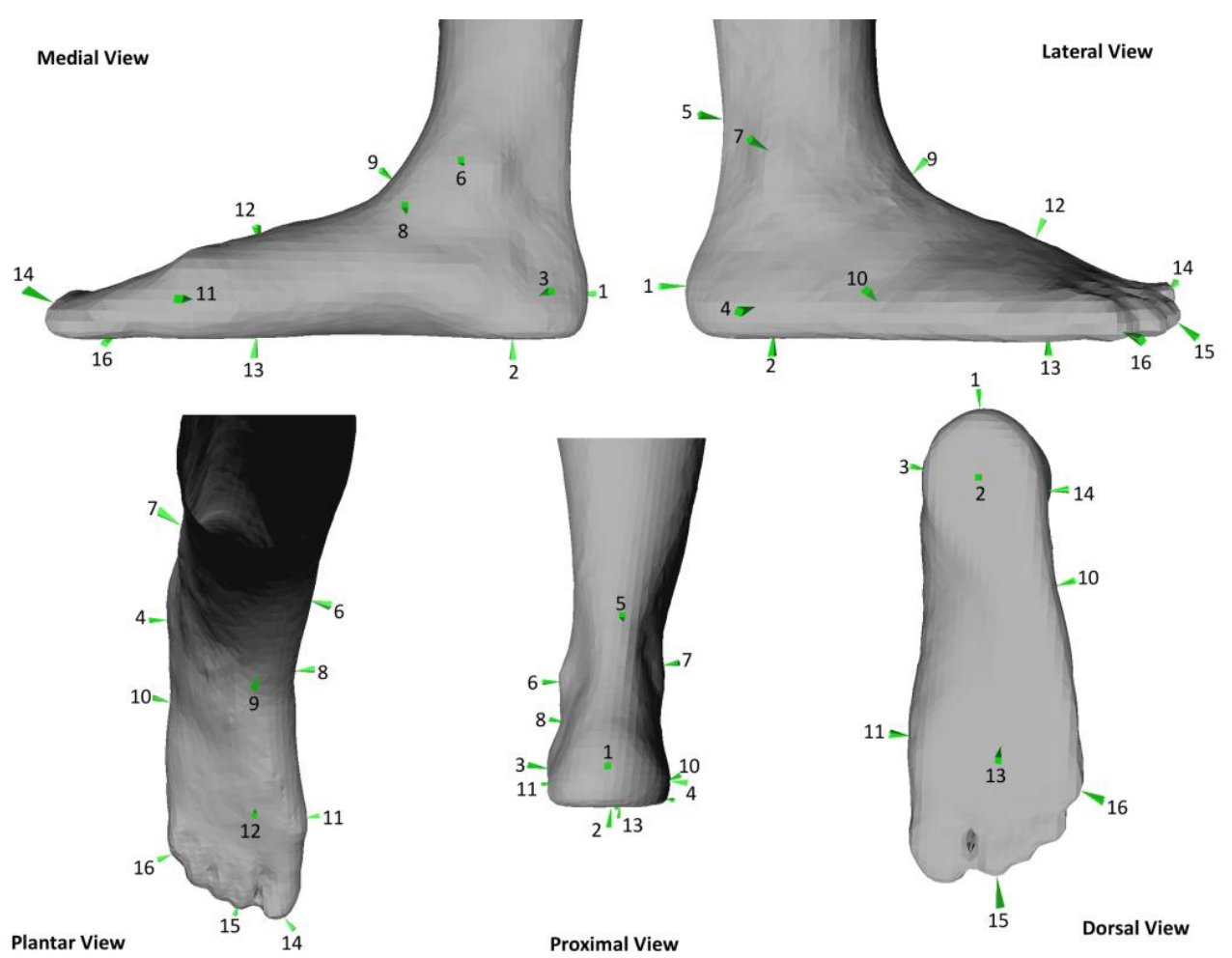

Figure 3.1 Points on which the scaling algorithm is based - 1) Posterior Calcaneus, distal of achillis tendon 2)Central plantar heel 3) Heel medial 4) Heel lateral 5) Achilles tendon between malleoli 6) Malleolus medial 7) Malleolus lateral 8) Navicular tuberosity 9) Navicular dorsal 10) Fifth metatarsal basis 11) First metatarsal head, medial 12)TMT2 dorsal 13) MTP3 plantar 14) Hallux tip 15) Second toe tip 16) Fifth toe tip

\section{Motion and Simulation}

The model was driven using motion capture data from all participants, 3 trials for each subject. A previously described marker protocol with 43 markers on the lower extremities was used ${ }^{16}$. The marker data was used to calculate joint angles in a kinematic analysis of an over-determinate system ${ }^{17}$.

\section{Data analysis}

To compare inter-subject joint angles and to avoid dependency to anatomical neutral position, all angles are subtracted by the angle on heel strike, so at heel strike all angles were set to 0 degrees range of motion (RoM). Data was resampled to intervals of $0.5 \%$ of stance phase, to obtain an inter subject comparison. The mean RoM was calculated per subject over three successful trials. Minimal and maximal RoM over participants was calculated as well as minimum and maximum joint angles. 


\section{Chapter 3}

To quantify the variance in joint angles over the different participants, an adapted version of the coefficient of variation was used. Since joint angles vary around zero, the coefficient of variation would increase significantly for smaller values. Therefore the standard deviation per time step was divided by the full RoM of the corresponding joint (instead of the mean, as undertaken for the coefficient of variation). Subsequently the percentage of the stance phase was calculated, for which this adapted measure was smaller than 0.25 . This measure implies the percentage of stance phase for which $68 \%$ of the participants had a joint angle that differs less than $25 \%$ of the range of motion of the joint. The value of 0.25 was chosen by performing a trial and error sensitivity analysis; it had to be able to distinguish joints with a small error band and those with a large error band. This measure of the variation was called COV25 (range $0-100$, where 0 is a high variance and 100 a low variance).

Since the motion of some DoF are coupled in this model, only selected movements are presented. TMT1 and navicular with medial cuneiform are not shown, as they are coupled with talus navicular (plantar flexion and adduction). Distal interphalangeal joints (2-5) were not shown, since these joints are directly coupled with corresponding proximal interphalangeal joint. All other coupled DoF, as described in the appendix are shown since these joints did not have a one-to-one relation with another joint.

\section{Results}

Combined motion curves for all studied joints are presented in Figure 3.2. In Figure 3.2 the calcaneocuboid and talonavicular joint, the two joints of Chopart's joint, shows different motions in all three directions. This difference can be seen in size and shape of the pattern. In the frontal plane, the calcaneocuboid joint shows both eversion (up to 65\% stance phase) and inversion (from 65\% stance phase), while talonavicular joint shows only eversion. In sagittal plane largest motion in talonavicular joint is in the late stance phase, while calcaneocuboid joint shows largest motion during mid stance. The largest difference is in the transverse plane, mean RoM of 9.8 degrees (calcaneocuboid) and 14.6 degrees (talonavicular), as can be found in Table 3.4.

The navicular to cuneiform joints in Figure $3.2 \mathrm{~b}$ show small RoM of maximal 2.8 degrees in all directions; the lateral and central cuneiform show a similar mean pattern as the talonavicular joint. However, when looking at individual participants different patterns are found in sagittal plane. In the central cuneonavicular joint, five out of six participants show a similar pattern, first dorsiflexion and in late stance phase a quick plantar flexion. While in the lateral cuneonavicular joint no consistency was found in the motion pattern of the different participants 


\section{GM-model}

In the Lisfranc joint in Figure $3.2 \mathrm{c}$ an increasing RoM is found from medial to lateral joints in sagittal plane. Motion in TMT1-3 is showing a different pattern than TMT4-5 in both directions. In the transverse plane an increasing abduction is seen in TMT 4-5, while TMT 2-3 are showing an increasing adduction. Mean RoM in sagittal plane of the GM-model for the individual MTP joints ranges from $22.4^{\circ}-33.5^{\circ}$, with increasing value from MTP 5 till 2 as can be seen in Figure $3.2 \mathrm{~d}$.

In general the largest COV25 within a joint is found in sagittal plane. In the sagittal plane the largest motion was found in MTP1 (RoM = 40.0 degrees, varying from $32.3-46.4$ degrees). 


\section{Chapter 3}
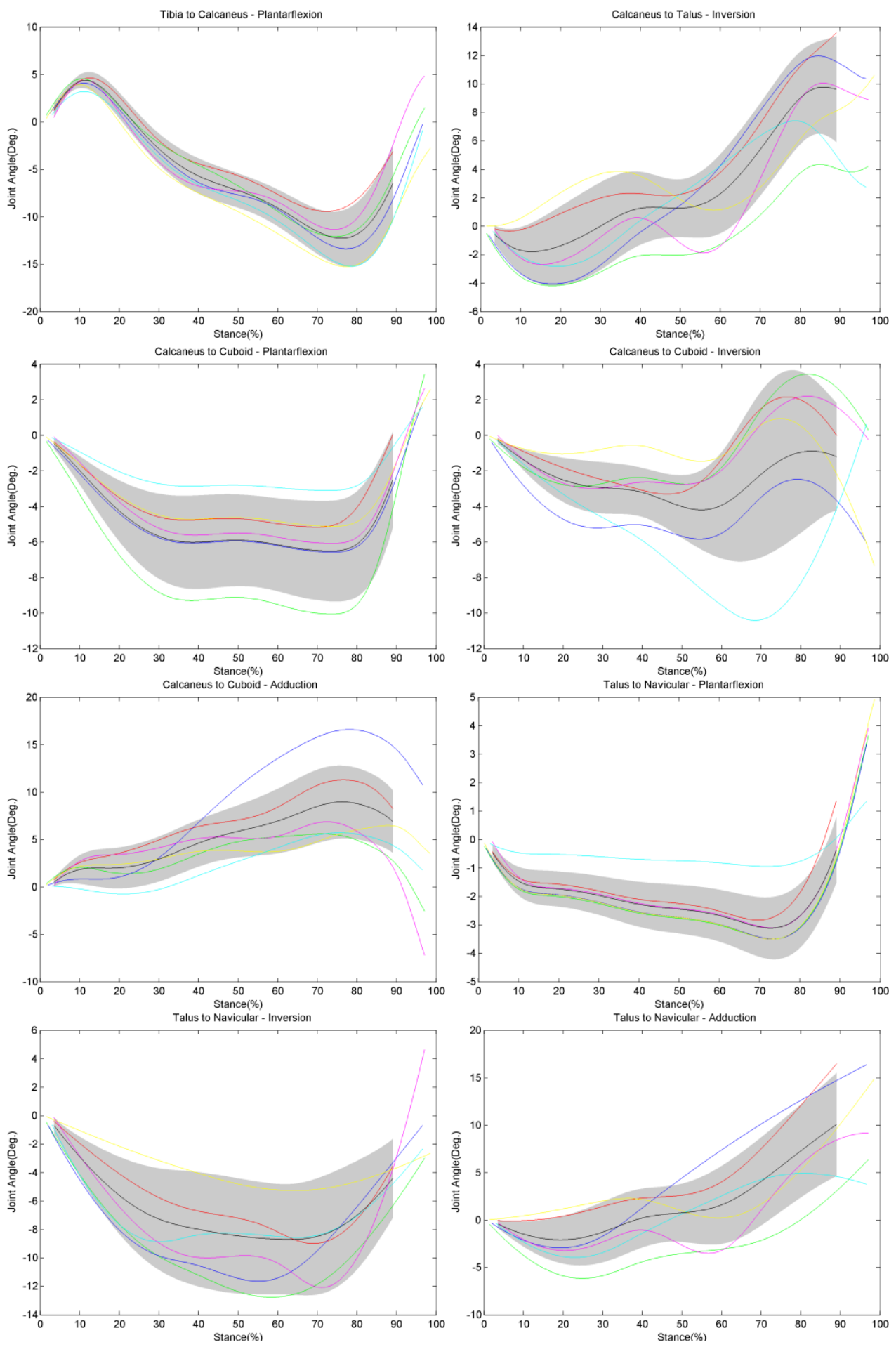
GM-model
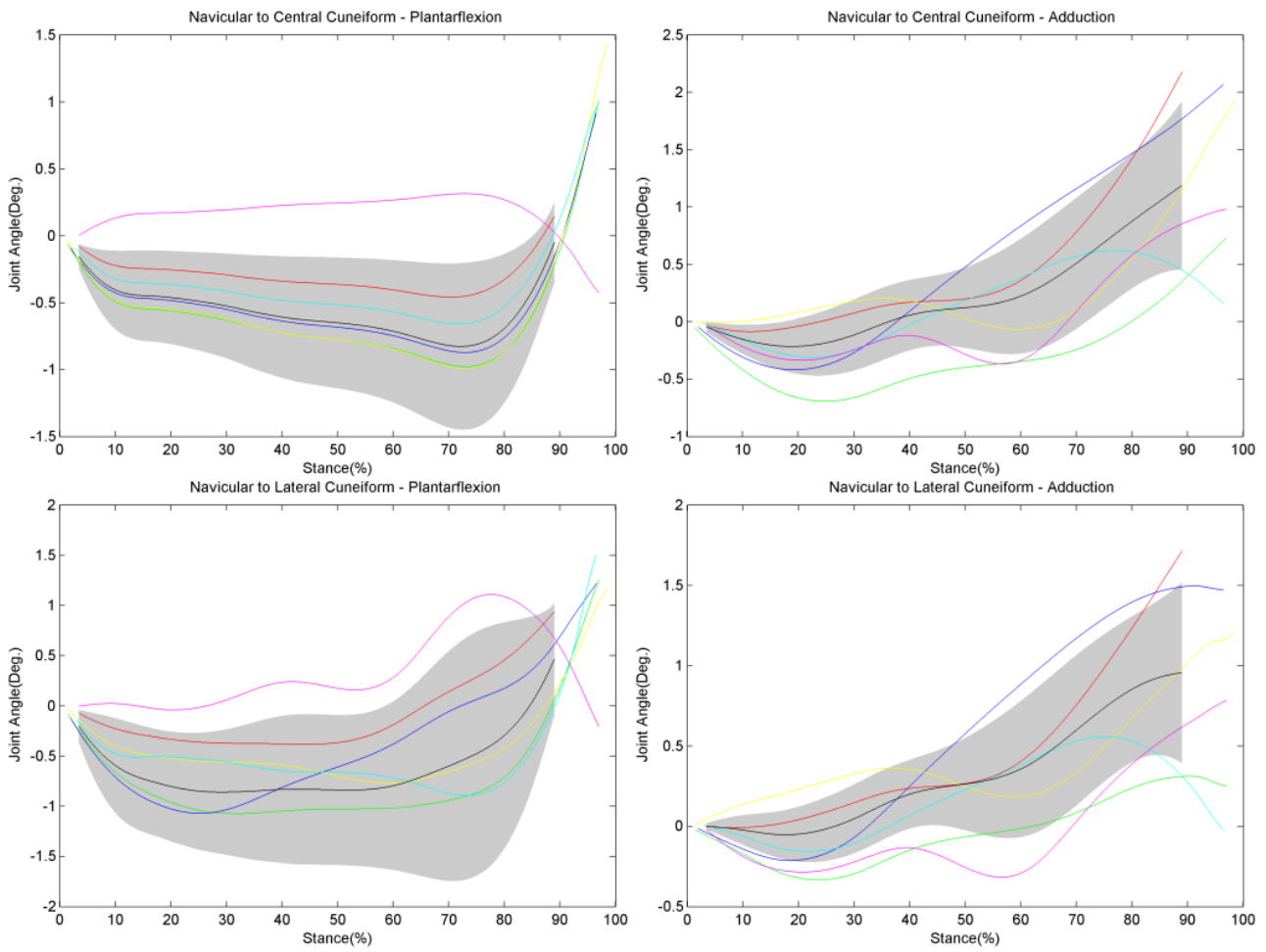


\section{Chapter 3}
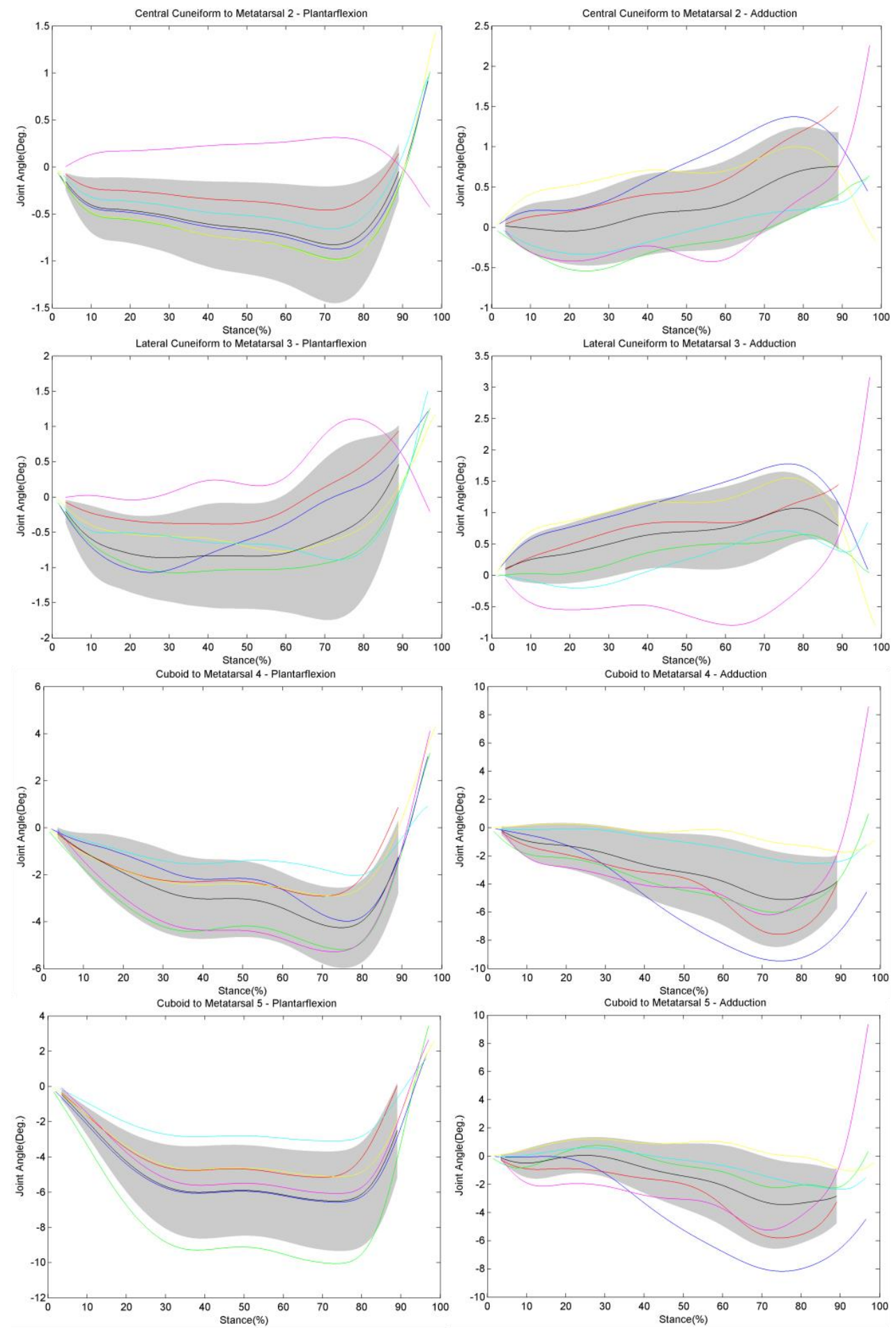
GM-model
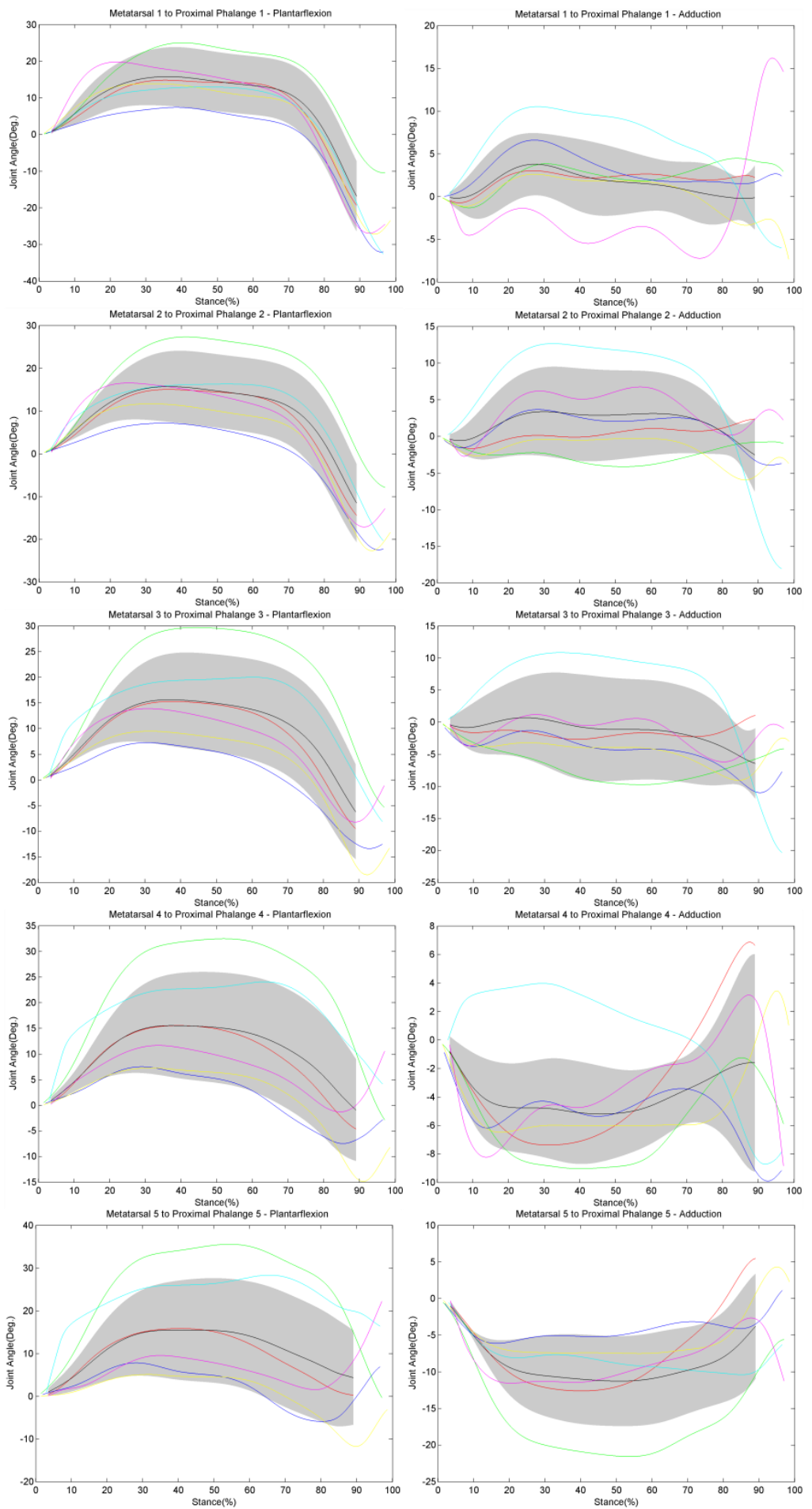


\section{Chapter 3}
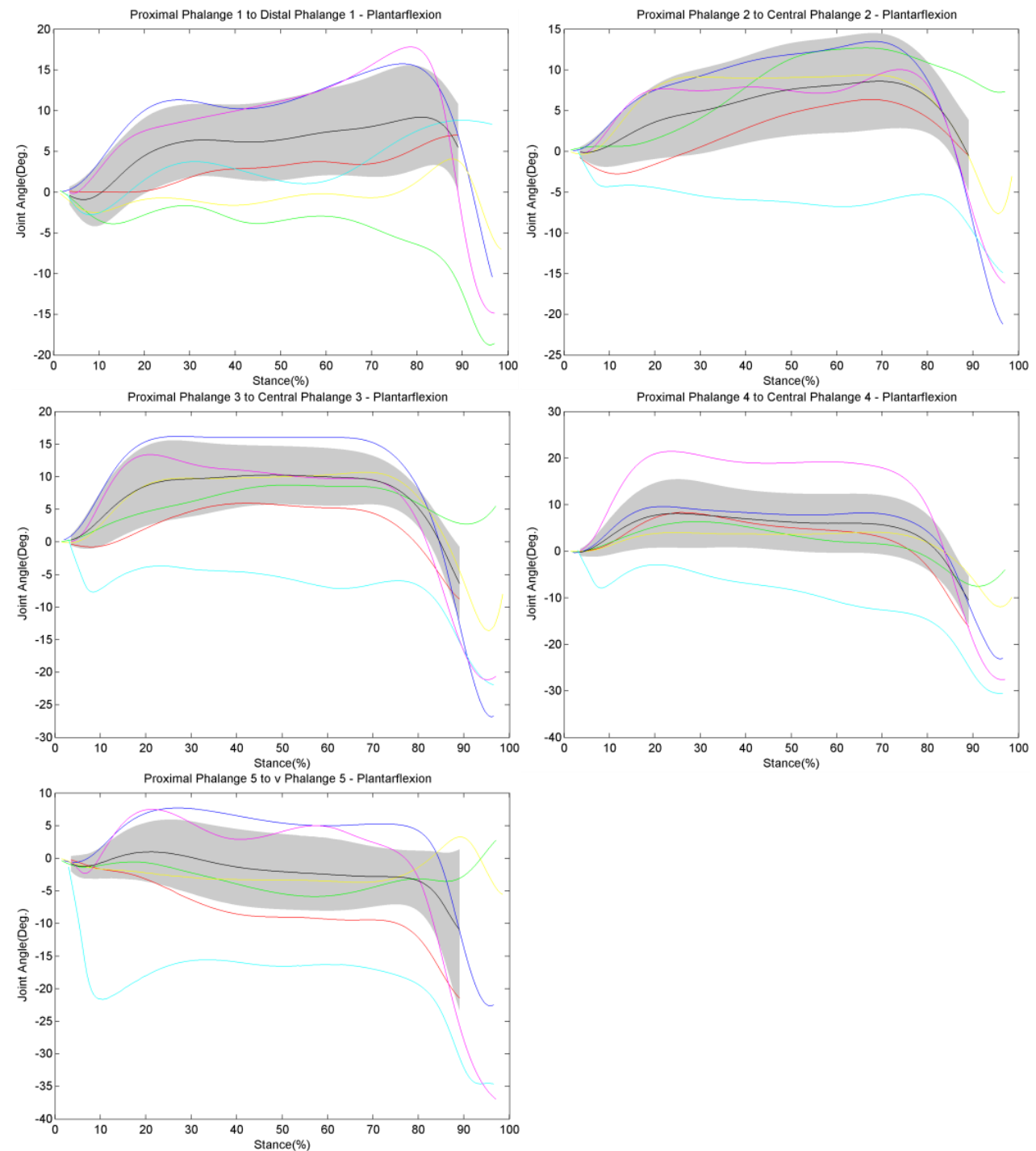

Figure 3.2a-e RoM for all joints - The bold black line is population average, grey band was the population standard deviation (which were only calculated when data for all participants was present on that particular time step). Coloured lines are averaged joint patterns per individual, where joints are grouped by: a) rearfoot to midfoot b) navicular to cuneiforms c) TMT d) MTP e) inter-phalangeal joints 
Table 3.4 Summary of the results - All data was calculated for the complete population

\begin{tabular}{|c|c|c|c|c|c|c|}
\hline & $\begin{array}{l}\text { Mean } \\
\text { RoM }\end{array}$ & $\begin{array}{l}\text { Max } \\
\text { RoM }\end{array}$ & $\begin{array}{l}\text { Min } \\
\text { RoM }\end{array}$ & $\begin{array}{l}\text { Max } \\
\text { Joint } \\
\text { Angle }\end{array}$ & $\begin{array}{c}\text { Min } \\
\text { Joint } \\
\text { Angle }\end{array}$ & $\begin{array}{c}\text { COV } \\
25 \\
(\%)\end{array}$ \\
\hline Tibia to Talus - Plantarflexion & 17.0 & 19.5 & 14.9 & 5.9 & -16.1 & 100 \\
\hline Calcaneus to Talus - Inversion & 12.9 & 16.2 & 9.3 & 15.1 & -4.0 & 97 \\
\hline Calcaneus to Cuboid - Plantarflexion & 8.3 & 13.1 & 5.0 & 3.3 & -11.7 & 29 \\
\hline Calcaneus to Cuboid - Inversion & 7.6 & 12.5 & 5.6 & 4.0 & -11.0 & 56 \\
\hline Calcaneus to Cuboid - Adduction & 9.8 & 15.3 & 6.1 & 15.3 & -4.0 & 27 \\
\hline Talus to Navicular - Plantarflexion & 6.3 & 8.4 & 2.6 & 5.0 & -4.3 & 100 \\
\hline Talus to Navicular - Inversion & 9.3 & 13.7 & 4.0 & 0.9 & -13.7 & 14 \\
\hline Talus to Navicular - Adduction & 14.6 & 18.6 & 9.6 & 17.8 & -6.0 & 70 \\
\hline $\begin{array}{l}\text { Navicular to Central Cuneiform - } \\
\text { Plantarflexion }\end{array}$ & 2.0 & 3.5 & 0.6 & 2.0 & -1.4 & 85 \\
\hline $\begin{array}{l}\text { Navicular to Central Cuneiform - } \\
\text { Adduction }\end{array}$ & 1.8 & 2.4 & 1.1 & 2.3 & -0.7 & 73 \\
\hline $\begin{array}{l}\text { Navicular to Lateral Cuneiform - } \\
\text { Plantarflexion }\end{array}$ & 2.8 & 7.0 & 1.2 & 4.5 & -2.5 & 34 \\
\hline $\begin{array}{l}\text { Navicular to Lateral Cuneiform - } \\
\text { Adduction }\end{array}$ & 1.3 & 1.8 & 0.7 & 1.8 & -0.2 & 58 \\
\hline $\begin{array}{l}\text { Central Cuneiform to Metatarsal } 2 \text { - } \\
\text { Plantarflexion }\end{array}$ & 2.0 & 3.5 & 0.6 & 2.0 & -1.4 & 85 \\
\hline $\begin{array}{l}\text { Central Cuneiform to Metatarsal } 2 \text { - } \\
\text { Adduction }\end{array}$ & 1.6 & 2.3 & 1.1 & 2.1 & -0.6 & 5 \\
\hline $\begin{array}{l}\text { Lateral Cuneiform to Metatarsal } 3 \text { - } \\
\text { Plantarflexion }\end{array}$ & 2.8 & 7.0 & 1.2 & 4.5 & -2.5 & 34 \\
\hline $\begin{array}{l}\text { Lateral Cuneiform to Metatarsal } 3 \text { - } \\
\text { Adduction }\end{array}$ & 2.1 & 3.0 & 1.0 & 2.6 & -0.9 & 26 \\
\hline $\begin{array}{llll}\text { Cuboid to } & \text { Metatarsal } 4 & - \\
\text { Plantarflexion } & & & \end{array}$ & 6.9 & 9.7 & 3.9 & 4.4 & -6.2 & 100 \\
\hline Cuboid to Metatarsal 4-Adduction & 6.4 & 11.1 & 1.8 & 4.9 & -8.2 & 17 \\
\hline $\begin{array}{l}\text { Cuboid to Metatarsal } 5 \text { - } \\
\text { Plantarflexion }\end{array}$ & 8.3 & 13.1 & 5.0 & 3.3 & -11.7 & 29 \\
\hline Cuboid to Metatarsal 5 - Adduction & 5.5 & 10.8 & 2.2 & 6.0 & -7.5 & 25 \\
\hline $\begin{array}{l}\text { Metatarsal } 1 \text { to Proximal Phalange } 1 \text { - } \\
\text { Plantarflexion }\end{array}$ & 40.0 & 46.4 & 32.3 & 28.9 & -33.7 & 100 \\
\hline $\begin{array}{l}\text { Metatarsal } 1 \text { to Proximal Phalange } 1 \text { - } \\
\text { Adduction }\end{array}$ & 11.5 & 19.7 & 5.7 & 12.0 & -10.0 & 12 \\
\hline $\begin{array}{l}\text { Metatarsal } 2 \text { to Proximal Phalange } 2 \text { - } \\
\text { Plantarflexion }\end{array}$ & 33.4 & 40.5 & 27.4 & 31.0 & -28.3 & 42 \\
\hline
\end{tabular}




\section{Chapter 3}

\begin{tabular}{|l|r|r|r|r|r|r|}
\hline $\begin{array}{l}\text { Metatarsal 2 to Proximal Phalange 2 - } \\
\text { Adduction }\end{array}$ & 11.5 & 33.7 & 4.9 & 13.3 & -20.4 & 6 \\
\hline $\begin{array}{l}\text { Metatarsal 3 to Proximal Phalange 3 - } \\
\text { Plantarflexion }\end{array}$ & 27.5 & 36.3 & 21.3 & 33.3 & -22.9 & 29 \\
\hline $\begin{array}{l}\text { Metatarsal 3 to Proximal Phalange 3 - } \\
\text { Adduction }\end{array}$ & 14.3 & 42.3 & 5.9 & 14.3 & -28.1 & 4 \\
\hline $\begin{array}{l}\text { Metatarsal 4 to Proximal Phalange 4 - } \\
\text { Plantarflexion }\end{array}$ & 23.4 & 35.8 & 14.1 & 35.8 & -17.5 & 21 \\
\hline $\begin{array}{l}\text { Metatarsal 4 to Proximal Phalange 4 - } \\
\text { Adduction }\end{array}$ & 11.0 & 16.1 & 9.1 & 8.7 & -10.8 & 4 \\
\hline $\begin{array}{l}\text { Metatarsal 5 to Proximal Phalange 5 - } \\
\text { Plantarflexion }\end{array}$ & 22.4 & 38.7 & 12.8 & 38.7 & -12.8 & 13 \\
\hline $\begin{array}{l}\text { Metatarsal 5 to Proximal Phalange 5 - } \\
\text { Adduction }\end{array}$ & 14.5 & 22.3 & 7.8 & 6.7 & -22.3 & 19 \\
\hline $\begin{array}{l}\text { Proximal Phalange 1 to Distal } \\
\text { Phalange 1 - Plantarflexion }\end{array}$ & 19.8 & 31.4 & 6.5 & 19.2 & -16.4 & 65 \\
\hline $\begin{array}{l}\text { Proximal Phalange 2 to Central } \\
\text { Phalange 2 - Plantarflexion }\end{array}$ & 16.1 & 30.4 & 5.9 & 17.6 & -13.7 & 13 \\
\hline $\begin{array}{l}\text { Proximal Phalange 3 to Central } \\
\text { Phalange 3 - Plantarflexion }\end{array}$ & 22.0 & 37.8 & 9.8 & 19.1 & -19.0 & 70 \\
\hline $\begin{array}{l}\text { Proximal Phalange 4 to Central } \\
\text { Phalange 4 - Plantarflexion }\end{array}$ & 25.5 & 48.1 & 16.3 & 21.1 & -27.0 & 27 \\
\hline $\begin{array}{l}\text { Proximal Phalange 5 to v Phalange 5 - } \\
\text { Plantarflexion }\end{array}$ & 22.4 & 42.9 & 8.0 & 17.4 & -35.8 & 13 \\
\hline
\end{tabular}

\section{Discussion}

A novel kinematic foot and ankle model is presented. This model is scalable via 3D surface scanning of the foot shape, and kinematically-driven by a set of 43 skin-mounted markers. To calculate kinematics for all joints connecting the 26 bones in the foot, seven rhythms are implemented. These rhythms are mathematical formulations that couple the motion of multiple bones, and are adaptable to model specific foot deformities in the future. To our knowledge this is the first study that reported on mobility of the majority of joints in the foot using skin based markers. Calculated RoM of the joints are in line with previous findings $2,3,5,9,13,18,19$, however for some joints no comparable data is available.

\section{Comparison with existing literature}

Full RoM of MTP1 in sagittal plane of $40.0^{\circ}$ is comparable with results on cadaver feet ${ }^{13}$ and existing multi-segment foot models $2,3,5,18$, also the timing of plantar flexion and 
dorsal flexion are visually comparable with existing data. Full RoM in the transverse plane of MTP1 is comparable to results from cadaver experiments ${ }^{13}$. However, the timing in the cadaver experiments is different, for instance in the GM-model no abduction was seen at the end of stance phase. This difference in timing might be caused by the timing of the external forces driving the cadaver experiments. Comparing with other multi-segment foot models that include MTP1 no consistency has been found between the various multisegment foot models 2, 3, 5, 18. As in other models, RoM for MTP1 in transverse plane in the GM-model also shows a low COV25, the reason for this could be a large inter subject variation or a DoF that is hard to measure.

Typically, the RoM of MTP joints 2-5 are not included separately in multi-segment foot models. However, MacWilliams et al. ${ }^{5}$ used a model that separated the phalanges in medial (second and third) and lateral (fourth and fifth) phalanges. Compared to our data, MacWilliams et al. ${ }^{5}$ showed larger RoM for the lateral phalanges in the sagittal plane. However, the shape of the curves was similar to our findings. This could be caused by the differences between the participant groups, the current study involved adults, while MacWilliams et al. were measuring on adolescents (12.49 \pm 2.6 years), Nigg et al. showed a decreasing flexibility with age in the foot ${ }^{20}$. For the transverse plane our results are comparable with the results of MacWilliams et al. ${ }^{5}$ for shape and magnitude. Although the GM-model shows a large inter-subject variation for MTP2-5, comparison with 1 other experiment ${ }^{5}$ shows a moderate comparison.

Motion for individual TMT-joints has not been reported using skin mounted markers. However, MacWilliams et al. ${ }^{5}$ did report motion between medial metatarsals and tarsal bones (mean RoM in sagittal plane $15^{\circ}$, in transverse plane $7^{\circ}$ ) and lateral metatarsals and tarsal bones (mean sagittal RoM $10^{\circ}$, in transverse plane $4^{\circ}$ ). Results of the GM-model showed a much lower RoM in sagittal plane for TMT I-V. However, transverse plane motion for TMT IV $\left(8^{\circ}\right)$ and $V\left(7^{\circ}\right)$ is higher in the GM-model compared to the MacWilliams model. The Ghent Foot Model ${ }^{3}$ divided the TMT motion in TMT I and a combined motion for TMT II-TMT V. In this model, TMT I motion is defined with respect to all tarsal bones in contrast to the GM-model in which it is only linked to the medial cuneiform, however motion pattern and magnitude in transverse and sagittal plane differs compared to our results. In the sagittal plane an opposite motion is noticed for TMT I and TMT II - TMT V in the Ghent Foot Model, this large difference seems to be an effect of the rigid body assumption to combine Metatarsal 2-5 and all tarsals. Alternatively, Leardini et al. ${ }^{9}$ measured combined tarsal and metatarsal bones, transverse and sagittal plane motion was in the same range as TMT IV and TMT V of the GM-model. However, the pattern is not comparable, this could be caused by the combination of all tarsals and all metatarsals into two segments by Leardini et al. ${ }^{9}$. Since the GM-model shows different patterns for TMTI- 


\section{Chapter 3}

TMTV, the summation of these different patterns into one motion of one joint that describes all these separate motions leads to a motion that cannot be compared.

Previous kinematic foot models have taken all tarsal bones as one segment, therefore the midfoot kinematics of the GM-model can only be compared with cadaver ${ }^{13}$ and bone-pin studies ${ }^{19}$. Compared to cadaver studies, the RoM of medial cuneonavicular joint in the sagittal plane was lower in the GM-model during start of stance phase but was similar at the end of the stance phase. No consistent pattern was observed for this joint in the bonepin study of Lundgren ${ }^{19}$. In the transverse plane the cadaver and bone-pin studies measured opposite motion. Our results are closer to bone-pin study ${ }^{19}$. The RoM of the other cuneonavicular joints (central and lateral cuneonavicular joint) has only been measured in cadaver experiments, for both joints sagittal joint motion was lower in the GM-model, however standard deviation in the cadaver experiments was very high $\left(5.1^{\circ} \pm\right.$ $9.8^{\circ}$ and $\left.3.6 \pm 14.3^{\circ}\right)$, where the consistency for the GM-model was moderate to high $(0.85$ and 0.34). The RoM in the transverse plane of central cuneonavicular joints was of the same magnitude and has a similar pattern of motion for the GM-model and the cadaver experiments; however the cadaver experiment showed a large variance $\left(2.2^{\circ} \pm 5.4^{\circ}\right)$.

The calculated RoM of talonavicular joint of the GM-model is partly comparable with previous bone pin data ${ }^{19}$, with a late stance plantar flexion, mid stance eversion. However, transverse plane motion of the GM-model shows a different pattern, comparable to the cadaver experiments ${ }^{13}$. Calcaneocuboid joint motion in frontal and sagittal plane followed the same pattern as the cadaver experiments. However transverse plane motion was of a different pattern in the cadaver experiment and bone pin studies. The RoM of calcaneocuboid joint in GM-model was similar in pattern and magnitude as reported by the MacWilliams model ${ }^{5}$, which is currently the only kinematic model that measures this joint. Other multi-segment foot models only measured complete Transverse tarsal (or Chopart's) joint. We did not combine the calcanocuboid and the talonavicular joint RoM of the GM-model into a combined joint, since these two separate joints show a different pattern.

To the authors' knowledge dynamic RoM of inter-phalangeal joints was not measured before, this might be because of the high resolution needed to accurately measure the motion of small bones.

All in all, no consensus was found in existing literature for most of the joints. However, the novel GM- model showed RoM's within the variations reported across existing literature. The source for the difference within existing literature and when compared with the GMmodel can be in different segment and joint definition and marker placement.. Furthermore, there could be compensation in directions in which no motion was allowed, most joints have 2 DoF and no motion is allowed for eversion and inversion, while cadaver 
and bone-pin studies have shown physical motion in all three planes. Therefore physical motion in a non-modelled direction, can be seen by the model as a motion in a direction that is modelled, this leads to a wrong prediction of the motion.

Another source of differences between existing literature and the results of the GM-model is the different angle definition. The GM-model used joint angles in the local orientation of that joint. While cadaver experiments and bone pin studies do not model joints, but consider absolute differences between the orientations of two bones with respect to the axis of the measurement system. Therefore more distal joints will have a larger deviation, since their orientation is influenced by proximal joints.

\section{Limitations}

Limitations of the study are: 1) the small number of participants, 2) the comparison with literature, rather than with subject specific golden standard data, 3) no separate analysis on the effect of scaling and 4) the lack of an inter- and intra-subject variations analysis.

One of the limitations of the current study is that data from six out of ten participants was used. The exclusion of three of the participants was caused by an incorrect marker tracking. This is probably caused by the number of cameras used in the experiment, since these three participants were measured at the Maastricht site, with an eight camera-set up. Due to this small number of cameras it is difficult to position the cameras. On the one hand they should be close enough to capture the small markers on the foot. On the other hand the cameras should have sufficient distance to the foot to avoid reflection of the foot and to increase the field of view. The bandwidth of this positioning is small and is a source error, which can be reduced by increasing the number of cameras or the resolution of the cameras.

The measurement of foot and ankle kinematics currently does not have a gold standard to measure bone motion in a non-invasive, three dimensional, dynamic situation. We have compared results of the GM-model with available data sources. However, a better validation would be possible when novel techniques are further developed, e.g. dynamic MRI and 3D fluoroscopy ${ }^{21}$.

Another limitation is that no experiments have been performed to the effect of the scaling. To decrease the error caused by marker misplacement, it has been chosen to use an extra surface scan to scale the model. However, this scaling is based on 16 points on the foot and ankle, in contrast to the $\mathbf{3 0}$ markers used to trace the dynamic system. A sensitivity analysis should be performed to calculate the effect of the scaling.

Before using this model for clinical research it is necessary to study intra- and inter-session variations ${ }^{22}$. This study only focussed on the development of the model and the validation 


\section{Chapter 3}

of its output. Intra session variations are expected to be small, due to the use of the kinematic analysis of an over-determinate system ${ }^{17}$.

The rhythms coupled the motion of various joints; therefore the total number of DoF is decreased. Nevertheless, this model shows the ability of driving all segments. Due to the set-up of the model, it is possible to adapt the model to the needs of a specific research question. It is also possible to model the biomechanical aspects of a specific pathology by adapting the parameters of the rhythms or change or remove and add certain rhythms if, for example, a joint is fixed by an arthrodesis. Since the position of all bones can be computed with this kinematic model, this model will be included in a novel musculoskeletal 26 segment foot model. Since muscles are attached to all bones of the foot, motion within the foot leads to different work lines for muscles and therefore different force characteristics.

\section{Conclusions}

In conclusion, we have developed a 26 segments kinematic foot model, which uses coupling of DoF to reduce the total number of DoF. The GM-model has showed a large inter subject variance in the kinematic results, which is in accordance to reported variances in previously reported kinematic foot models. Also in comparison with highly invasive, in-vivo, measurements, the novel model gives similar results. An application of this model is the possibility to test the effect of assumptions made in earlier models, by comparing the results of the model with current settings to a model with locked joints to simulate multi-bone segments. Another application of this model is the use as an input for a musculoskeletal foot model, giving further insights in the intrinsic muscle activation during gait. 


\section{References}

1. Apkarian J, Naumann S, Cairns B. A three-dimensional kinematic and dynamic model of the lower limb. Journal of Biomechanics. 1989;22:143-155.

2. Carson MC, Harrington ME, Thompson N, O'Connor JJ, Theologis TN. Kinematic analysis of a multi-segment foot model for research and clinical applications: a repeatability analysis. Journal of Biomechanics. 2001;34:1299-1307.

3. De Mits S, Segers V, Woodburn J, Elewaut D, De Clercq D, Roosen P. A clinically applicable six-segmented foot model. Journal of Orthopaedic Research. 2012;30:655-661.

4. Tome J, Nawoczenski DA, Flemister A, Houck J. Comparison of Foot Kinematics Between Subjects With Posterior Tibialis Tendon Dysfunction and Healthy Controls. Journal of Orthopaedic \& Sports Physical Therapy. 2006;36:635-644.

5. MacWilliams BA, Cowley M, Nicholson DE. Foot kinematics and kinetics during adolescent gait. Gait \& Posture. 2003;17:214-224.

6. Davis RB, Jameson EG, Davids JR, Christopher LM, Rogozinski BM, Anderson JP. The Design, Development and Initial Evaluation of a Multisegment Foot Model for Routine Clinical Gait Analysis. In: Harris GF, Smith PA, Marks RM, eds. Foot and Ankle Motion Analysis: CRC Press; 2008:425-444.

7. Saraswat P, MacWilliams BA, Davis RB. A multi-segment foot model based on anatomically registered technical coordinate systems: Method repeatability in pediatric feet. Gait \& Posture. 2012;35:547-555.

8. Rattanaprasert U, Smith R, Sullivan M, Gilleard W. Three-dimensional kinematics of the forefoot, rearfoot, and leg without the function of tibialis posterior in comparison with normals during stance phase of walking. Clinical Biomechanics. 1999;14:14-23.

9. Leardini A, Benedetti MG, Berti L, Bettinelli D, Nativo R, Giannini S. Rear-foot, mid-foot and fore-foot motion during the stance phase of gait. Gait and Posture. 2007;25:453-462.

10. Leardini A, Benedetti MG, Catani F, Simoncini L, Giannini S. An anatomically based protocol for the description of foot segment kinematics during gait. Clinical Biomechanics. 1999;14:528-536.

11. Hunt $A E, M$. Smith $R$, Torode $M$, Keenan $A-M$. Inter-segment foot motion and ground reaction forces over the stance phase of walking. Clinical Biomechanics. 2001;16:592-600.

12. Arampatzis $A$, Brüggemann G-P, Klapsing GM. A three-dimensional shank-foot model to determine the foot motion during landings. Medicine and science in sports and exercise. 2002;34:130-138.

13. Nester CJ, Liu AM, Ward E, Howard D, Cocheba J, Derrick T, Patterson P. In vitro study of foot kinematics using a dynamic walking cadaver model. Journal of Biomechanics. 2007;40:19271937.

14. Wolf P, Stacoff A, Liu A, Nester C, Arndt A, Lundberg A, Stuessi E. Functional units of the human foot. Gait \& Posture. 2008;28:434-441.

15. Buhmann MD. Radial basis functions: theory and implementations: Cambridge university press Cambridge; 2003.

16. Oosterwaal M, Telfer S, Torholm S, Carbes S, van Rhijn LW, Macduff R, Meijer K, Woodburn J. Generation of subject-specific, dynamic, multisegment ankle and foot models to improve orthotic design: a feasibility study. BMC Musculoskelet Disord. 2011;12:256.

17. Andersen MS. Kinematically Over-determinate Musculoskeletal Systems: Aalborg University. Department of Mechanical Engineering; 2009. 


\section{Chapter 3}

18. Simon J, Doederlein L, McIntosh AS, Metaxiotis D, Bock HG, Wolf SI. The Heidelberg foot measurement method: Development, description and assessment. Gait \& Posture. 2006;23:411-424.

19. Lundgren $P$, Nester $C$, Liu A, Arndt A, Jones R, Stacoff A, Wolf $P$, Lundberg A. Invasive in vivo measurement of rear-, mid- and forefoot motion during walking. Gait \& Posture. 2008;28:93-100.

20. Nigg B, Fisher V, Allinger T, Ronsky J, Engsberg J. Range of motion of the foot as a function of age. Foot \& Ankle International. 1992;13:336-343.

21. laquinto JM, Tsai R, Haynor DR, Fassbind MJ, Sangeorzan BJ, Ledoux WR. Marker-based validation of a biplane fluoroscopy system for quantifying foot kinematics. Medical engineering \& physics. 2014;36:391-396.

22. Deschamps K, Staes F, Roosen P, Nobels F, Desloovere K, Bruyninckx H, Matricali GA. Body of evidence supporting the clinical use of $3 \mathrm{D}$ multisegment foot models: a systematic review. Gait \& posture. 2011;33:338-349. 


\section{Appendix - Rhythms}

\section{Inter phalangeal plantar flexion}

A toe flexion rhythm was introduced in order to link the flexion of all toes. The kinematic measures of proximomedialphalange flexion (PIP joint flexion: $\phi$ ) and distalphalange flexion (DIP joint flexion: $\omega$ ) are linked together by one coefficient, so that it becomes oneDoF. For phalange 2-5, the rhythm equation can subsequently be written (in degrees):

$$
2.2 \varphi=\omega
$$

In which the factor 2.2 is an estimation based on visual observations on healthy volunteers.

\section{Metatarsophalangeal plantar flexion1-5}

The five metatarsophalangeal joint flexions are linked together by three linear equations so that when the first and fifth metatarsophalangeal flexions are defined, the second, third and fourth are evenly distributed in between. The rhythm equations can subsequently be written (in degrees):

$$
\begin{aligned}
& \vartheta_{2}=\vartheta_{1}-1 / 4\left(\vartheta_{1}-\vartheta_{5}\right) \\
& \vartheta_{3}=\vartheta_{1}-2 / 4\left(\vartheta_{1}-\vartheta_{5}\right) \\
& \vartheta_{4}=\vartheta_{1}-3 / 4\left(\vartheta_{1}-\vartheta_{5}\right)
\end{aligned}
$$

\section{Metatarsal tranverse arch 1-5}

A rhythm has been implemented to control the curvature of the metatarsal transverse arch, and thus its rising and flattening. The height of the second $(\alpha)$, third $(\beta)$ and fourth $(\gamma)$ metatarsal head is measured from a base line connecting the first and fifth metatarsal head. Then the heights of the second and fourth metatarsal head are linked by a coefficient to the height of the third (equations 5 and 6 ).

$$
\begin{aligned}
& \alpha=0.7 B \\
& \gamma=0.9 B
\end{aligned}
$$

\section{Tarsal tranverse arch 1-5}

The tarsal transverse arch consisting of the three cuneiform, the cuboid, and the base of the five metatarsals is modeled to flatten like the metatarsal transverse arch during the stance phase of gait. The base line connects the plantar base of the first metatarsal and the plantar base of the fifth metatarsal. The curvature is controlled by the height of the plantar base of the second metatarsal. 


\section{Chapter 3}

\section{Longitudinal medial arch}

The plantar flexion angle of the talonavicular joint, naviculomedialcuneiform joint and first tarsometatarsal joint are linked by two coefficients to form a single degree of freedom. The curvature is thus controlled by the talonavicular flexion angle.

TaloNavicularFlexion $=2 *$ NaviculoMedCunFlexion $=2 *$ TMT1Flexion $\quad(7)$

\section{Longitudinal lateral arch}

The longitudinal lateral arch is defined similarly by linking the flexion angle of the calcaneocuboid joint and fifth tarsometatarsal joint. The curvature is thus controlled by the calcaneocuboid plantarflexion angle.

CalcaneoCuboidFlexion $=2 *$ TMT5Flexion 


\section{CHAPTER 4}

\section{TEST-RETEST REPEATABILITY OF THE GLASGOW- MAASTRICHT FOOT MODEL}

Michiel Oosterwaal, Joost van Dijsseldonk, Adhiambo Witlox, Lodewijk van Rhijn, Kenneth Meijer

Submitted 


\section{Chapter 4}

\section{Abstract}

Recently a 26 segments kinematic foot model has been presented: the GlasgowMaastricht foot model. This model is used to estimate the kinematics in 22 joints in the foot and ankle. However, test-retest repeatability of the model has not been studied. This paper reports on the intra subject repeatability of the Glasgow-Maastricht foot model.

Gait analysis of the right foot of eight healthy participants was performed during two sessions with approximately four days $(4.4 \pm 2.6$ days) in between. Kinematics were calculated using the Glasgow-Maastricht foot-model. Subsequently, the range of motion of each degree of freedom was calculated. By comparing the two sessions the overall intraclass coefficient $(3, \mathrm{k})$ (ICC) of the model was calculated. Mean ICC and standard errors for the maximum and minimum joint angle and the range of motion for all degrees of freedom was calculated.

The ICC of the Glasgow-Maastricht foot model is 0.67 ( $95 \% \mathrm{Cl}-0.51$ to 0.95 ). ICC of the range of motion showed good to excellent agreement for most (57\%) of the degrees of freedom. Three degrees of freedom showed an unacceptable standard error of the measurement $(\mathrm{SEM})$ for range of motion $\left(>5^{\circ}\right)$. The minimum angle showed unacceptable SEM for four degrees of freedom and for the maximum angle this was the case for eight degrees of freedom. All unacceptable SEMs were found in the forefoot.

This study showed moderate to good test-retest repeatability of the Glasgow-Maastricht foot model. 


\section{Background}

Last two decades various kinematic foot and ankle models have been presented ${ }^{1-12}$. Due to technical restrictions the first studies modelled the complete foot and ankle complex as a single segment connected to the shank with a hinge joint ${ }^{13}$. As spatial and temporal resolution increased, more detailed foot and ankle models were made possible. In 2002 the Oxford foot model ${ }^{1}$ was presented, modelling hindfoot, forefoot and hallux. Later the Heidelberg ${ }^{2}$, Rizzoli ${ }^{3}$ and Ghent model ${ }^{4}$ were introduced, with an increased number of segments. These models, as well as all other reported kinematic foot and ankle models, use a rigid body assumption to capture motion of 26 bones in a reduced number of kinematic segments. According to this assumption multiple bones can be combined into a single segment. Which bones are combined and where the joints are located varies between the kinematic models.

Recently, Oosterwaal et al. ${ }^{14}$ presented the Glasgow Maastricht foot model (GM-model), a 26 segment model. The reported model has 22 joints in the foot and ankle. Instead of using a rigid body assumption, this model introduces rhythms to coordinate kinematics of multiple bones. In principle, this modelling approach allows modelling of kinematics in all joints of the foot and ankle.

The kinematics of the GM-model have shown good comparison with in vitro measurements of cadaver experiments and in vivo invasive bone pin studies. However, the repeatability of the model outputs has not yet been tested. Repeatability is necessary in clinical intervention studies to assure that the change in foot and ankle kinematics between pre and post intervention can be attributed to the intervention and is not obscured by the lack of repeatability of the model. Therefore, an intra and inter session repeatability study with the GM-model is necessary.

Repeatability studies of existing foot models have shown moderate to good repeatability. For instance, the Rizzoli model has shown to have inter day coefficient of multiple correlations $(\mathrm{CMC})$ ranging from 0.51 for calcaneus metatarsus to 0.86 for calcaneus midfoot angle ${ }^{15}$. Research into the repeatability of the Oxford foot model in adults has shown similar results. For example van Hoeve et al. ${ }^{16}$ showed intraclass correlation coefficient (ICC) for intra-observer repeatability on RoM from 0.50 to 0.99 . It is unknown if the high level of detail in the GM-model is combined with a good test-rets repeatability. The aim of current study is to examine the test-retest repeatability of the GM-model in healthy subjects. 


\section{Chapter 4}

\section{Methods}

\section{Study population}

Eight healthy participants were included in this study. Patient demographics (height, weight, foot/lower leg/upper leg length, knee/ankle width) were collected; these data are used in the scaling of the model. Inclusion criteria were: subjects should be able to walk barefooted for $100 \mathrm{~m}$ without any complaints and should be older than 18 years. Exclusion criteria were: history of foot and ankle injuries, anatomical abnormalities (pes planus, pes valgus and hallux valgus), neuro-muscular abnormalities and diabetes mellitus. All participants volunteered and were included in May - December 2014. All participants signed informed consent; the study was approved by the institutional ethics committee at Maastricht University Medical Centre (METC 14-04-80).

\section{Study design}

Gait analysis of the right foot was performed twice, with approximately four days in between. A weight bearing 3D surface scan (Easy Foot Scan, Orthobaltic, Kaunas, Lithuania) of the bare foot was conducted, which is required for the scaling of the GMmodel ${ }^{14}$. Subjects were outfitted with 30 markers attached with double sided tape on the right foot and an additional 13 markers on the leg and pelvis, in Table 4.1 markers have been listed. Marker placement was performed by one researcher, who has placed the markers of the GM-model on ten subjects prior to this experiment. Marker location was found using physical palpation while the participant was in weight bearing position. To assess the foot kinematics, 3D motion capture was conducted using a motion capture system with 16 camera's (6 MX3, 8 T10 and 2 T20 running at $200 \mathrm{~Hz}$, Vicon Motion System Ltd., Oxford metric, UK). Assessment of foot kinematics was synchronised with recordings of the ground reaction force (GRF) (BP400600, AMTI, USA) to identify stance phase in normal gait. 
Table 4.1 List of markers of the GM-model

\begin{tabular}{|c|c|c|}
\hline Number & Landmark/Location & Label Name \\
\hline 1 & Right iliac crest & RAIC \\
\hline 2 & Left iliac crest & LAIC \\
\hline 3 & Right posterior superior iliac spine & RPSI \\
\hline 4 & Left posterior superior iliac spine & LPSI \\
\hline 5 & Right greater trochanter & RGT \\
\hline 6 & Left greater trochanter & LGT \\
\hline 7 & Thigh $1^{\text {st }}$ & THI1 \\
\hline 8 & Thigh $2^{\text {nd }}$ & THI2 \\
\hline 9 & Lateral knee & LKNE \\
\hline 10 & Tibial tuberosity & TTUB \\
\hline 11 & Head of fibula & HFIB \\
\hline 12 & Shin $1^{\text {st }}$ & SHN1 \\
\hline 13 & Shin $2^{\text {nd }}$ & SHN2 \\
\hline 14 & Superior calcaneum & SCAL \\
\hline 15 & Inferior calcaneum & ICAL \\
\hline 16 & Medial malleolus & MMAL \\
\hline 17 & Medial calcaneum & MCAL \\
\hline 18 & Tuberosity navicular & NAV \\
\hline 19 & Proximal $1^{\text {st }}$ met head & P1MT \\
\hline 20 & Central $1^{\text {st }}$ met & C1MT \\
\hline 21 & Medial $1^{\text {st }}$ met head & M1MT \\
\hline 22 & Lateral $1^{\text {st }}$ met head & L1MH \\
\hline 23 & Hallux $1^{\text {st }}$ & HLX1 \\
\hline 24 & Hallux $2^{\text {nd }}$ & HLX2 \\
\hline 25 & Hallux $3^{\text {rd }}$ & HLX3 \\
\hline 26 & Lateral malleolus & LMAL \\
\hline 27 & Lateral calcaneum & LCAL \\
\hline 28 & Cuboid & CUB \\
\hline 29 & Proximal $5^{\text {th }}$ met & P5MT \\
\hline 30 & Distal $5^{\text {th }}$ met & D5MT \\
\hline 31 & Intermediate cuneiform & ICUN \\
\hline 32 & Lateral cuneiform & LCUN \\
\hline 33 & $2^{\text {nd }}$ met head & $\mathrm{D} 2 \mathrm{MT}$ \\
\hline 34 & $3^{\text {rd }}$ met head & D3MT \\
\hline 35 & $4^{\text {th }}$ met head & D4MT \\
\hline 36 & $2^{\text {nd }}$ proximal phalanx & D2PP \\
\hline 37 & $3^{\text {rd }}$ proximal phalanx & D3PP \\
\hline 38 & $4^{\text {th }}$ proximal phalanx & D4PP \\
\hline 39 & $5^{\text {th }}$ proximal phalanx & D5PP \\
\hline 40 & $2^{\text {nd }}$ distal phalanx (on nail) & D2DP \\
\hline 41 & $3^{\text {rd }}$ distal phalanx (on nail) & D3DP \\
\hline 42 & $4^{\text {th }}$ distal phalanx (on nail) & D4DP \\
\hline 43 & $5^{\text {th }}$ distal phalanx (on nail) & D5DP \\
\hline
\end{tabular}




\section{Chapter 4}

\section{Data analysis}

Identification and labelling of the 43 markers in the Vicon Nexus software was performed according to the GM-model by one researcher. The marker tracks were exported to C3D format. The surface scan was used to identify 16 landmarks for geometry using 'Meshlab version 1.3.3', also by one researcher.

The C3D-data, demographics and the landmarks from the surface scan was used to run the GM-model in Anybody 6.0 (AnyBody Technology, Aalborg, Denmark). The landmarks from the surface scan were used to scale the physical dimensions of the foot of the GM-model. Subsequently the demographics and C3D-data were used to further scale the GM-model. The marker data was used to calculate joint angles in a kinematic analysis of an overdeterminate system ${ }^{17}$. Table 4.2 gives an overview of the kinematic output of the GMmodel.

The kinematic output files were further processed in a custom made algorithm in 'Matlab R2012a'. This algorithm calculates per joint the average kinematic pattern of five successful trials per participant. The motion of some joints is coupled in the GM-model ${ }^{14}$; therefore only selected directions have been analysed (see Table 4.2). TMT1F and TMT1A and NavMCunF and NavMCunA have not been analysed, since they have been coupled with TalNavF and TalNavA. Also DIP2-5 have not been analysed, since these joints have been directly coupled with corresponding PIP-joints.

\section{Statistical analysis}

Baseline characteristics were presented with descriptive statistics. Minimum and maximum angle during stance phase of the average kinematic pattern per degree of freedom per subject were calculated. RoM was calculated by taking the difference between maximum and minimum angle during stance phase. A paired t-test was conducted to compare the RoM between session 1 and session 2. Test-retest repeatability was determined by a two way mixed intraclass correlation coefficient (ICC 3, k) with $95 \%$ confidence intervals $(\mathrm{CI})^{18}$. The ICCs were classified as $<0.40$ poor to fair agreement, 0.41 0.60 moderate agreement, $0.61-0.80$ good agreement, and 0.81-1.00 excellent agreement 19.

Mean ICC of the total model was calculated by 1) Fisher r-to-z transformation of the individual ICCs, 2) calculation of the average of the transformed ICCs and 3) Fisher z-to-r transformation of this average. $95 \% \mathrm{Cl}$ of the mean ICC was calculated by performing the same steps on lower and upper bounds of individual ICCs.

Standard error of the measurement (SEM) was calculated to compute the absolute amount of error in degrees. SEM was calculated as SEM $=$ STD * $(1-\text { ICC })^{1 / 2}$, with STD 
being standard deviation ${ }^{18,19}$. Recommendations by McGinley et al. were used. When the SEM is higher than $5^{\circ}$, it is considered to be unacceptable ${ }^{20}$.

Table 4.2 Kinematic output of the GM-model. Degrees of freedom marked as 'not used' in the column part of the foot, are not used, due to coupled motion.

\begin{tabular}{|c|c|c|c|c|}
\hline Joint & $\begin{array}{l}\text { Type of } \\
\text { joint }\end{array}$ & Directions & Abbreviation & $\begin{array}{l}\text { Location } \\
\text { in the } \\
\text { foot }\end{array}$ \\
\hline Calcaneocuboid & spherical & $\begin{array}{l}\text { Flexion, Eversion, } \\
\text { Abduction }\end{array}$ & $\begin{array}{l}\text { CalCubF, } \\
\text { CalCubE, } \\
\text { CalCubA }\end{array}$ & hindfoot \\
\hline Talonavicular & spherical & $\begin{array}{l}\text { Flexion, Eversion, } \\
\text { Abduction }\end{array}$ & $\begin{array}{l}\text { TaloNavF, } \\
\text { TaloNavE, } \\
\text { TaloNavA } \\
\end{array}$ & hindfoot \\
\hline Navicular-medialcuneiform & universal & Flexion, Abduction & $\begin{array}{l}\text { NavMCunF, } \\
\text { NavMCunA }\end{array}$ & not used \\
\hline $\begin{array}{l}\text { Navicular-intermediate } \\
\text { cuneiform }\end{array}$ & universal & Flexion, Abduction & $\begin{array}{l}\text { NaviCunF, } \\
\text { NaviCunA }\end{array}$ & midfoot \\
\hline Navicular-lateralcuneiform & universal & Flexion, Abduction & $\begin{array}{l}\text { NavLCunF, } \\
\text { NavLCunA }\end{array}$ & midfoot \\
\hline Tarsometatarsal 1 & universal & Flexion, Abduction & TMT1F, TMT1A & not used \\
\hline Tarsometatarsal 2 & universal & Flexion, Abduction & TMT2F, TMT2A & lisfranc \\
\hline Tarsometatarsal 3 & universal & Flexion, Abduction & TMT3F, TMT3A & lisfranc \\
\hline Tarsometatarsal 4 & universal & Flexion, Abduction & TMT4F, TMT4A & lisfranc \\
\hline Tarsometatarsal 5 & universal & Flexion, Abduction & TMT5F, TMT5A & lisfranc \\
\hline Metatarsalphalangeal 1 & universal & Flexion, Abduction & MTP1F, MTP1A & MTP \\
\hline Metatarsalphalangeal 2 & universal & Flexion, Abduction & MTP2F, MTP2A & MTP \\
\hline Metatarsalphalangeal 3 & universal & Flexion, Abduction & MTP3F, MTP3A & MTP \\
\hline Metatarsalphalangeal 4 & universal & Flexion, Abduction & MTP4F, MTP4A & MTP \\
\hline Metatarsalphalangeal 5 & universal & Flexion, Abduction & MTP5F, MTP5A & MTP \\
\hline Interphangeal 1 & revolute & Flexion & IP1F & IP/PIP/DIP \\
\hline Proximal interphalangeal 2 & revolute & Flexion & PIP2F & IP/PIP/DIP \\
\hline Distal interphalangeal 2 & revolute & Flexion & DIP2F & not used \\
\hline Proximal interphalangeal 3 & revolute & Flexion & PIP3F & IP/PIP/DIP \\
\hline Distal interphalangeal 3 & revolute & Flexion & DIP3F & not used \\
\hline Proximal interphalangeal 4 & revolute & Flexion & PIP4F & IP/PIP/DIP \\
\hline Distal interphalangeal 4 & revolute & Flexion & DIP4F & not used \\
\hline Proximal interphalangeal 5 & revolute & Flexion & PIP5F & IP/PIP/DIP \\
\hline Distal interphalangeal 5 & revolute & Flexion & DIP5F & not used \\
\hline
\end{tabular}




\section{Chapter 4}

\section{Results}

All 8 subjects were able to complete the study. However, due to mall tracking of the markers, data of 1 subject could not be used for further analysis. Table 4.3 shows demographics and baseline characteristics of the remaining 7 subjects. Figure 4.1 gives for all studied degrees of freedom the average kinematic curves and standard deviation for all subjects combined in the first and second session.

Table 4.3 Baseline characteristics Average \pm standard deviation (range)

\begin{tabular}{|l|l|}
\hline $\mathbf{N}$ & $\mathbf{7}$ \\
\hline Sex $(\%$ male) & $43 \%$ \\
\hline Age & $23.29 \pm 1.60(20-25)$ \\
\hline Length & $1.73 \pm 0.072(1.64-1.86)$ \\
\hline Weight & $68.0 \pm 9.33(50-76)$ \\
\hline BMI & $22.68 \pm 2.55(18.59-26.13)$ \\
\hline Days between sessions & $4.43 \pm 2.64(1-7)$ \\
\hline
\end{tabular}

\section{Test-retest repeatability and reliability}

Total ICC on RoM of the GM-model is 0.67 ( $95 \% \mathrm{Cl}-0.51$ to 0.95$)$. Table 4.4 shows the testretest ICC per degree of freedom for RoM, minimum and maximum angle during stance phase. This table also shows the average, standard deviation and SEM for each degree of freedom. Three degrees of freedom have an unacceptable SEM for RoM $\left(>5^{\circ}\right)$ : MTP5F, DIP2F and DIP4F. For the minimum and maximum angle more degrees of freedom show an unacceptable SEM; for the minimum angle these are MTP1F, MTP4A, MTP5A and DIP4F; for the maximum angles these are MTP1F, MTP2F, MTP3F, MTP4F, MTP5A, DIP2F, DIP3F and DIP4F.

The ICC values for RoM, 7 (21\%) joints showed poor to fair agreement, 7 (21\%) joints showed moderate agreement, 8 (24\%) joints showed good agreement and 11 (33\%) showed excellent agreement. Therefore 19 (57\%) joints showed good to excellent agreement, an overview has been given in Table 4.5. 
Repeatability
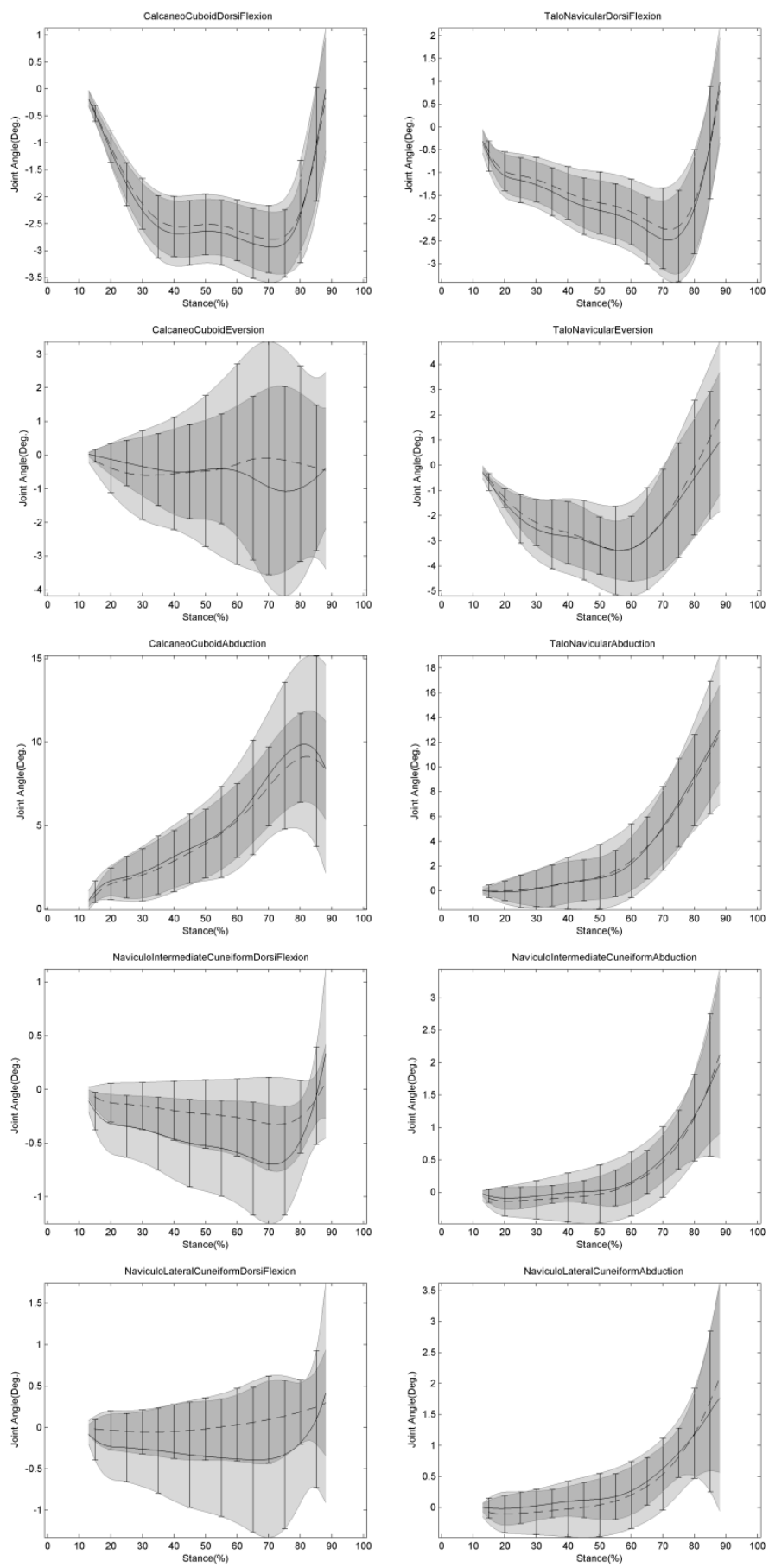

Figure 4.1 a-d Average kinematic curves and standard deviation for all subjects combined in the first (dashed line) and second session 


\section{Chapter 4}
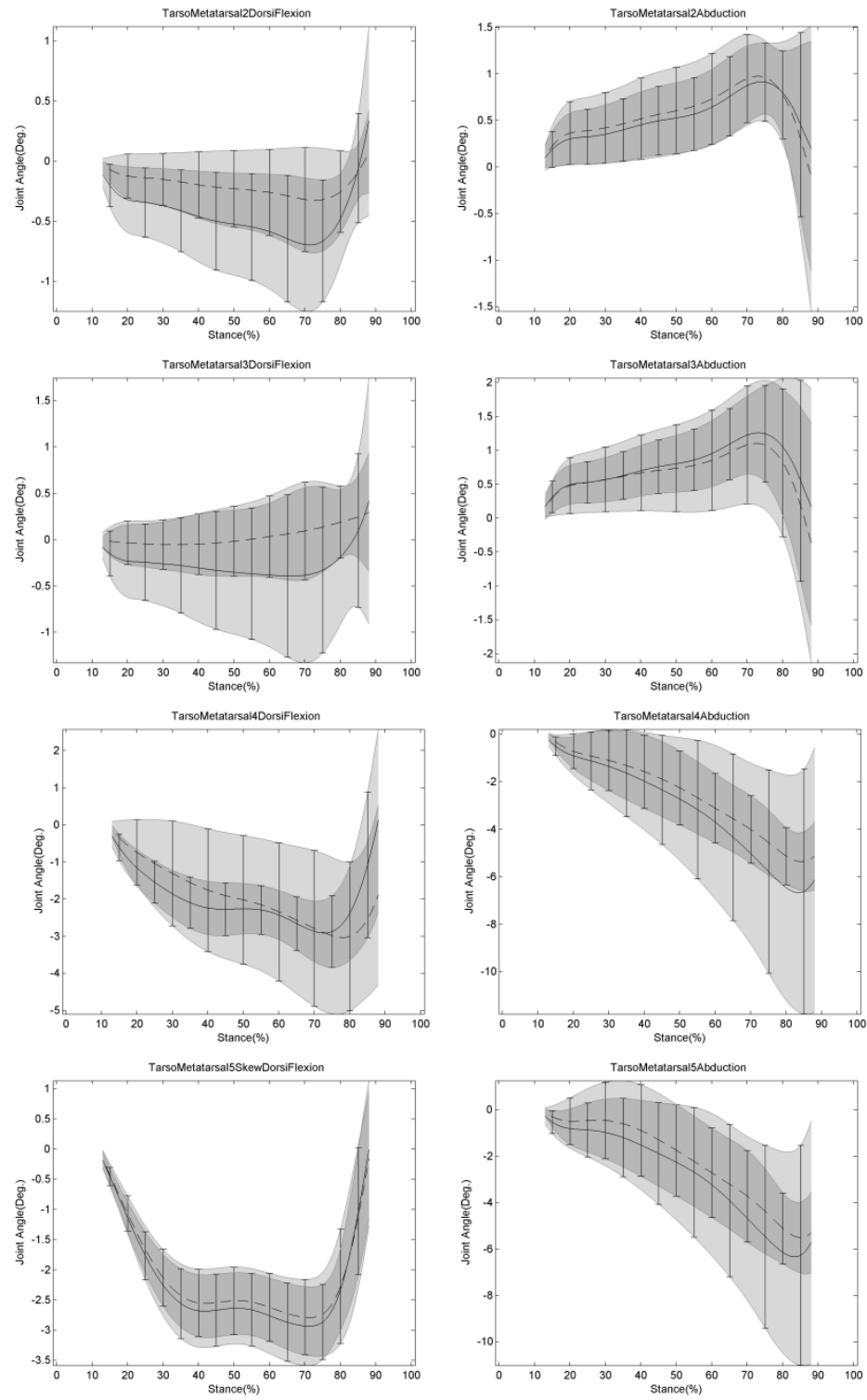


\section{Repeatability}
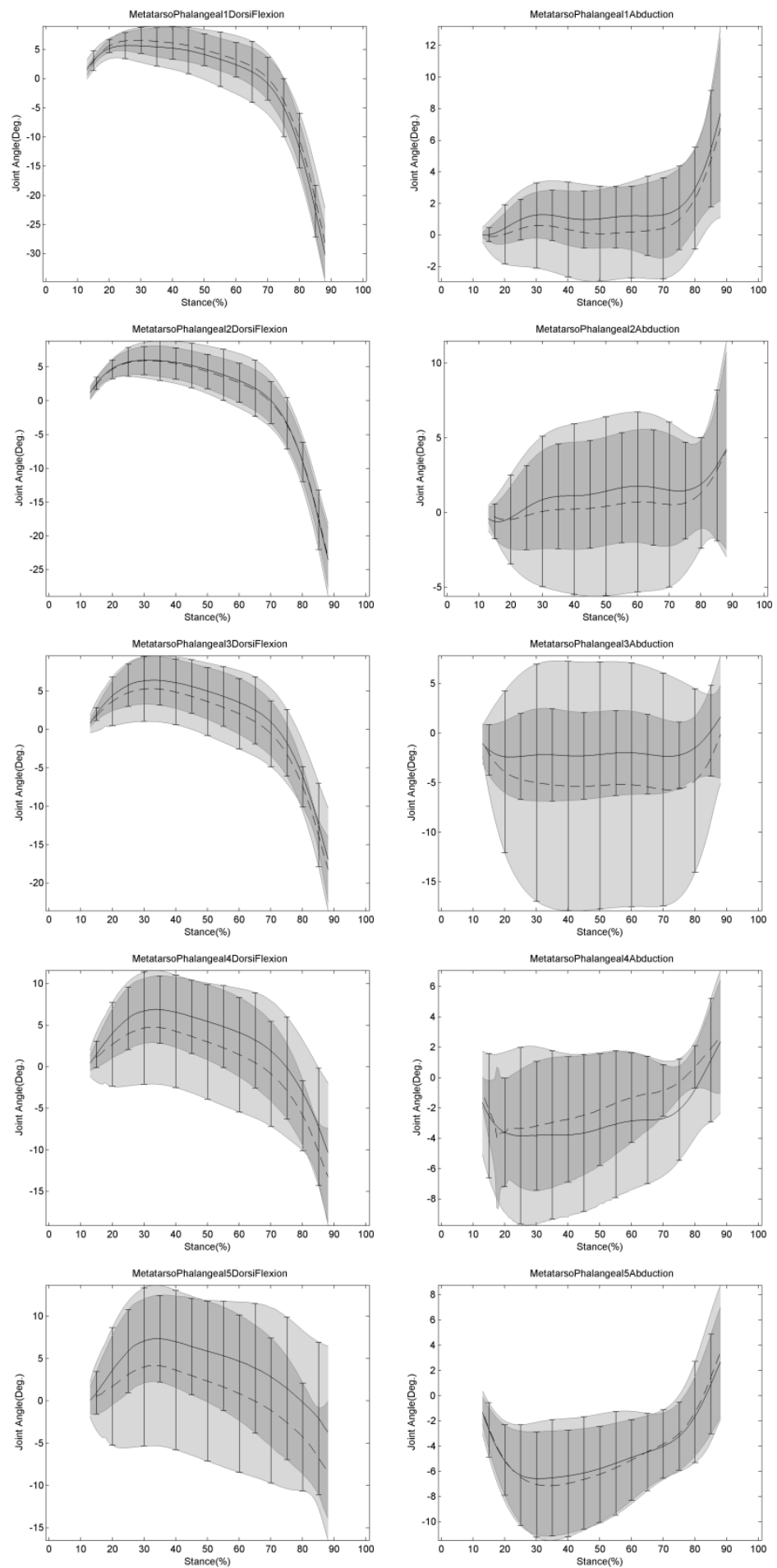


\section{Chapter 4}
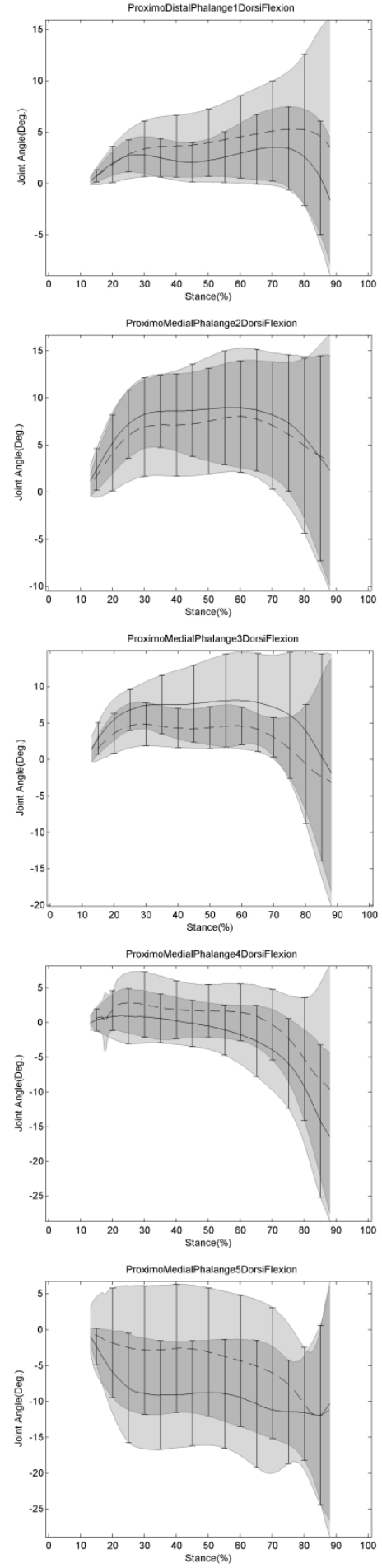
Table 4.4 Results per Degree of Freedom for RoM and minimum and maximum angles during stance phase, angles, ICC and SEM have been given

\begin{tabular}{|c|c|c|c|c|c|c|c|c|c|c|}
\hline \begin{tabular}{|c|} 
\\
$\tilde{z}$ \\
$\tilde{0}$
\end{tabular} & $\sum_{\text {出 }} \widehat{\frac{d 0}{0}}$ & $\underset{\sim}{\stackrel{\sim}{-}}$ & นึ̊ & $\stackrel{ }{\stackrel{ }{\hookrightarrow}}$ & $\stackrel{\substack{n \\
r i}}{r}$ & $\stackrel{n}{\sim}$ & $\stackrel{\infty}{\sim}$ & $\stackrel{\overbrace{}}{\neg}$ & ન્- & $\stackrel{\substack{n \\
0}}{\circ}$ \\
\hline 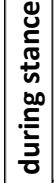 & 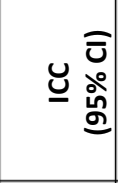 & 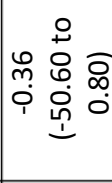 & 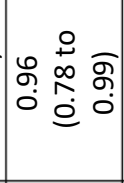 & 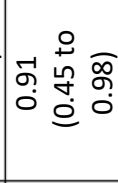 & 总 & 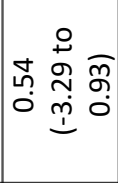 & 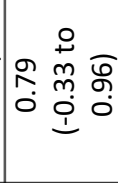 & 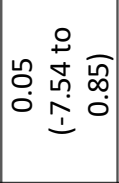 & 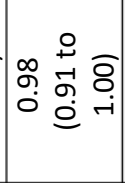 & 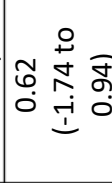 \\
\hline 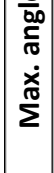 & 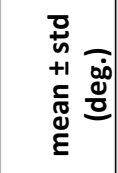 & $\begin{array}{l}\overrightarrow{0} \\
\dot{+} \\
+ \\
+1 \\
\infty \\
m \\
\rightarrow\end{array}$ & 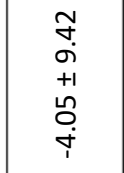 & $\begin{array}{l}+10 \\
\stackrel{+}{\infty} \\
\stackrel{\infty}{\sim} \\
\stackrel{\sim}{\sim}\end{array}$ & $\begin{array}{l}\hat{b} \\
\dot{+} \\
+1 \\
m \\
\stackrel{\sim}{i}\end{array}$ & $\begin{array}{l}0 \\
+1 \\
\infty \\
+1 \\
+ \\
+ \\
\infty \\
1\end{array}$ & $\begin{array}{l}\infty \\
0 \\
i n \\
+1 \\
\sim \\
m \\
\infty\end{array}$ & 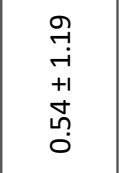 & 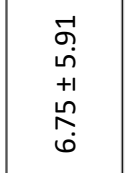 & 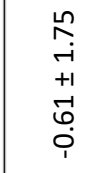 \\
\hline \multirow{3}{*}{ 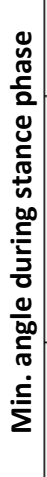 } & $\begin{array}{l}\sum_{\tilde{\omega}} \overline{0} \\
\overline{0}\end{array}$ & $\stackrel{\text { mे }}{-}$ & $\underset{-}{\mathscr{i}}$ & శ్ & $\stackrel{-1}{-i}$ & $\stackrel{n}{\sim}$ & 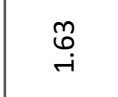 & $\underset{-}{\stackrel{8}{-}}$ & $\stackrel{n}{\stackrel{n}{0}}$ & $\underset{-}{\stackrel{\Delta}{-}}$ \\
\hline & 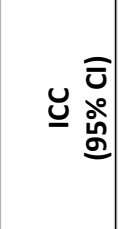 & 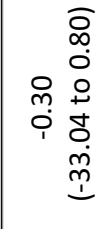 & 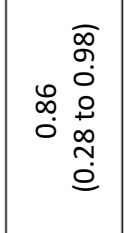 & $\begin{aligned} & \bar{\sigma} \\
& 0 \\
& 0 \\
& 0 \\
& 0 \\
& 0 \\
& 0 \\
& 0 \\
& 0 \\
& 0 \\
& 0\end{aligned}$ & 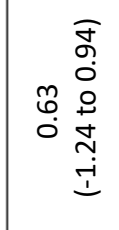 & 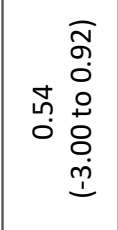 & 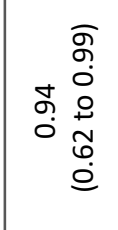 & 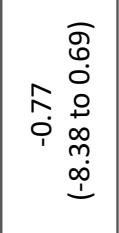 & 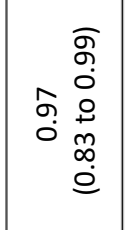 & 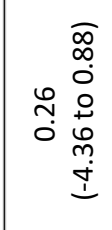 \\
\hline & 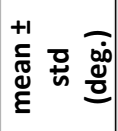 & 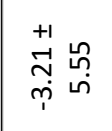 & 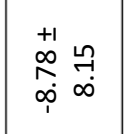 & $\begin{array}{l}+1 \\
\stackrel{n}{\stackrel{n}{n}} \\
\stackrel{m}{m}\end{array}$ & $\begin{array}{l}+1 \\
\stackrel{+}{f} \\
\stackrel{+}{\sim}\end{array}$ & 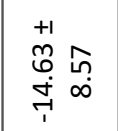 & $\underset{\substack{n \\
\infty}}{\stackrel{+1}{\infty}}$ & 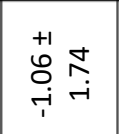 & 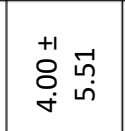 & $\begin{array}{ll}\stackrel{+1}{\infty} & \infty \\
\stackrel{+}{+} & \stackrel{+}{\sim}\end{array}$ \\
\hline \multirow{3}{*}{$\begin{array}{l}\sum_{0} \\
\propto\end{array}$} & $\sum_{\text {岃 }} \widehat{\frac{8}{0}}$ & $\underset{0}{N}$ & $\stackrel{\varphi}{i}$ & $\underset{\sim}{\mathbb{U}}$ & ஒ̊̊ & $\stackrel{\text { mి }}{-}$ & $\vec{m}$ & मू & $\underset{0}{\infty}$ & ㅇำ \\
\hline & $\begin{array}{l}\overline{\bar{v}} \\
\underline{\underline{u}} \\
\stackrel{0}{0}\end{array}$ & 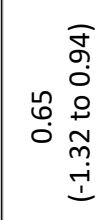 & 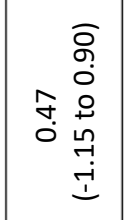 & 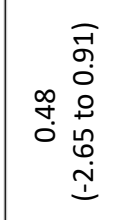 & 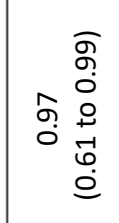 & 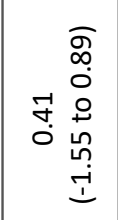 & 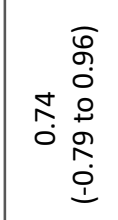 & 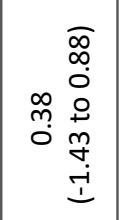 & 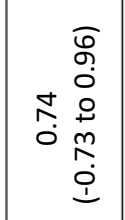 & 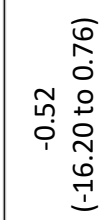 \\
\hline & 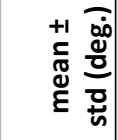 & 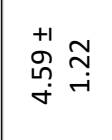 & $\stackrel{+1}{\stackrel{n}{\sim}} \underset{\sim}{\stackrel{\infty}{\sim}}$ & $\begin{array}{l}+1 \\
\text { ğ } \\
\sigma\end{array}$ & 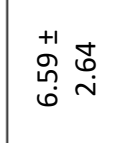 & \begin{tabular}{ll}
+1 & -1 \\
$\stackrel{-}{-1}$ & $\infty$ \\
\hdashline & -1
\end{tabular} & 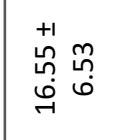 & 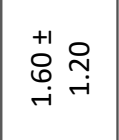 & $\stackrel{+1}{\stackrel{n}{N}} \stackrel{m}{-}$ & 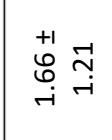 \\
\hline$\sum_{\substack{0 \\
\propto}}$ & 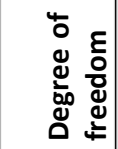 & $\frac{\frac{4}{0}}{\frac{0}{3}}$ & $\frac{\omega}{\frac{\omega}{3}}$ & $\frac{\overleftarrow{0}}{\frac{\pi}{3}}$ & $\begin{array}{l}\frac{1}{\pi} \\
\frac{\pi}{2} \\
\frac{0}{10} \\
1\end{array}$ & 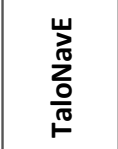 & $\begin{array}{l}\frac{\pi}{\delta} \\
\sum_{0}^{0} \\
\frac{0}{\pi} \\
⺊\end{array}$ & $\begin{array}{l}\frac{U}{5} \\
\frac{5}{3} \\
\frac{0}{2} \\
\frac{\pi}{2}\end{array}$ & $\begin{array}{l}\frac{\pi}{5} \\
\frac{0}{2} \\
\frac{\pi}{2}\end{array}$ & 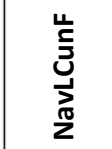 \\
\hline
\end{tabular}


Chapter 4

\begin{tabular}{|c|c|c|c|c|c|c|c|c|c|c|}
\hline \multirow{3}{*}{ 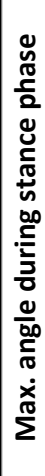 } & $\sum_{\tilde{\omega}} \widehat{\frac{0}{0}}$ & $\stackrel{\sim}{N}$ & $\stackrel{\text { f }}{\rightarrow}$ & $\stackrel{\overrightarrow{7}}{\stackrel{\sigma}{0}}$ & $\begin{array}{l}\stackrel{n}{\kappa} \\
0\end{array}$ & $\stackrel{7}{-1}$ & 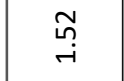 & ન્' & $\stackrel{\text { \& }}{\sim}$ & $\begin{array}{c}\hat{\infty} \\
0\end{array}$ \\
\hline & ư & 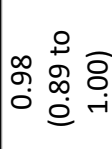 & 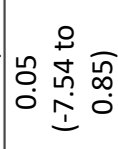 & 용 & 桒 & $\begin{array}{l}\stackrel{+}{+} \\
\text { gे } \\
\stackrel{+}{\circ} \\
0\end{array}$ & 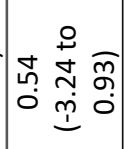 & J $\begin{array}{l}\stackrel{0}{+} \\
0 \\
0 \\
0\end{array}$ & 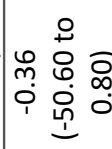 & 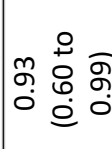 \\
\hline & 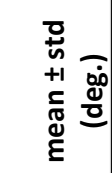 & $\begin{array}{l}\infty \\
\infty \\
\dot{\omega} \\
+1 \\
\stackrel{1}{0} \\
\stackrel{n}{n}\end{array}$ & 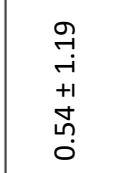 & $\begin{array}{l}\hat{N} \\
\dot{0} \\
+1 \\
+ \\
\stackrel{m}{i}\end{array}$ & $\begin{array}{l}n \\
\\
+1 \\
+1 \\
-1 \\
6 \\
0 \\
1\end{array}$ & 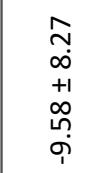 & $\begin{array}{l}\stackrel{v}{m} \\
\text { ñ } \\
+1 \\
m \\
m \\
\dot{p}\end{array}$ & 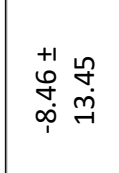 & $\begin{array}{l}\stackrel{-1}{\infty} \\
\dot{+} \\
+1 \\
\infty \\
m \\
+ \\
-i\end{array}$ & 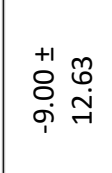 \\
\hline \multirow{3}{*}{ 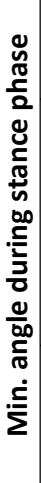 } & $\sum_{\tilde{w}} \widehat{0}$ & 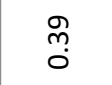 & $\underset{-}{\stackrel{0}{0}}$ & $\stackrel{\infty}{\stackrel{1}{0}}$ & $\underset{-}{\stackrel{\Delta}{0}}$ & ને- & $\underset{\sim}{\stackrel{\sigma}{\sigma}}$ & 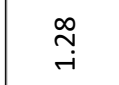 & 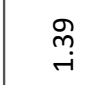 & $\begin{array}{l}\underset{-}{-} \\
-\end{array}$ \\
\hline & ư & 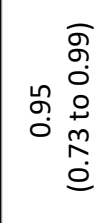 & 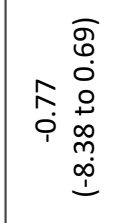 & 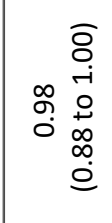 & 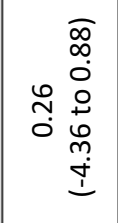 & 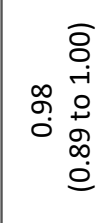 & 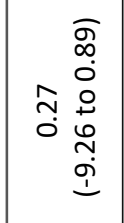 & 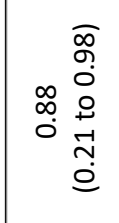 & 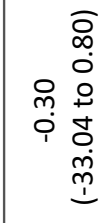 & 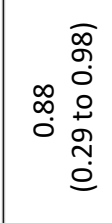 \\
\hline & 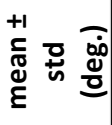 & $\begin{array}{l}+1 \\
\stackrel{+}{\sim} \\
\stackrel{n}{n}\end{array}$ & 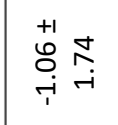 & 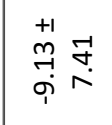 & $\stackrel{+1}{\stackrel{\infty}{\infty}} \underset{\substack{+\sim}}{\sim}$ & 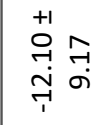 & $\begin{array}{l}+1 \\
\stackrel{+1}{8} \\
\stackrel{8}{0} \\
\dot{\varphi}\end{array}$ & 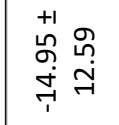 & 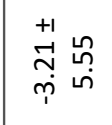 & $\begin{array}{l}+1 \\
\stackrel{+}{0} \underset{\sim}{\sim} \\
\stackrel{1}{\sim} \\
\stackrel{1}{\sim}\end{array}$ \\
\hline \multirow{4}{*}{$\sum_{\substack{x \\
0}}$} & $\sum_{\tilde{w}} \widehat{0}$ & ஸ̊ & హ్ & นึ & 우 & $\begin{array}{l}\mathscr{0} \\
\ddot{0}\end{array}$ & 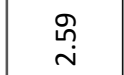 & $\begin{array}{l}\text { ț } \\
\text { i }\end{array}$ & $\underset{0}{N}$ & ô \\
\hline & 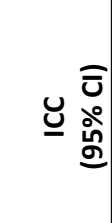 & 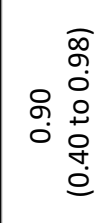 & 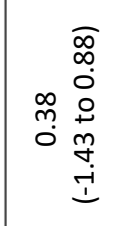 & 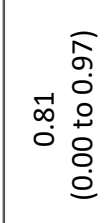 & 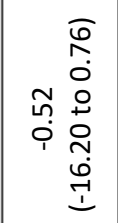 & 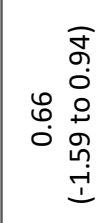 & 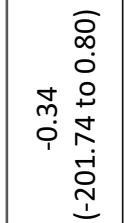 & 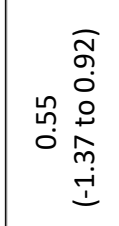 & 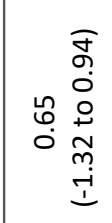 & 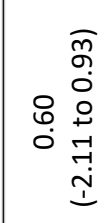 \\
\hline & 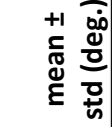 & 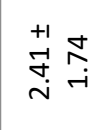 & 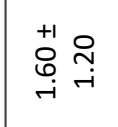 & 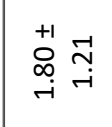 & 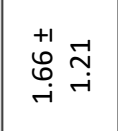 & $\stackrel{+1}{\underset{N}{\sim}} \underset{\sim}{\stackrel{+}{i}}$ & 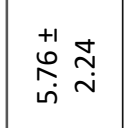 & 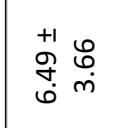 & $\begin{array}{l}+1 \\
\stackrel{+}{\sim} \underset{+}{\sim} \\
\sim\end{array}$ & 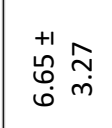 \\
\hline & 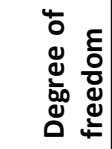 & $\underbrace{5}_{\substack{0 \\
z}}$ & $\sum_{i}^{\stackrel{U}{E}}$ & $\underset{\Sigma}{\mathbb{E}}$ & $\sum_{i}^{\stackrel{\omega}{m}}$ & $\sum_{k}^{\stackrel{\nwarrow}{m}}$ & $\sum_{i}^{\stackrel{U}{E}}$ & 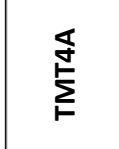 & $\sum_{i}^{\stackrel{4}{E}}$ & $\sum_{i=}^{\mathbb{n}}$ \\
\hline
\end{tabular}




\begin{tabular}{|c|c|c|c|c|c|c|c|c|c|c|}
\hline 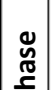 & $\sum_{\text {出 }} \overline{\frac{0}{0}}$ & 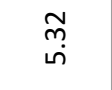 & $\underset{\sim}{\stackrel{n}{N}}$ & $\underset{f}{\stackrel{f}{+}}$ & $\stackrel{\substack{\infty \\
\sim}}{\sim}$ & $\begin{array}{l}\vec{b} \\
\dot{m}\end{array}$ & $\underset{\sim}{\stackrel{\gamma}{+}}$ & 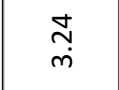 & ô & 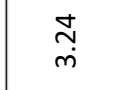 \\
\hline 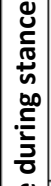 & 능 & 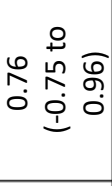 & 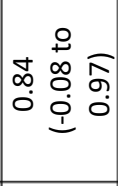 & 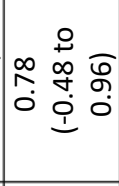 & 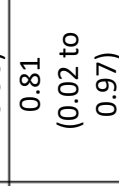 & 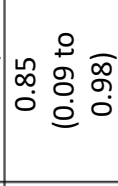 & 芒 & 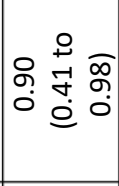 & 茎总 & 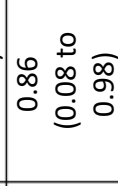 \\
\hline 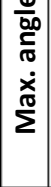 & 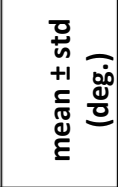 & 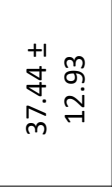 & $\begin{array}{l}\stackrel{m}{m} \\
\stackrel{1}{+1} \\
+\infty \\
o \\
⿱ 亠 \\
1\end{array}$ & 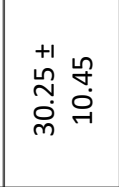 & $\begin{array}{l}\stackrel{N}{N} \\
\infty \\
+1 \\
0 \\
\\
\end{array}$ & $\begin{array}{l}\hat{N} \\
a \\
+1 \\
0 \\
\stackrel{-}{1} \\
\stackrel{N}{N}\end{array}$ & $\begin{array}{l}0 \\
\infty \\
\omega \\
+1 \\
0 \\
0 \\
\infty\end{array}$ & $\begin{array}{l}+1 \\
\stackrel{+1}{\rightarrow} \\
\stackrel{-}{-} \\
\stackrel{-}{-} \\
-\end{array}$ & $\begin{array}{l}\underset{-}{\sigma} \\
+ \\
+1 \\
\stackrel{N}{ } \\
\underset{\sim}{\sim}\end{array}$ & 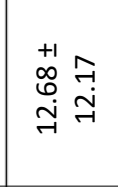 \\
\hline \multirow{3}{*}{ 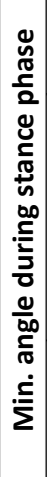 } & $\sum_{\tilde{w}} \widehat{\frac{d 0}{0}}$ & $\hat{\circ}$ & $\stackrel{\vec{n}}{\sim}$ & $\stackrel{\infty}{\leftrightarrow}$ & $\stackrel{\text { L }}{\text { N }}$ & 라 & $\stackrel{\stackrel{n}{+}}{m}$ & $\stackrel{\text { İ }}{\text { in }}$ & 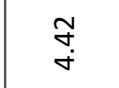 & $\begin{array}{l}\infty \\
\stackrel{+}{+}\end{array}$ \\
\hline & 능 & 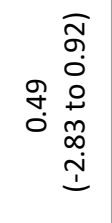 & 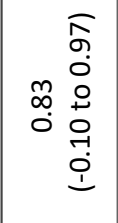 & 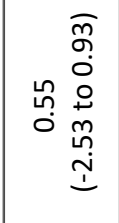 & 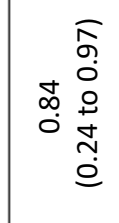 & 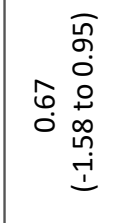 & 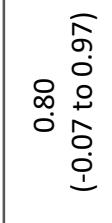 & 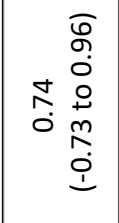 & 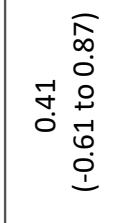 & 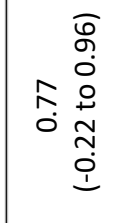 \\
\hline & 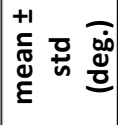 & 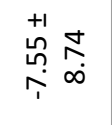 & 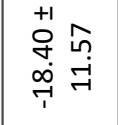 & 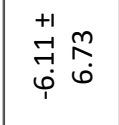 & $\begin{array}{l}\stackrel{+1}{\circ} \\
\stackrel{\leftrightarrow}{ન} \\
\stackrel{+}{+}\end{array}$ & 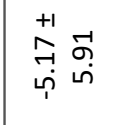 & 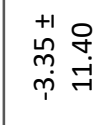 & 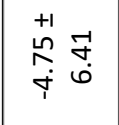 & $\stackrel{+1}{\stackrel{n}{N}}$ & $\stackrel{+1}{\stackrel{+}{n}} \underset{\sim}{\stackrel{n}{\infty}} \stackrel{\infty}{\infty}$ \\
\hline \multirow{4}{*}{$\begin{array}{l}\sum_{0} \\
\mathbb{x}\end{array}$} & $\sum_{\vec{w}} \widehat{\overrightarrow{00}}$ & 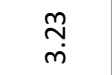 & $\stackrel{\text { 군 }}{\text { ㄱ. }}$ & 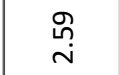 & $\stackrel{\stackrel{n}{m}}{\sim}$ & $\stackrel{\stackrel{\infty}{\infty}}{\sim}$ & 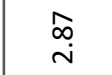 & 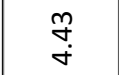 & 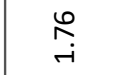 & $\stackrel{-1}{6}$ \\
\hline & 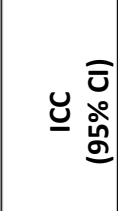 & 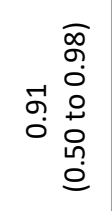 & 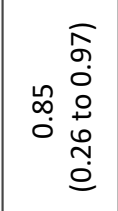 & 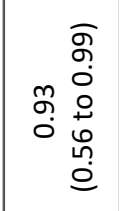 & 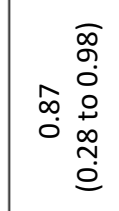 & 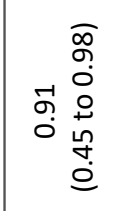 & 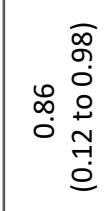 & 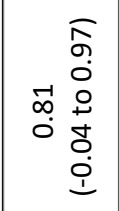 & 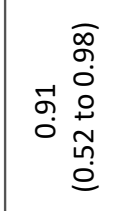 & 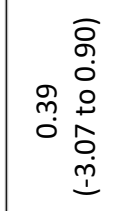 \\
\hline & 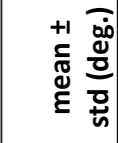 & 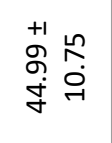 & 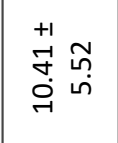 & $\begin{array}{l}+1 \\
\dot{\omega} \\
m \\
\dot{\omega} \\
\dot{m} \\
\dot{m}\end{array}$ & $\begin{array}{l}+1 \\
\stackrel{+}{\infty} \\
\stackrel{9}{f} \\
\stackrel{-}{\rightarrow}\end{array}$ & 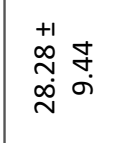 & $\begin{array}{l}+1 \\
\underset{\sim}{0} \underset{-}{\stackrel{N}{r}} \\
\stackrel{\Gamma}{r}\end{array}$ & $\begin{array}{ll}+1 & m \\
\text { Jे } \\
\stackrel{0}{0} \\
\text { ○े }\end{array}$ & 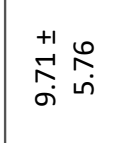 & 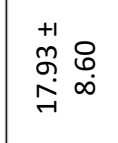 \\
\hline & 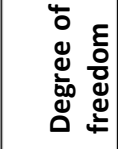 & $\frac{u}{\overrightarrow{1}}$ & 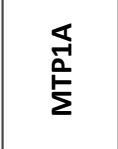 & $\frac{\substack{N \\
\Sigma}}{\Sigma}$ & $\underset{\Sigma}{\stackrel{\nwarrow}{\Sigma}}$ & 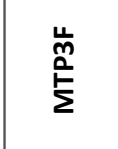 & 芯 & 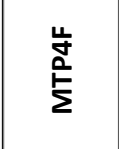 & 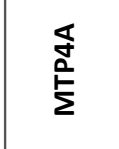 & 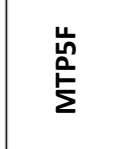 \\
\hline
\end{tabular}




\section{Chapter 4}

\begin{tabular}{|c|c|c|c|c|c|c|c|}
\hline & 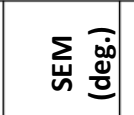 & $\stackrel{\Re}{i}$ & 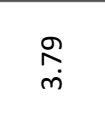 & ఫ్ & $\underset{j}{q}$ & đָ̃ & $\stackrel{8}{g}$ \\
\hline & & 舁总 & 苂 & 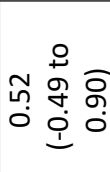 & 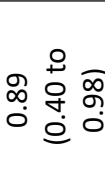 & 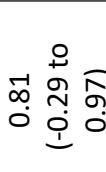 & 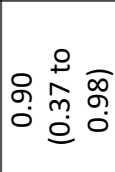 \\
\hline$\tilde{E}$ & 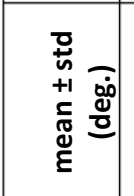 & $\begin{array}{l}\overrightarrow{7} \\
i \\
+1 \\
\infty \\
\infty \\
\infty \\
0 \\
\dot{H}\end{array}$ & 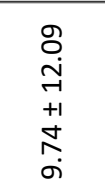 & $\begin{array}{l}\infty \\
\stackrel{\infty}{+} \\
\stackrel{+1}{+1} \\
\stackrel{\imath}{0} \\
\dot{0}\end{array}$ & 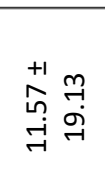 & 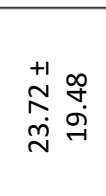 & 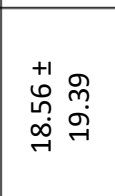 \\
\hline & 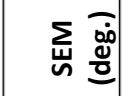 & 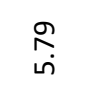 & $\underset{\substack{\infty \\
\sim}}{\sim}$ & ָָ & กึ & $\underset{\substack{n \\
G}}{ }$ & $\stackrel{+}{m}$ \\
\hline 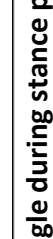 & $\begin{array}{ll}\overline{\mathrm{u}} & \overline{\mathrm{v}} \\
\underline{\mathrm{o}} \\
\mathrm{g}\end{array}$ & 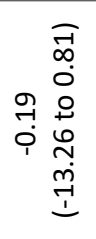 & 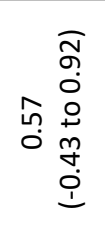 & 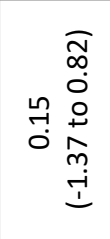 & 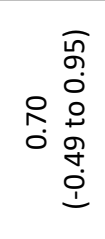 & 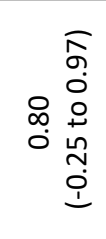 & 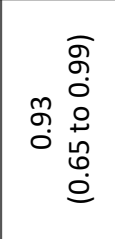 \\
\hline & 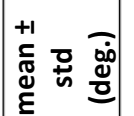 & 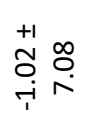 & 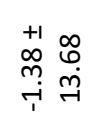 & 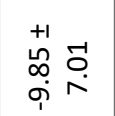 & 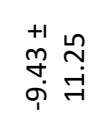 & 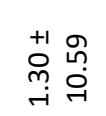 & 茾柋 \\
\hline & 出 & $\underset{m}{\stackrel{9}{m}}$ & $\underset{f}{\mathcal{f}}$ & هి & S్ & कू & $\begin{array}{l}\dot{d} \\
\stackrel{+}{+}\end{array}$ \\
\hline & 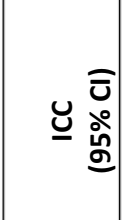 & 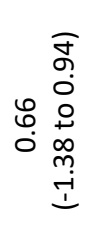 & 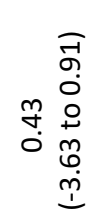 & $\begin{array}{r}\widehat{\infty} \\
0 \\
0 \\
0 \\
0 \\
0 \\
0 \\
0 \\
0 \\
0 \\
0\end{array}$ & 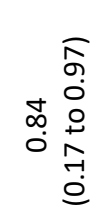 & 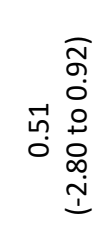 & 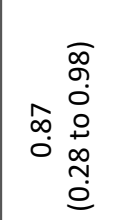 \\
\hline & 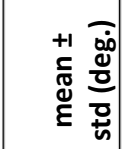 & $\begin{array}{l}+1 \\
\vec{n} \\
\overrightarrow{9} \\
\vec{y} \\
\vec{y}\end{array}$ & 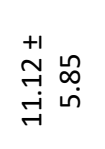 & 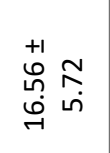 & 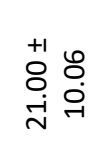 & 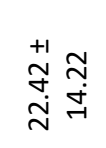 & 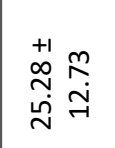 \\
\hline & 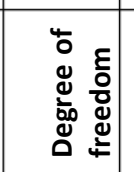 & $\begin{array}{l}\text { 芯 } \\
\stackrel{\hat{n}}{\Sigma}\end{array}$ & $\stackrel{\underline{\underline{U}}}{\underline{\underline{\Delta}}}$ & 莖 & $\begin{array}{l}\text { 訔 } \\
\stackrel{\bar{a}}{\bar{a}}\end{array}$ & 崖 & $\frac{\text { 产 }}{\frac{0}{0}}$ \\
\hline
\end{tabular}




\section{Repeatability}

Table 4.5 Summary of ICCs on RoM Number of ICCs per location in the foot and per direction of motion (percentage)

\begin{tabular}{|c|c|c|c|c|c|}
\hline \multirow{3}{*}{ 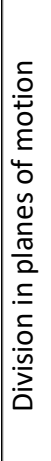 } & 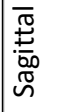 & $\wedge$ ळे & $\sim \stackrel{\widehat{\stackrel{\circ}{ت}}}{ت}$ & 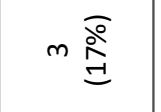 & 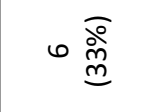 \\
\hline & 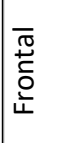 & ○ ळे & 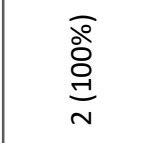 & $\circ$ ळे & $\circ$ oे \\
\hline & 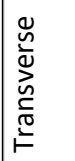 & $\circ$ ঃे & $m \stackrel{\bar{\partial}}{\stackrel{D}{d}}$ & nn $\begin{array}{l}\widehat{\widehat{o}} \\
\stackrel{m}{m}\end{array}$ & in $\begin{array}{c}\widehat{\widehat{o}} \\
\stackrel{m}{m}\end{array}$ \\
\hline & & & & & \\
\hline \multirow{5}{*}{ 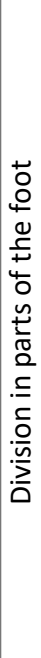 } & $\frac{a}{\underline{\alpha}} \frac{a}{\underline{\underline{a}}}$ & - ठ্̊ & N & $\frac{\widehat{0}}{\text { o }}$ & $\sim$ 亭 \\
\hline & 哀 & 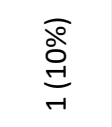 & $\circ$ 。ㅇ & 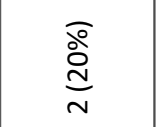 & $\frac{\bar{\circ}}{\stackrel{2}{n}}$ \\
\hline & 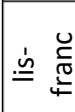 & $m \stackrel{\widehat{\circ}}{\stackrel{0}{m}}$ & 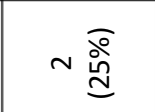 & $m \stackrel{\widehat{\stackrel{\rho}{\rho}}}{\stackrel{m}{m}}$ & $\frac{\widehat{0}}{0}$ \\
\hline & 旁 & 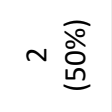 & $\frac{\widehat{0}}{0}$ & 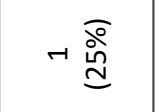 & 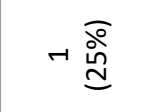 \\
\hline & $\begin{array}{l}\overrightarrow{0} \\
0 \\
\frac{0}{1} \\
\frac{1}{0} \\
. \frac{c}{\varepsilon}\end{array}$ & ○ ฏे & $m$ 总 & $\sim \underset{\stackrel{m}{0}}{\stackrel{0}{0}}$ & $-\stackrel{\widehat{\stackrel{0}{I}}}{=}$ \\
\hline & 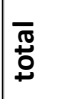 & $\wedge \frac{\widehat{a}}{\mathfrak{d}}$ & $\wedge \frac{\bar{a}}{\stackrel{a}{a}}$ & $\infty$ d্̊ & $\Rightarrow \underset{\stackrel{m}{\rho}}{\widehat{\rho}}$ \\
\hline & & 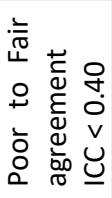 & 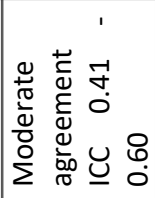 & 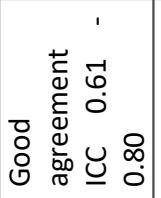 & 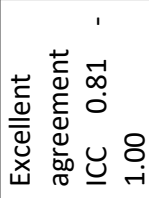 \\
\hline
\end{tabular}




\section{Chapter 4}

\section{Discussion}

Recently the 26 segments GM-model has been presented, this model compared reasonably with previous cadaver and bone-pin experiments and other kinematic models. However, the test-retest repeatability of the GM-model had not been studied before. Aim of this study was to examine the test-retest repeatability of the GM-model. Overall ICC is 0.67 (95\% Cl -0.51 to 0.95$)$. 30 of 33 examined degrees of freedom showed an acceptable $\operatorname{SEM}\left(<5^{\circ}\right)$.

This is the first reliability study of the GM-model. The repeatability of the GM-model seems to compare reasonably well to the intra observer repeatability of other kinematic foot models. Mahaffey et al. ${ }^{19}$ compared three kinematic foot models on children. Mahaffey et al. found for the Oxford Foot Model mean ICC of 0.55 ( $95 \% \mathrm{Cl} 0.16$ to 0.77 ), for 3DFoot a mean ICC of $0.47(95 \% \mathrm{Cl} 0.15$ to 0.64$)$ and for Kinfoot a mean ICC of 0.43 (95\% Cl -0.03 to 0.59$)$. The results of the GM-model showed a higher mean ICC than all models in this study, with a larger $95 \% \mathrm{Cl}$ interval. However a comparison with the results of this study should be interpreted carefully, due to the difference in participants (children versus adults).

Repeatability studies of other kinematic foot and ankle models on adults showed higher ICC's, although no $95 \% \mathrm{Cl}$ for mean ICC was reported in these studies ${ }^{16} 21,22$. The mean ICC of the Oxford foot model studied by Wright et al. ${ }^{21}$ was 0.82 (ranging from 0.38 to 0.97 ) which is higher than we found. However Wright et al. ${ }^{21}$ measured with only 30 minutes of time between the sessions, what possibly explains higher ICCs for the Oxford foot model. With only 30 minutes in between the sessions the marker placement during the second session might be biased by the first session. Adhesive residues, and redness of skin because of pulled hair can still be present, furthermore a researcher can possibly still remember how the markers were placed. A similar effect might have been occurred in the study of Hoeve et al. ${ }^{16}$. They reported ICCs ranging from 0.71-0.97 when using the Oxford foot model on healthy participants in two sessions on the same day. Seo et al. ${ }^{22}$ investigated a three segment foot model and found an excellent repeatability of 0.886 $( \pm 0.047)$. This suggests that the increase in detail of the GM-model decreases the testretest repeatability. However, due to the large $95 \% \mathrm{Cl}$ in this study and the lack of $95 \% \mathrm{Cl}$ in the other studies a conclusion on this cannot be drawn.

Major limitation of current study is the number of participants. Although the test-retest repeatability was good, the ICC of this study has a large $95 \% \mathrm{Cl}$. This might be reduced by collecting data from more participants. The method that was used to calculate overall $95 \%$ $\mathrm{Cl}$ is a rigorous method, since the small variance between average ICC's of individual degrees of freedom is not taken into account. Other researchers using the same method 


\section{Repeatability}

to report on repeatability of kinematic foot models also showed large $95 \% \mathrm{Cl}^{19}$. The effect of increasing participant number should be further investigated.

Largest source of variability in test-retest repeatability has been shown to be marker positioning ${ }^{23}$. A small difference in marker positions might lead to large differences in kinematics ${ }^{24}$. The GM-model uses more markers on the foot and ankle than previous models to increase the level of detail. This can be the cause of lower test-retest repeatability than other foot models on adults.

\section{Conclusions}

In conclusion, current study showed moderate to good test-retest repeatability of the Glasgow Maastricht foot model. However a large $95 \% \mathrm{Cl}$ was found for the ICCs. Before using this model for clinical research extra validation test should be performed. These include, inter observer reliability and other subjects such as children and people with foot deformities. 


\section{Chapter 4}

\section{References}

1. Carson MC, Harrington ME, Thompson N, O'Connor JJ, Theologis TN. Kinematic analysis of a multi-segment foot model for research and clinical applications: a repeatability analysis. Journal of Biomechanics. 2001;34:1299-1307.

2. Simon J, Doederlein L, McIntosh AS, Metaxiotis D, Bock HG, Wolf SI. The Heidelberg foot measurement method: Development, description and assessment. Gait \& Posture. 2006;23:411-424.

3. Leardini A, Benedetti MG, Berti L, Bettinelli D, Nativo R, Giannini S. Rear-foot, mid-foot and fore-foot motion during the stance phase of gait. Gait and Posture. 2007;25:453-462.

4. De Mits S, Segers V, Woodburn J, Elewaut D, De Clercq D, Roosen P. A clinically applicable six-segmented foot model. Journal of Orthopaedic Research. 2012;30:655-661.

5. Tome J, Nawoczenski DA, Flemister A, Houck J. Comparison of Foot Kinematics Between Subjects With Posterior Tibialis Tendon Dysfunction and Healthy Controls. Journal of Orthopaedic \& Sports Physical Therapy. 2006;36:635-644.

6. MacWilliams BA, Cowley M, Nicholson DE. Foot kinematics and kinetics during adolescent gait. Gait \& Posture. 2003;17:214-224.

7. Davis RB, Jameson EG, Davids JR, Christopher LM, Rogozinski BM, Anderson JP. The Design, Development and Initial Evaluation of a Multisegment Foot Model for Routine Clinical Gait Analysis. In: Harris GF, Smith PA, Marks RM, eds. Foot and Ankle Motion Analysis: CRC Press; 2008:425-444.

8. Saraswat P, MacWilliams BA, Davis RB. A multi-segment foot model based on anatomically registered technical coordinate systems: Method repeatability in pediatric feet. Gait \& Posture. 2012;35:547-555.

9. Rattanaprasert U, Smith R, Sullivan M, Gilleard W. Three-dimensional kinematics of the forefoot, rearfoot, and leg without the function of tibialis posterior in comparison with normals during stance phase of walking. Clinical Biomechanics. 1999;14:14-23.

10. Leardini A, Benedetti MG, Catani F, Simoncini L, Giannini S. An anatomically based protocol for the description of foot segment kinematics during gait. Clinical Biomechanics. 1999;14:528-536.

11. Hunt AE, M. Smith R, Torode M, Keenan A-M. Inter-segment foot motion and ground reaction forces over the stance phase of walking. Clinical Biomechanics. 2001;16:592-600.

12. Arampatzis A, Brüggemann G-P, Klapsing GM. A three-dimensional shank-foot model to determine the foot motion during landings. Medicine and science in sports and exercise. 2002;34:130-138.

13. Davis III RB, Ounpuu S, Tyburski D, Gage JR. A gait analysis data collection and reduction technique. Human Movement Science. 1991;10:575-587.

14. Oosterwaal M, Carbes S, Telfer S, Woodburn J, Tørholm S, Al-Munajjed AA, van Rhijn L, Meijer K. The Glasgow-Maastricht foot model, evaluation of a 26 segment kinematic model of the foot. Journal of Foot and Ankle Research. 2016;9:1-10.

15. Deschamps K, Staes F, Bruyninckx H, Busschots E, Jaspers E, Atre A, Desloovere K. Repeatability in the assessment of multi-segment foot kinematics. Gait \& Posture. 2012;35:255-260.

16. van Hoeve S, de Vos J, Weijers PHE, Verbruggen J, Willems P, Poeze M, Meijer K. Repeatability of the Oxford Foot Model for Kinematic Gait Analysis of the Foot and Ankle. Clinical research on foot \& ankle. 2015;3:171. 
17. Andersen MS. Kinematically Over-determinate Musculoskeletal Systems: Aalborg University. Department of Mechanical Engineering; 2009.

18. Shrout PE, Fleiss JL. Intraclass correlations: uses in assessing rater reliability. Psychological bulletin. 1979;86:420-428.

19. Mahaffey R, Morrison S, Drechsler W, Cramp M. Evaluation of multi-segmental kinematic modelling in the paediatric foot using three concurrent foot models. Journal of Foot and Ankle Research. 2013;6:43.

20. McGinley JL, Baker $\mathrm{R}$, Wolfe $\mathrm{R}$, Morris ME. The reliability of three-dimensional kinematic gait measurements: a systematic review. Gait \& posture. 2009;29:360-369.

21. Wright CJ, Arnold BL, Coffey TG, Pidcoe PE. Repeatability of the modified Oxford foot model during gait in healthy adults. Gait \& posture. 2011;33:108-112.

22. Seo S, Lee D, Moon H, Kim S, Kim J, Lee K, Chung C, Choi I. Repeatability of a multi-segment foot model with a 15-marker set in healthy adults. Journal of Foot and Ankle Research. 2014;7:24.

23. Gorton GE, Hebert DA, Gannotti ME. Assessment of the kinematic variability among 12 motion analysis laboratories. Gait \& posture. 2009;29:398-402.

24. France L, Nester C. Effect of errors in the identification of anatomical landmarks on the accuracy of Q angle values. Clinical Biomechanics. 2001;16:710-713. 



\section{CHAPTER 5}

\section{NON-INVASIVE ASSESSMENT \\ OF THE EFFECT OF SOFT \\ TISSUE ARTEFACTS ON MARKER POSITIONS OF KINEMATIC FOOT MODELS}

Michiel Oosterwaal, Scott Telfer, Jim Woodburn, Lodewijk van Rhijn, Adhiambo Witlox, Kenneth Meijer

Submitted 


\section{Chapter 5}

\section{Abstract}

Over the past two decades kinematic foot models have evolved into multi-segment models, offering more sophisticated analytical methods and new insights into foot and ankle function. Recently the 26 segments Glasgow-Maastricht foot model has been presented, however the increased complexity leads to greater risk of introducing Soft Tissue Artefacts (STA) errors.

This study uses a method to quantify the effect of soft tissue motion on marker positions based on imaging data, in order to gain better insight in the potential kinematic errors of the Glasgow-Maastricht foot model. In particular, a method is used to quantify soft tissue motion that is non-surgical, three dimensional and independent of the rigid body assumption. The approach was based on computed tomography measurements of the foot and ankle in a variety of poses and loading states and calculated the motion of a skin mounted radio opaque marker, with respect to its related bone.

The effect of soft tissue motion on marker positions of the Glasgow-Maastricht foot model ranged from $1.9-6.7 \mathrm{~mm}$. Although a high accuracy of calculation was achieved, no specific cause for relative marker motion could be significantly defined. Application of the method on the hindfoot and midfoot showed a low correlation between the size of the bones, the soft tissue thickness and the marker motion.

This study has quantified the effect of soft tissue motion on marker positions of the Glasgow-Maastricht foot model, using a novel method based on four static CT-scans in varying loading positions. 


\section{Background}

Over the past decades, kinematic foot models have evolved from modelling the foot as a single segment ${ }^{1}$ to a model with up to 9 segments ${ }^{2}$. As the number of small foot segments increases, the detail of the model increases, on the other hand so does the sensitivity to measurement errors. Important sources of measurement errors are soft tissue artefacts (STA), caused by the relative movement of the skin based marker with respect to the bone it is assumed to track ${ }^{3,4}$.

Recently, the Glasgow-Maastricht foot model has been presented, modelling movement of all bones in a 26 segment model with 41 degrees of freedom (DoF) ${ }^{5}$. This model uses new marker positions compared to previous presented models. Although locations of the marker position have been defined to avoid underlying tendons, muscles and joints, the sensitivity of these new marker positions to STA is currently unknown. Moreover, the number of segments in the novel model and the size of foot bones relative to the resolution of the measurement make the accuracy of measurements of foot and ankle kinematics highly sensitive to STA.

Several methods have been used to quantify STA in foot and ankle models ${ }^{6-11}$. For example, Nester et al. ${ }^{6}$ applied STA quantification by using surgical applied bone pins. Here, comparisons were made between 3D dynamic motion of skin markers and marker clusters that were, by surgical intervention, directly attached to the bone. However, due to insufficient space, bone and skin mounted markers were not measured simultaneously. This was overcome by repeating the measurements subsequently and comparing stance time, ground reaction forces and tibial kinematics. Nester et al. ${ }^{6}$ divided the foot in four segments; calcaneus, navicular-cuboid, medial forefoot and lateral forefoot. Maximal difference in joint angles derived from bone pins and skin mounted markers was $10^{\circ}$, between navicular-cuboid and medial forefoot in transversal plane. However, since both segments are composed of multiple bones, these STA-measurements could be influenced by the rigid body assumption. The measured error is therefore a summation of the rigid body assumption and STA. Chen et al. ${ }^{7}$ measured the underlying effect of STA, a relative motion of the markers caused by soft tissue motion, by tracking multiple skin markers associated with a segment with a 3D motion capture system. By measuring the distance between several markers on one segment, during normal gait, maximal marker motion of $8.74 \mathrm{~mm}$ was reported at the loading phase during standing. However, partitioning of the measurement error into STA and errors by the rigid body assumption is not possible, since bone position was not measured.

Alternatively, STA and the relative motion of markers can be quantified without surgical intervention by using imaging techniques like fluoroscopy or $x$-ray to quantify dynamic STA ${ }^{8-11}$. For markers, positioned on the medial side of the foot, Tranberg, Karlsson ${ }^{8}$ showed 


\section{Chapter 5}

motion of 1.8-4.3 mm between several static loading positions of the foot. Wrbaškić, Dowling ${ }^{9}$ have investigated correlations $(0.536<r<0.995)$ between motion of bones in the first ray and motion of connecting skin markers for three dynamic tasks. However, patterns in marker movement were not detected. Schultz et al ${ }^{10}$ performed dynamic measurements using fluoroscopy in the sagittal plane, and found that marker motion ranged from $6.46-16.72 \mathrm{~mm}$. Maslen, Ackland ${ }^{11}$ showed skin displacement of $6.8 \mathrm{~mm}$ in vertical and $4.0 \mathrm{~mm}$ in horizontal direction (with respect to field of gravity) going from neutral position to inversion of $10^{\circ}$. These fluoroscopy based methods are not influenced by the rigid body assumption, since the motion is derived directly by measuring bone and marker position. However, by using fluoroscopy, the effect of soft tissue motion is only measured in one plane; hence projection errors could be of influence of these measurements. The majority of projection errors are caused by out of plane motion ${ }^{10}$, this is partly solved by using bi-planar fluoroscopy. This problem aggravates in foot and ankle kinematics which is known to be three dimensional, this could also influence in plane STA measurements.

Sangeux et al ${ }^{12}$ used MRI to quantify STA in knee kinematics. MRI was used to image skin mounted markers and underlying bones in four different static positions. The relative motion of the markers with respect to the bones was measured and used to calculate STA. However, directly using this method in the foot and ankle is less suitable. The high number of markers and bones in the foot and ankle require small markers and therefore a high resolution. This implies a longer scanning time than the 1 minute protocol presented in the knee protocol. To apply a steady loading force for a long time on the foot when seated increases the chance of motion artefacts of the MRI.

The aim of this work is to quantify the influencing factors on soft tissue motion on the relative motion of markers of the Glasgow-Maastricht foot model. Previous research towards quantification techniques on soft tissue motion has shown that these methods for the foot and ankle models should be: non-surgical; dynamic; three dimensional; simultaneously measuring motion of bone and skin marker; and independent of the rigid body assumption. No current method is known to meet all requirements. The paper presented here uses a method to quantify the effects of soft tissue motion, that is comparable with the method presented by Sangeux et al. ${ }^{12}$ to measure STA in the knee. This study uses CT-measurement to acquire data, since 1) a scale, containing metal particles, is used to provide feedback on the level of applied load to the participants, which makes MRI not feasible and 2) applying a steady load on the foot when seated for a longer time is hard, therefore a short acquisition time is required. All in all we quantify the effect of soft tissue motion on marker positions based on a series of statically loaded CTmeasurements and calculate motion of a skin mounted radio opaque marker, with respect 
to its associated bone. Based on conclusions of Cappozzo et al. ${ }^{4}$, it is hypothesized that skin markers on the rear foot will be less influenced by soft tissue motion, due to high mobility of the ankle joint. Secondly, it is hypothesized that the thickness of the soft tissue layer would be correlated with the magnitude of motion of the markers.

\section{Methods}

The study is conducted in accordance to the Declaration of Helsinki. Ethical approval for this study has been granted by the West of Scotland Research Ethics Committee (application reference 10/S1001/24) and National Health Service Greater Glasgow and Clyde Research and Development Committee (reference GN10RH187) for the UK site. At the Dutch centre, the study has been granted approval by the Medical Ethical Committee azM/UM (reference number NL31656.068.10/MEC 08-2-028). Detailed information on the data capturing of the measurements in this chapter has been described by Oosterwaal et al. ${ }^{13}$. This section gives a brief overview of the measurements performed to acquire input data for measuring the relative motion of markers caused by soft tissue motion.

\section{Subjects}

12 subjects were measured at two clinical centres, Glasgow Caledonian University and Maastricht University Medical Centre, following the protocol of Oosterwaal et al. ${ }^{13}$. All subjects gave informed consent.

\section{Data acquisition}

Subjects' right feet and ankle were palpated and anatomical landmarks were indicated with a non-permanent marker, following the marker set of Table 5.1. This marker set is a subset of that used for the Glasgow Maastricht foot model ${ }^{13}$. The phalangeal markers and the markers positioned on the posterior side of the calcaneus were excluded, since latter markers were positioned on an extending heel plate and this heel plate could interfere with positioning the foot in the CT scanner. Radiopaque markers ( $4 \mathrm{~mm}$ diameter Beekley Spots $^{\circledR}$, Oncology Imaging Systems, East Hoathly, UK) were attached to the landmarks. CT scans were made on an Aquilion 64 slice scanner (Toshiba, Tokyo, Japan) at the Glasgow centre or a Brilliance 64 slices (Phillips, Amsterdam, the Netherlands) at Maastricht. CT scans were taken, in randomised order, in four positions, using a custom made loading device. On the loading device a scale with a large LED display was mounted. This display was used to provide visual feedback to the participant on the level of applied loading. The relatively short time frame of the CT scan (5-10 seconds) allowed medium level loads to be applied and maintained over its duration. One unloaded scan in neutral ankle position and three loaded scans in which the foot was loaded to $50 \%$ body weight. Loaded scans were: 


\section{Chapter 5}

foot in neutral ankle position, foot in $25^{\circ}$ plantar flexion and foot in $10^{\circ}$ dorsiflexion. CT scans were performed with $1 \mathrm{~mm}$ slices with a resolution of $512 * 512$ voxels.

Table 5.1 Marker set, subset of the marker set for the 26 segments kinematic model

\begin{tabular}{|c|c|c|}
\hline Markername & Bone & Position on bone \\
\hline MCAL & Calcaneus & Medial calcaneum \\
\hline LCAL & Calcaneus & Lateral calcaneum \\
\hline CUB & Cuboid & Lateral Cuboid \\
\hline LCUN & Lateral Cuneiform & Lateral Cuneiform \\
\hline ICUN & $\begin{array}{l}\text { Intermediate } \\
\text { cuneiform }\end{array}$ & Intermediate cuneiform \\
\hline NAV & Navicular & Tuberosity navicular \\
\hline P1MT & 1st metatarsal & 1st metatarsal proximal base \\
\hline C1MT & 1st metatarsal & $\begin{array}{l}\text { Central 1st metatarsal (middle of line P1MT } \\
\text { and } \mathrm{M} 1 \mathrm{MH} \text { ) }\end{array}$ \\
\hline $\mathrm{M} 1 \mathrm{MH}$ & 1st metatarsal & Medial 1st metatarsal head \\
\hline L1MH & 1st metatarsal & Lateral 1st metatarsal head \\
\hline D2MT & 2nd metatarsal & 2nd metatarsal head \\
\hline D3MT & 3rd metatarsal & 3rd metatarsal head \\
\hline D4MT & 4th metatarsal & 4th metatarsal head \\
\hline P5MT & 5th metatarsal & 5th metatarsal proximal base \\
\hline D5MT & 5th metatarsal & 5th metatarsal head \\
\hline
\end{tabular}




\section{Image processing}

CT slides were 3D reconstructed and segmented using Mimics (Materialise, Belgium) into bones and related markers (Figure 5.1). Segmentation was performed via: 1) thresholding on bone values (226-3071 HU), 2) manually separating connecting objects by deleting voxels, 3) for the Maastricht subjects, missing internal voxels were added manually 4) converting the mask into a $3 \mathrm{~d}$ object and exporting its surface in stl-format.

In a custom developed Matlab algorithm (Mathworks, USA ) surface files of each marker and its corresponding bone were imported. Subsequently, the surface file was transformed to a volume mesh with a grid of $50 \times 50 \times 50$, where equal mass distribution over the object was assumed. Principal axes and geometric centre of the bones were computed from the inertia matrix of the bone (Figure 5.1). This was repeated for the marker and corresponding bone in each loading condition. Potentially, the direction of the principal axes can be unequal for each loading condition; e.g. a principal axis might be in opposite direction in two loading conditions, which leads to a rotated coordinate system between two loading conditions. This was solved by rotating the loading conditions amongst the four possible orientations (original orientation and $180^{\circ}$ rotated over all 3 principal axes). The rotational case in which the bone volumes matched best was used in further analysis. Closest match is defined as the rotation with the highest grid accuracy between two loading cases; see output parameters for the definition of grid accuracy. The directions of the principal axes were used as the local coordinate system of the bone. The centre of the marker was computed and saved in the local coordinate system of corresponding bone.
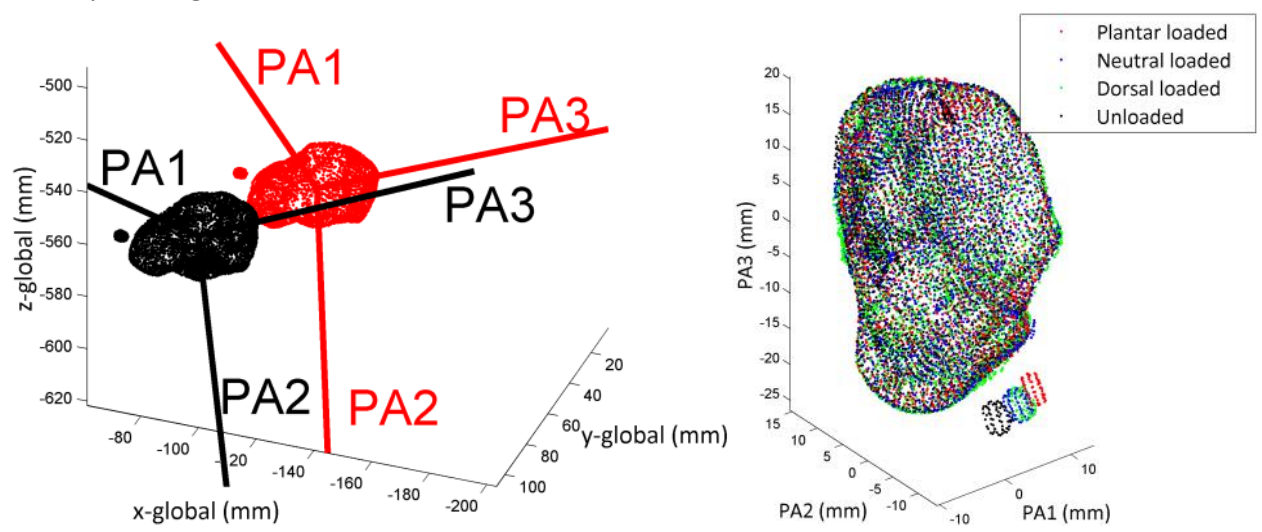

Figure 5.1 Visual representation of the method to calculate STA

1) Navicular bone, its principal axis (PA) and NAV marker in two different loading conditions, in the CT-scan coordinate system 2) Navicular bone and NAV marker oriented on principal axis for four loading conditions 


\section{Chapter 5}

\section{Output parameters}

The local coordinates of the markers and corresponding bones are used to calculate summarizing parameters. Four output parameters have been examined:

Relative motion of a marker is the final goal of the method. The location of the centre of a marker is computed for four different loading conditions. Relative motion is defined as the maximal distance between the centres of all loading conditions.

To calculate the bone volume from the surface STL-file a mesh of $100 * 100 * 100$ voxels was constructed, of which dimensions are matched to surround the bone. Bone volume was then defined such that all voxels were inside the bones surface. This volume was part of the accuracy calculation.

Soft tissue thickness is defined as the minimal distance of the centre of the marker to the surface of the connecting bone. This distance was decreased with $2 \mathrm{~mm}$, the radius of the radiopaque markers.

Accuracy of the method could be influenced by CT-resolution, quality of segmentation of images and the ratio of the dimensions of the bone. The accuracy of the matching between two coordinate systems is tested by the matching percentage of two separate grids in their own coordinate system. This is called grid accuracy and is computed by comparing bone volumes of two loading cases:

$A c c=1-\frac{O_{\text {load } 1} \cup O_{\text {load } 2}}{100^{3}}$,

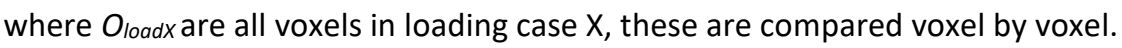

\section{Statistics}

Subjects were excluded if by a technical error not all 4 CTs were taken or if in one or more scans the distal part of the metatarsals were missing. Single bones were excluded from patient datasets when they were not completely captured during CT scanning. If not all loading conditions of a bone were captured, the bone was excluded from further analysis. Mean $(\bar{x})$ and standard deviation (std) of bone volume and relative motion were computed. Correlations between all output parameters and relative motion were computed to calculate the source of relative motion. To test if relative motion was different for various locations on the foot a one-way repeated-measures ANOVA test was used, where the marker location is the independent variable and the relative motion the dependent variable, post hoc testing was corrected with the Bonferroni method. The level of significance was set at $p<0.05$. 


\section{Results}

CT data of 12 subjects ( 9 in Maastricht, 3 in Glasgow; age: $29.7 \pm 8.9 \mathrm{yr}$, length: $1.75 \pm 0.1$ m, weight: $78 \pm 18.7 \mathrm{~kg}, 8$ male) was successfully collected. In three CT scans the calcaneus was not completely in the field of view of the CT-scan. Therefore, relative motion of the calcaneus markers was calculated for 9 subjects. Relative motion of the remaining 13 markers could be determined in all 12 subjects.

\section{Relative motion}

Table 5.2 Summary table of relative motion and bone volume. Bone volume is reported once per bone (Calcaneus, first metarsal and fifth metarsal have multiple markers)

\begin{tabular}{|c|c|c|c|}
\hline Marker & \# subjects & $\begin{array}{l}\text { Relative motion }(\overline{\mathrm{x}} \pm \\
\mathrm{std})[\mathrm{mm}]\end{array}$ & $\begin{array}{l}\text { Bone volume corresponding } \\
\text { bone }(\bar{x} \pm s t d)\left[\mathrm{cm}^{3}\right]\end{array}$ \\
\hline MCAL & 9 & $3.0 \pm 0.7$ & \multirow{2}{*}{$67.1 \pm 17.5$} \\
\hline LCAL & 9 & $2.9 \pm 1.1$ & \\
\hline CUB & 12 & $4.0 \pm 2.1$ & $12.8 \pm 3.2$ \\
\hline LCUN & 12 & $5.4 \pm 2.9$ & $5.7 \pm 1.1$ \\
\hline ICUN & 12 & $6.7 \pm 3.7$ & $4.2 \pm 1.0$ \\
\hline NAV & 12 & $3.2 \pm 1.0$ & $11.4 \pm 2.2$ \\
\hline P1MT & 12 & $2.6 \pm 0.7$ & \multirow{4}{*}{$17.9 \pm 4.2$} \\
\hline C1MT & 12 & $1.9 \pm 0.6$ & \\
\hline $\mathrm{M} 1 \mathrm{MH}$ & 12 & $2.1 \pm 1.0$ & \\
\hline L1MH & 12 & $2.4 \pm 1.4$ & \\
\hline D2MT & 12 & $2.6 \pm 1.7$ & $9.4 \pm 2.1$ \\
\hline D3MT & 12 & $3.2 \pm 1.8$ & $8.1 \pm 1.9$ \\
\hline D4MT & 12 & $3.3 \pm 1.7$ & $8.0 \pm 1.8$ \\
\hline P5MT & 12 & $2.5 \pm 0.8$ & \multirow{2}{*}{$8.4 \pm 2.1$} \\
\hline D5MT & 12 & $2.5 \pm 1.3$ & \\
\hline
\end{tabular}




\section{Chapter 5}

The mean relative motion of the markers ranged from 1.9-6.7 mm (Table 5.2). A one-way repeated-measures ANOVA showed a significant difference in relative motion when comparing all markers, where markers in the midfoot area (CUB, LCUN, ICUN) had a significant larger relative motion. However, post hoc comparisons with Bonferroni correction were not significant. The markers, related to the same bone, showed similar relative motion (MCAL $(2.9 \mathrm{~mm})$ vs $\operatorname{LCAL}(3.0 \mathrm{~mm})$; $\operatorname{P} 1 \mathrm{MT}(2.6 \mathrm{~mm}), \operatorname{L} 1 \mathrm{MH}(2.4 \mathrm{~mm})$, $\mathrm{M} 1 \mathrm{MH}(2.1 \mathrm{~mm})$ vs C1MT(1.9 mm),).

Since relative motion is defined as the largest displacement between two loading conditions a closer look at the conditions responsible for the largest of relative motion was taken (Table 5.3). For only $18 \%$ of the cases, relative motion was computed by comparing a loading case with the neutral loaded case.

Soft tissue thickness ranged from $2.7-22.8 \mathrm{~mm}(\bar{x}=7.7 \mathrm{~mm}$ std $=4.4 \mathrm{~mm})$. However, very low correlation between relative motion and soft tissue thickness was found $\left(R^{2}=0.04, p\right.$ $<0.01$ ). Largest soft tissue thickness was found for P1MT, smallest for D5MT.

Table 5.3 Distribution of highest difference in marker position (relative motion) between all loading conditions

\begin{tabular}{|l|l|}
\hline Plantar loaded - Neutral loaded & $3 \%$ \\
\hline Plantar loaded - Dorsal loaded & $34 \%$ \\
\hline Plantar loaded - Unloaded & $31 \%$ \\
\hline Neutral loaded - Dorsal loaded & $7 \%$ \\
\hline Neutral loaded - Unloaded & $8 \%$ \\
\hline Dorsal loaded - Unloaded & $17 \%$ \\
\hline
\end{tabular}

\section{Accuracy of the method}

Grid accuracy ranged from 0.87-1.0 ( $\bar{x}=0.96 \mathrm{std}=0.02)$, a significant $(p<0.001)$, but low correlation $\left(\mathrm{R}^{2}=0.12\right)$ between relative motion and grid accuracy was found. The largest errors in grid accuracy $(<0.9$, so more than $10 \%$ of the segmented bones did not match), were not associated with the largest relative motion.

Volumes of the bones in the foot vary, in average the bones ranged from $4.2-93.6 \mathrm{~cm}^{3}$, where the fifth metatarsal was the smallest, the calcaneus the largest. Correlation between bone volume and grid accuracy was low: $R^{2}=0.02(p<0.01)$, a relatively higher correlation $\left(R^{2}=0.13, p<0.001\right)$ was found when excluding the calcaneus. 


\section{Discussion}

Aim of this study was to quantify the influencing factors on soft tissue artefacts on the relative motion of markers of the Glasgow-Maastricht foot model. To measure relative motion a novel method to quantify relative motion has been developed. This method uses static CT-scans in various poses and loading conditions, computes the principal axes of the segmented bones and compares the local coordinates of skin-mounted markers over the various static positions. Relative motion of the markers of the Glasgow-Maastricht foot model ranged from $1.9-6.7 \mathrm{~mm}$, where markers in the midfoot showed more motion, however this was not a significant difference. No correlation with thickness of the soft tissue was found. Calculations on the accuracy did not show a correlation between parameters related to the accuracy and relative motion. It is therefore concluded that this novel method is an accurate measurement to calculate relative motion.

The accuracy of the method (grid accuracy) is independent on the bone size. Consequently, it is concluded that current resolution is high enough to accurately calculate relative motion. Therefore if bone/voxel volume ratio is 500 , imaging resolution is sufficient. It is therefore recommended to define image resolution based on bone size, to lower radiation dose and reduce acquisition time. The consistency of segmentation and the ratio of the dimensions of the bone are examined by looking at the relation between relative motion and grid accuracy. Since low correlation was found, it can be concluded that the output of the method is not significantly influenced by the accuracy of the method.

Low correlation was found between the size of the bones, the soft tissue thickness and the relative motion of the markers. Relative motion for markers connected to larger bones is shown to be influenced by thickness the soft tissue ${ }^{14}$. The small effect of soft tissue thickness on relative motion might be dominated by the size of the foot and its bones. It is suggested in literature ${ }^{4}$ to avoid attaching skin surface markers close to joints, since two or more moving bones would influence marker movement of each other. As a result of the relatively small size of the foot, it is often not possible to position markers suitable distances from all joints. Therefore, our findings confirm that STA compensation techniques are not applicable in foot and ankle models.

By using principal axis no manual registration is needed to match the position of two images of the same object, as is the case for example for the widely used methods based on an iterative closest point algorithm ${ }^{15}$. The current method could be improved by decreasing the effect of segmentation variations over the scans and the necessity of scanning the full bone, e.g. by the introduction of iso-shaping techniques ${ }^{16}$. By combining this method with a cyclic movement in an MRI-scan, dynamic relative motion can be computed. Since kinematic foot models are usually used for measurements during gait, 


\section{Chapter 5}

the dynamic effects of STA are of interest. This is also shown by the variance in the loading positions causing the relative motion of markers (Table 5.3), since these loading cases vary it is not sufficient to measure two single loading cases.

This study found differences in skin motion between static positions therefore it is recommended to report the loading condition and position of the subject while palpating the marker positions. This is in accordance to the standards on reporting of foot and ankle

models by Bishop et al. ${ }^{2}$. Furthermore, although relative marker motion in the foot and ankle is smaller than relative motion of markers attached proximal to the ankle, STA should be taken relative to the related bones, since small measurement errors could lead to large miscalculations in kinematics. Relative motion could possibly be caused by wrong palpation of the marker positions. Since the anatomy of the foot shows multiple ligaments, tendons and muscles between marker and bone it is possible that motion artefacts are introduced. If therefore a marker is marginally miss positioned, relative motion could be amplified or, worse, counter directed. However, from the current results it is difficult to pin point a direct cause for the observed relative motion.

A limitation of the current study is the fact that it is comparing several static positions of the foot and ankle. It will therefore not measure the extra effects on relative marker motion that occur during gait, e.g. transient shear forces and inertial effects of both soft tissue and markers. Furthermore forces on the foot are higher during gait than static forces applied in this study. Another improvement is to translate the relative marker motion towards STA via the effect of relative marker motion on kinematic angles. The Glasgow-Maastricht foot model is developed and validated for dynamic simulations. The use of rhythms ${ }^{5}$ to couple kinematics of several joints requires data capturing during full stance phase of the gait. The Glasgow-Maastricht foot model is therefore not suited for static simulations and translation from relative marker motion towards the effects of STA on kinematic angles.

\section{Conclusions}

In conclusion, this study has quantified relative marker motion of the Glasgow-Maastricht foot model, using a novel method based on four static CT-scans in varying loading positions. This method creates the possibility to calculate relative marker motion in a nonsurgical way and in three dimensions. Other application of this method could be in other imaging modalities, such as MRI. Moreover, the method can be used in 3D dynamic measurements, since the method can easily be applied to multiple numbers of images. 


\section{References}

1. Apkarian J, Naumann S, Cairns B. A three-dimensional kinematic and dynamic model of the lower limb. Journal of Biomechanics. 1989;22:143-155.

2. Bishop C, Paul G, Thewlis D. Recommendations for the reporting of foot and ankle models. Journal of biomechanics. 2012;45:2185-2194.

3. Peters A, Galna B, Sangeux M, Morris M, Baker R. Quantification of soft tissue artifact in lower limb human motion analysis: A systematic review. Gait \& Posture. 2010;31:1-8.

4. Cappozzo A, Catani F, Leardini A, Benedetti MG, Della Croce U. Position and orientation in space of bones during movement: experimental artefacts. Clinical Biomechanics. 1996;11:90-100.

5. Oosterwaal M, Carbes S, Telfer S, Woodburn J, Tørholm S, Al-Munajjed AA, van Rhijn L, Meijer K. The Glasgow-Maastricht foot model, evaluation of a 26 segment kinematic model of the foot. Journal of Foot and Ankle Research. 2016;9:1-10.

6. Nester C, Jones RK, Liu A, Howard D, Lundberg A, Arndt A, Lundgren P, Stacoff A, Wolf P. Foot kinematics during walking measured using bone and surface mounted markers. Journal of Biomechanics. 2007;40:3412-3423.

7. Chen S-J, Mukul M, Chou L-S. Soft-Tissue Movement at the Foot During the Stance Phase of Walking. Journal of the American Podiatric Medical Association. 2011;101:25-34.

8. Tranberg R, Karlsson D. The relative skin movement of the foot: a 2-D roentgen photogrammetry study. Clinical Biomechanics. 1998;13:71-76.

9. Wrbaškić N, Dowling JJ. An investigation into the deformable characteristics of the human foot using fluoroscopic imaging. Clinical Biomechanics. 2007;22:230-238.

10. Shultz R, Kedgley AE, Jenkyn TR. Quantifying skin motion artifact error of the hindfoot and forefoot marker clusters with the optical tracking of a multi-segment foot model using single-plane fluoroscopy. Gait \& Posture. 2011;34:44-48.

11. Maslen BA, Ackland TR. Radiographic study of skin displacement errors in the foot and ankle during standing. Clinical Biomechanics. 1994;9:291-296.

12. Sangeux M, Marin F, Charleux F, Dürselen L, Ho Ba Tho MC. Quantification of the 3D relative movement of external marker sets vs. bones based on magnetic resonance imaging. Clinical Biomechanics. 2006;21:984-991.

13. Oosterwaal M, Telfer S, Torholm S, Carbes S, van Rhijn LW, Macduff R, Meijer K, Woodburn J. Generation of subject-specific, dynamic, multisegment ankle and foot models to improve orthotic design: a feasibility study. BMC Musculoskelet Disord. 2011;12:256.

14. Karlsson D, Tranberg R. On skin movement artefact-resonant frequencies of skin markers attached to the leg. Human Movement Science. 1999;18:627-635.

15. Chen $\mathrm{Y}$, Medioni G. Object modelling by registration of multiple range images. Image and Vision Computing. 1992;10:145-155.

16. Saha PK, Udupa JK, Falcao AX, Hirsch BE, Siegler S. Iso-shaping rigid bodies for estimating their motion from image sequences. IEEE transactions on medical imaging. 2004;23:63-72. 

Chapter 6

CHAPTER 6

GENERAL DISCUSSION

0 


\section{General Discussion}

The objective of this thesis is to develop a kinematic foot model, to (i) improve knowledge of foot biomechanics in general and foot kinematics of joints that were previously not measured and (ii) as a first link in the chain of models to predict the effect of foot orthoses by using the kinematic model proposed in the introduction of this thesis.

A novel protocol for data acquisition was developed and applied to obtain data on healthy subjects and patients with foot complaints (Chapter 2). Subsequently, these measurements have been used to develop the 26 segments kinematic foot model (Chapter 3). The model has been evaluated in three steps. Firstly, the output of the model was compared with the limited data on foot kinematics in existing literature (Chapter $\mathbf{3}$ ). Secondly, the test-retest repeatability of the model was evaluated (Chapter 4). Thirdly, the relative marker motion of the model was investigated; by taking a deeper look in the effect of soft tissue motion on the relative motion of the markers (Chapter 5).

This chapter first discusses the kinematic foot model, by describing its strengths, weaknesses and recommendations for future research. Subsequently, the potential applications of the kinematic model and future work to increase the added value of the model into improving knowledge in foot kinematics and to predict the effect of foot orthoses by using the kinematic model as a first link in the chain of models.

\section{The kinematic foot model}

Chapter 3 describes the development of kinematic foot model: the GM-model. A guideline of 5 standards on how to report kinematic foot and ankle models has been given by Bishop et al. ${ }^{1}$. This thesis only suits partly to the standards. This is mainly caused by the different modelling approach. The 5 standards and the degree to which this thesis meets these criteria are listed below:

Report the location, accuracy and reliability of marker placement. Correct marker placement is essential in kinematic models, since motion of markers is used to calculate kinematics. ${ }^{2}$ Correct marker placement requires description of the location, but also tests on accuracy and reliability of this placements.

Locations of the markers of the GM-model have been listed in Chapter 2. No specific test has been performed in this thesis to test accuracy and reliability of marker placement. However, test-retest repeatability was good to moderate with mean ICC of 0.67 (Chapter 4).

Report the definition of segment(s). Motion of markers is used to calculate motion of the segments. In kinematic foot models, that use the rigid body assumption, it is therefore required to report of which bones a segment exists. Furthermore it is required to report the joint types used to link the separate bones or segments. 
Since the GM-model does not use the rigid body assumption to combine multiple bones into segments, this has not been reported. Chapter 3 reports joints and the rhythms used to link motion of multiple joints.

Report the definition of segment coordinate systems. After anatomically defining the segments, it is necessary to define the orientation of the segments. More specific a detailed description of how the axes of the segments are defined is required. E.g. X-axis is marker 1 to marker 2, Y-axis is perpendicular to X-axis through marker 3, etc.

Since the GM-model uses the method of Andersen ${ }^{3}$ to scale the model and define segment and joint orientation, no one-on-one relation between marker and segment coordinate system can be given. However, the optimisation algorithms have been reported in Chapter 3.

Report the definition of joint parameters. This standard addresses the definition on how to translate motion marker to segments. How are the degrees of freedom of the joints oriented with respect to segments coordinate system? And in what way is the order of motion in degrees of freedom defined in joints with multiple degrees of freedom defined? Due to the same reason as the third standard, no report of the joint directions of the GMmodel can be given. Although the optimisation algorithms and the rhythms have been reported in Chapter 3.

Report the reliability of joint kinematics. Last standard involves the reliability of the total model, the reliability of the translation of the markers into kinematics. This reliability is affected by soft tissue artefacts (STA) and the sensitivity to marker placement. Latter can be tested by test-retest reproducibility experiments and studying the inter observer reproducibility.

Current version of the GM-model is incapable in performing a static simulation. This is due to the rhythms that require dynamic simulation.Chapter 5therefore does not fully address STA. However, linear relative motion of the markers with respect to underlying bones was similar to other models $(1-7 \mathrm{~mm})$. Furthermore, Chapter 4 reported a moderate to good test-retest reproducibility for $57 \%$ of the joints, with an overall ICC of 0.67 , furthermore 30 of 33 joints showed an acceptable SEM.

Where possible this thesis addresses the standards defined by Bishop et al. ${ }^{1}$. This thesis therefore is a proper description of the GM-model. We will now focus on the strengths of the model, as well as the weaknesses and future work to further improve the model.

\section{Strengths of the model}

\section{Close to reality}

The foot is comprised of 26 bones, excluding the sesamoids. Cadaver ${ }^{4}$ and bone-pin studies ${ }^{5}$ have shown movements between all 26 bones. For example, an in vitro study of 


\section{General Discussion}

Nester et al. ${ }^{4}$ has shown substantial motion in three dimensions between navicular and medial cuneiform, central cuneiform and lateral cuneiform of $4.5^{\circ}-11.4^{\circ}, 5.4^{\circ}-9.8^{\circ}$ and $11.2^{\circ}-14.3^{\circ}$ respectively. However the majority of kinematic foot models uses the rigid body assumption ${ }^{6}$. This assumption assumes some joints in the foot to be rigid, which joints are rigid vary between the different models. In particular, to date over 15 multisegment foot models 7,8 have been developed, all modelling the navicular bone and the three cuneiforms as a single rigid segment. Before the introduction of the GM-model the most complete kinematic foot model has been presented by MacWilliams et al. ${ }^{9}$ with 8 segments in the foot.

Instead of using a rigid body assumption, the GM-model, introduced rhythms to combine kinematics of multiple bones and models. In particular, the model is developed by implementing seven rhythms to connect the 26 bones in the foot. These rhythms are mathematical formulations that couple the motion of multiple bones. The benefit of this approach is that these rhythms are adaptable to model specific foot deformities in the future. This modelling approach allows modelling of kinematics in all joints of the foot and ankle and thereby improves on existing models. This thesis only used one set of rhythms, simulating the gait of a healthy foot. However, the model setup of the GM-model creates the possibility to change parameters to simulate clinical deformities of the foot.

\section{Scalable in multiple directions}

By scanning the 3D shape of the foot the shape of the foot is scaled in three dimensions. After this initial step in scaling, the model is further scaled by an optimisation algorithm to calculate the size and locations of the bones in the foot and the location and directions of the foot joints. Furthermore the models kinematic properties can be adapted to match patient specific properties by changing the rhythms.

In this way different foot deformities can be evaluated. In case of for example mid foot osteoarthritis, parameters can be changed to stimulate this clinical deformity of the foot. In addition the effect of different treatment options; reconstruction by arthrodesis can be evaluated pre operatively. In this way all kind of foot deformities can be simulated and post-operative predictions can be made. When performing an arthrodesis the best position can be evaluated pre operatively with the GM-model in this way optimizing the post-operative results.

\section{Partially validated}

In Chapter 2-5 the first important steps in evaluation of the GM-model were taken. The GM-model was evaluated by comparison with existing literature, test-retest repeatability was investigated and the relative motion of the markers was studied. 
Coherence with literature was performed by comparing kinematics of the GM-model with kinematics of cadaver experiments, bone pin studies and other kinematic models (0). Although conclusions of literature differ across the various studies, the kinematics of the GM-model were within range of these studies. Timing and amplitude of kinematics were similar for most joints of the model. This validation step shows the sensitivity of the GMmodel to different types of (healthy) feet and gaits. The model outputs are most likely due to true inter subject difference, since Chapter 4 showed that intra subject repeatability was good to moderate.

The overall test-retest repeatability of the model is good, with an intraclass correlation coefficient of 0.67 (95\% $\mathrm{Cl}-0.51$ to 0.95$)$ as described in Chapter 4 . This is in line with previous reported kinematic foot models, which have less degree of freedom. Furthermore $57 \%$ of the joints showed good to excellent agreement. This validation is necessary to establish if the model can be used in the future in clinical studies. In these studies it is required to know that the change in foot and ankle kinematics between two sessions (eg pre and post intervention) is caused by the intervention and not by the lack of repeatability of the model.

The research into measurement errors caused by soft tissue motion showed that motion of the markers with respect to the underlying bone is between $1 \mathrm{~mm}$ and $7 \mathrm{~mm}$. This is comparable with existing models. However, the effect of this small motion on the kinematics should be further studied.

\section{Weaknesses of the model and recommendations for future research}

Despite these first steps in the validation of the GM-model further validation steps should be taken to use this model in a clinical setting:

\section{STA in a loaded situation and translation into kinematics}

Although the method presented in Chapter 5 did calculate linear motion of the skin mounted markers with respect to the underlying bones, the effect of this motion on the measurement on kinematics during gait has not been studied.

However when comparing the linear STA errors with linear STA of other kinematic foot models these are in the same range. STA in the GM-model ranged from 1-6.7 mm. Chen et al. ${ }^{10}$ measured STA by tracking skin markers with a 3D motion capture system. By measuring the distance between several markers on one segment, during normal gait, maximal STA of $8.74 \mathrm{~mm}$ was reported at the loading phase during standing. For markers, positioned on the medial side of the foot, Tranberg, Karlsson ${ }^{11}$ showed STA of 1.8-4.3 mm between several static loading positions of the foot by using X-ray. Using a similar method, Maslen, Ackland ${ }^{12}$ showed STA of $6.8 \mathrm{~mm}$ in vertical and $4.0 \mathrm{~mm}$ in horizontal direction 


\section{General Discussion}

(with respect to field of gravity) going from neutral position to inversion of $10^{\circ}$. Schultz et al ${ }^{13}$ performed dynamic measurements using fluoroscopy in the sagittal plane, STA ranged from 6.46-16.72mm.

In a systematic review by Peters et al. ${ }^{14}$ it was found that STA measurements differ depending on the tasks performed by the subject. This means that the effect of STA in a dynamic situation should be further studied, since the GM-model has been designed for dynamic use. It is assumed that STA will increase in a dynamic situation due to transient shear forces and inertial effects of both soft tissue and markers. Furthermore forces on the foot are higher during gait than in a static situation ${ }^{15}$ as were applied in Chapter 5.

Intra observer repeatability has a large variance and has not been studied in pathological feet

Chapter 4 showed a moderate to good repeatability of the GM-model; however this study also showed large confidence intervals, e.g. overall ICC was 0.67 ( $95 \% \mathrm{Cl}-0.51$ to 0.95 ). It is unknown if these large $\mathrm{Cls}$ are due to the statistical method of calculation $\mathrm{Cl}$, the low number of participants in this study (seven), or a trade off with the increased level of detail of the GM-model.

Current statistical method of calculating overall $\mathrm{Cl}$ is 1) Fisher r-to-z transformation of the individual ICCS, 2) calculation of the upper and lower bound of the transformed ICCs and 3) Fisher z-to-r transformation of this upper and lower bound. This method is a rigorous method, since the small variance between average ICC's of individual degrees of freedom is not taken into account. Furthermore, other researchers using the same method to report on repeatability of kinematic foot models also showed large $95 \% \mathrm{Cl}^{16}$. Mahaffey et al. ${ }^{16}$ investigated three different multi-segmented foot models (Oxford, 3D Foot, and Kinfoot) at children they found an overall moderate repeatability and reliability. the results of the GM-model showed a higher mean ICC, with a larger $95 \% \mathrm{Cl}$ interval. Mahaffey et al. found for the Oxford Foot Model mean ICC of 0.55 ( $95 \% \mathrm{Cl} 0.16$ to 0.77 ), for 3DFoot a mean ICC of $0.47(95 \% \mathrm{Cl} 0.15$ to 0.64$)$ and for Kinfoot a mean ICC of 0.43 (95\% $\mathrm{Cl}-0.03$ to 0.59 ).

The effect of increasing number of participants on the $95 \% \mathrm{Cl}$ of the intra observer repeatability of the GM-model should be further investigated. The latter will clarify if the large $\mathrm{Cl}$ is a trade off with the increased level of detail of the GM-model. To achieve this high level of detail, the GM-model needs more markers than previous reported multisegment kinematic foot models. Gorton et al. ${ }^{17}$ found that marker positioning is the largest source of variability in test-retest repeatability. This is because a small difference in marker positions might lead to large differences in kinematics ${ }^{18}$.

Furthermore, the model should be tested on pathological feet. Although the model is technically capable in simulating pathological feet, all validation tests on the GM-model 
have been performed on healthy subjects. Before using the model in clinical setting on patients with foot pathologies validation on this group has to be performed. Different frequently seen foot deformities can be tested in different settings thereby improving the clinical usage of the model.

\section{Inter observer repeatability should be studied}

In Chapter 4 the same researcher performed the test-retest measurements. In Chapter 3 two different researchers performed the measurements, one in Glasgow, one in Maastricht. At this moment it is unknown what the effect of these different researchers is on the current results. Additionally, before this model can be used in clinical research, this validation step is necessary. This enables the intra centre comparison of clinical measurements and thereby possibility to interpret data on different locations. It has been shown for other kinematic models that largest source of error in multi centre ${ }^{17}$ studies is the difference between observers . Inter observer repeatability studies for other kinematic foot models showed a lower inter than intra observer repeatability ${ }^{19,} 20$

\section{Various sensitivity analyses should be performed}

All output results in this thesis were taken directly from the model. Nevertheless, it is unknown what the effect is of small changes in the model parameters on the output of the model. This sensitivity analysis should be in e.g. the definition of the landmarks in the 3D surface scan, since these landmarks directly influence the scaling of the model. During the experiments the authors experienced the sensitivity of the converging of the model to the iteration parameters in the optimisation routine ${ }^{3}$. More specific when the model did not converge with an optimisation parameter, changing this parameter might result in converging of the model and therefore a solution of the model. However, what the effect is of changing the size of the iteration parameters on the calculated kinematics has not been quantified.

\section{Not modelling the swing phase}

The GM-model only models stance phase of gait. Yet, human gait exists of the contact phase and the swing phase. During stance phase the foot is on the ground, a force is applied on the foot, followed by a ground reaction force. No external forces are applied on the foot during swing phase, it is hypothesised that for that reason no injuries are associated with swing phase. However, when the model is used as an input for an inverse dynamic musculoskeletal model, the swing phase is possibly of more interest. Tibialis anterior muscle for example is activated during swing phase for positioning of the foot ${ }^{21}$. This muscle is attached to multiple bones in the forefoot. Since the GM-model does model the individual movement of these bones, problems with this muscle during swing phase 


\section{General Discussion}

can be investigated when the swing phase will also be modelled, this enables possible clinical solutions.

\section{Rhythms result in standardization}

In the GM-model several degrees of freedom are coupled by rhythms. This might lead to standardisation of the kinematics. This can be showed in the extreme case of measuring foot kinematics with the GM-model on a patient with a DIP arthrodesis:

The rhythm 'Inter phalangeal plantar flexion' (see appendix of Chapter 3) couples the kinematics of the PIP and DIP joint in one phalange. This rhythm has shown to be correct for healthy subjects. However, if a DIP arthrodesis has been performed at a patient this rhythm is not correct anymore since motion in the PIP joint is possible where no RoM in the DIP joint is possible. At this moment it is unknown if the model is able to compute a solution, by dividing the motion in the PIP joint in PIP and DIP kinematics or the model is unable to compute a solution. Both scenarios are not correct, the effect of the rhythms should therefore further be studied.

\section{Applications of the model}

The key driver to develop the GM-model was the creation of input parameters for the forward dynamic model of Ruimerman et al. ${ }^{22}$. This application of the GM-model will be discussed in the last part of this general discussion. The GM-model by itself can also have direct applications. These applications are improving measurement of foot kinematics and performing clinical research with intervention studies.

\section{Added value of the model in modelling foot kinematics}

Other kinematic foot models all use the rigid body assumption by which the models fixate joints between bones that have been proven to move in cadaver and bone pin studies. Nester et al. ${ }^{23}$ used a cadaver model to study the effect of errors in foot models caused by the rigid body assumption. They measured motion of 10 bones in the midfoot and forefoot and by applying the rigid body assumption afterwards they investigated the effect of this assumption. Following this method they found maximal errors of $6.9^{\circ}$ in cadaver feet. Which means in some cases the rigid body assumption invalidates the outcomes of the model and is in favour of a model that does not use the rigid body assumption.

The development of the GM-model creates a unique opportunity to define the optimal segmentation of the foot in an in vivo situation. This optimal segmentation exists of defining both, number of segments as well as composition of these segments. The GMmodel exists of 26 segments which number of DoF can be adapted by fixating joints. 
Fixating these joints leads to a reduction in number of segments. By following this method, the GM-model can be used to simulate other (lesser segments) kinematic foot models. By following this method the effect of the rigid body assumption can be studied. Another possibility is to perform a sensitivity analysis or optimisation routine to calculate the optimal architecture of a kinematic foot model. This might lead to the definition of a novel kinematic foot model based on the foot biomechanics rather than measurement limitations.

\section{Using the kinematic model as an input for an inverse dynamic model}

Next to direct application of the model by measuring foot kinematics the model can be used as an input to an inverse dynamic model, to form a musculoskeletal model. This inverse dynamic model has already been implemented by AnyBody Techonology in their software (AnyBody Modelling System), it uses the kinematic GM-model as input for the inverse dynamic modelling. This is the first inverse dynamic model that uses a foot composed of 26 moving segments. Although further independent validation of the inverse dynamic foot model is needed, first results show the effectivity of this model ${ }^{24}$.

\section{Future clinical applications}

Clinical applications of the GM-model can be by direct using the kinematic model or by using the musculoskeletal model, the combination of the kinematic model with the inverse dynamic model. The latter model can give further insight in the use of intrinsic and extrinsic muscles when detailed foot motion is taken into account.

\section{Foot orthoses}

The GM-model has been developed to be used as the start in a chain of models to predict the effect of an FO, see Figure 6.1 for a visual representation of this chain. Coupling of the forward dynamic model with the inverse dynamic model would be last step into closing the chain to predict the effect of an orthotic device. Since this model can solve the major drawbacks of the forward dynamic model. Firstly, the movement of the foot is currently not clinically relevant. Second drawback is that validation of the output is not possible, because the model is based on the lower extremity of a $50^{\text {th }}$ percentile male cadaver 25 . Third drawback is that the anatomy of the model is the anatomy of a healthy subject, instead of that of a pathological foot. 


\section{General Discussion}

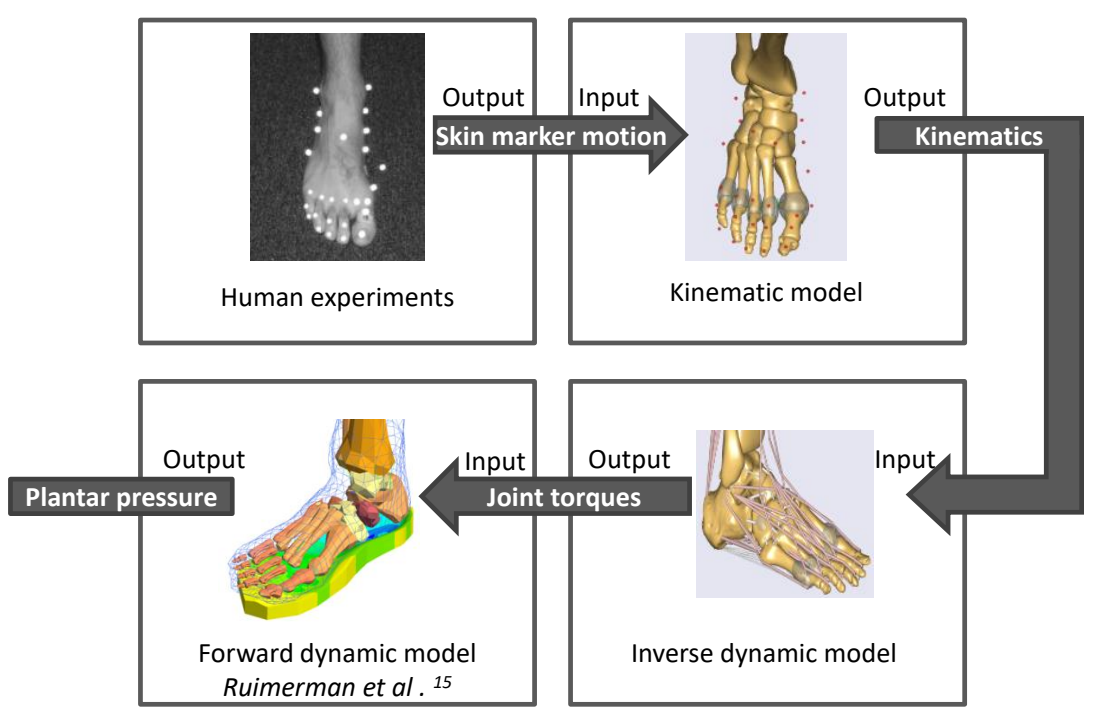

Figure 6.1 Chain of models to come from a patient specific measurement to the prediction of the effect of an orthotic device on (e.g.) plantar pressure distribution (duplicate of Figure 1.3 in the general introduction)

Several problems should be overcome before the coupling of the forward dynamic model in the MADYMO software with the inverse dynamic model in the AnyBody technology software can be implemented. The practical issue of different programming languages has been overcome by development of an algorithm to translate the AnyBody model into a MADYMO model. This algorithm also translates the output files of AnyBody into input files of MADYMO. However, major issue to solve is the lack of mechanical damping in the AnyBody model. The MADYMO model requires mechanical damping to develop a computational stable model, while this mechanical damping cannot be modelled in the inverse dynamic model. A solution for this issue can be in the introduction of a mechanical damper in the AnyBody software or by introduction of an extra computational control loop.

\section{Clinical evaluation of foot kinematics after surgery}

In the foot and ankle painful joints, caused by e.g. osteoarthritis, are often treated by an arthrodesis ${ }^{26}$, the fixation of a joint. However, the effect of this arthrodesis on kinematics of other joints in the foot, caused by compensation, is often unsure. For example patients suffering on osteoarthritis on MTP 1 receive an arthrodesis on this joint. However no consensus in literature can be found in which angle the joint should be fixed ${ }^{27-29}$. In 
addition it is not yet clear in which joints compensations takes place. This is particularly important to predict the effect of an arthrodesis on the remaining mobile joints in the foot.

Next to arthrodesis, joints can be replaced with prosthesis. This is applicable for the MTPI

30 joint or for example the ankle joint ${ }^{31}$. No overall preference can be given for a arthrodesis or a prosthesis. The GM-model may help to decide which operative option is best applicable for each individual patient.

Furthermore different changes in gait pattern have been shown ${ }^{32-34}$, caused by mechanical compensation. Brodsky et al. ${ }^{33}$ for example did not find a difference in preand post-operative ankle kinematics after MTP 1 arthrodesis, using the 'Helen Hayes foot model' ${ }^{35}$. This model models the foot as one rigid segment. Use of the GM-model on this patient group might provide further insight. Since all joints of the MTP1 joint are separately modelled and the alteration in intrinsic foot kinematics can be studied.

Future treatment in osteoarthritis is more directed towards chondral replacement, or chondral cellular treatment ${ }^{36}$. Weight baring profiles and kinematics changing pressure patterns have shown their effect in osteoarthritis in hip ${ }^{37}$ and knee ${ }^{38}$. This may add to better regeneration of chondral deficits or the prediction for which patient sub group chondral replacement will not be successful.

\section{Conclusions}

This thesis described the development of the GM-model, a 26 segments kinematic foot model. This model has been partially validated by comparison with literature, test-retest repeatability and calculating the effect of soft tissue artefacts. RoM of the joints of the GM-model was similar when comparing it with the output of bone-pin studies, cadaver experiments and existing multi-segment foot models. Test-retest repeatability was tested with the ICC, overall ICC was 0.67 ( $95 \% \mathrm{Cl}-0.51$ to 0.95 ). Relative motion caused by soft tissue motion of the markers of the Glasgow-Maastricht foot model ranged from $1.9-6.7$ $\mathrm{mm}$,

The GM-model can be used by itself as a research tool to gather further insight in foot and ankle biomechanics and to investigate the effect on kinematics of clinical interventions. Furthermore the model can be used as an input in the chain of models to predict the effect of FO's. This latter step needs further development of this chain of models. 


\section{General Discussion}

\section{References}

1. Bishop C, Paul G, Thewlis D. Recommendations for the reporting of foot and ankle models. Journal of biomechanics. 2012;45:2185-2194.

2. Della Croce U, Leardini A, Chiari L, Cappozzo A. Human movement analysis using stereophotogrammetry. Gait \& Posture. 2005;21:226-237.

3. Andersen MS. Kinematically Over-determinate Musculoskeletal Systems: Aalborg University. Department of Mechanical Engineering; 2009.

4. Nester CJ, Liu AM, Ward E, Howard D, Cocheba J, Derrick T, Patterson P. In vitro study of foot kinematics using a dynamic walking cadaver model. Journal of Biomechanics. 2007;40:19271937.

5. Lundgren P, Nester C, Liu A, Arndt A, Jones R, Stacoff A, Wolf P, Lundberg A. Invasive in vivo measurement of rear-, mid- and forefoot motion during walking. Gait \& Posture. 2008;28:93-100.

6. Cappozzo A, Catani F, Leardini A, Benedetti MG, Della Croce U. Position and orientation in space of bones during movement: experimental artefacts. Clinical Biomechanics. 1996;11:90-100.

7. Deschamps K, Staes F, Roosen P, Nobels F, Desloovere K, Bruyninckx H, Matricali GA. Body of evidence supporting the clinical use of 3D multisegment foot models: a systematic review. Gait \& posture. 2011;33:338-349.

8. Rankine L, Long JT, Canseco K, Harris GF. Multisegmental Foot Modeling: A Review. 2008;36:127-181.

9. MacWilliams BA, Cowley M, Nicholson DE. Foot kinematics and kinetics during adolescent gait. Gait \& Posture. 2003;17:214-224.

10. Chen S-J, Mukul M, Chou L-S. Soft-Tissue Movement at the Foot During the Stance Phase of Walking. Journal of the American Podiatric Medical Association. 2011;101:25-34.

11. Tranberg $R$, Karlsson D. The relative skin movement of the foot: a 2-D roentgen photogrammetry study. Clinical Biomechanics. 1998;13:71-76.

12. Maslen BA, Ackland TR. Radiographic study of skin displacement errors in the foot and ankle during standing. Clinical Biomechanics. 1994;9:291-296.

13. Shultz R, Kedgley AE, Jenkyn TR. Quantifying skin motion artifact error of the hindfoot and forefoot marker clusters with the optical tracking of a multi-segment foot model using single-plane fluoroscopy. Gait \& Posture. 2011;34:44-48.

14. Peters A, Galna B, Sangeux M, Morris M, Baker R. Quantification of soft tissue artifact in lower limb human motion analysis: A systematic review. Gait \& Posture. 2010;31:1-8.

15. Bresler B, Frankel J. The forces and moments in the leg during level walking. Trans. Asme. 1950;72:25-35.

16. Mahaffey R, Morrison S, Drechsler W, Cramp M. Evaluation of multi-segmental kinematic modelling in the paediatric foot using three concurrent foot models. Journal of Foot and Ankle Research. 2013;6:43.

17. Gorton GE, Hebert DA, Gannotti ME. Assessment of the kinematic variability among 12 motion analysis laboratories. Gait \& posture. 2009;29:398-402.

18. France L, Nester C. Effect of errors in the identification of anatomical landmarks on the accuracy of $Q$ angle values. Clinical Biomechanics. 2001;16:710-713. 
19. Deschamps K, Staes F, Roosen P, Nobels F, Desloovere K, Bruyninckx H, Matricali GA. Body of evidence supporting the clinical use of 3D multisegment foot models: a systematic review. Gait \& posture. 2011;33:338-349.

20. Deschamps K, Staes F, Bruyninckx H, Busschots E, Jaspers E, Atre A, Desloovere K. Repeatability in the assessment of multi-segment foot kinematics. Gait \& Posture. 2012;35:255-260.

21. Winter DA, Yack HJ. EMG profiles during normal human walking: stride-to-stride and intersubject variability. Electroencephalography and Clinical Neurophysiology. 1987;67:402-411.

22. Ruimerman R, Oosterwaal M, Guldemond NA. Optimalisatie van inlegzoolontwerp door gebruik van computer simulaties. NOV2009. Rosmalen, the Netherlands 2009.

23. Nester CJ, Liu AM, Ward E, Howard D, Cocheba J, Derrick T. Error in the description of foot kinematics due to violation of rigid body assumptions. Journal of Biomechanics. 2010;43:666-672.

24. Al-Munajjed AA, Bischoff JE, Dharia MA, Telfer S, Woodburn J, Carbes S. Metatarsal Loading During Gait-A Musculoskeletal Analysis. Journal of Biomechanical Engineering. 2016;138:034503-034503.

25. Robin S. HUMOS: human model for safety-a joint effort towards the development of refined human-like car occupant models. 17th international technical conference on the enhanced safety vehicle 2001:297.

26. Nihal A, Gellman RE, Embil JM, Trepman E. Ankle arthrodesis. Foot and Ankle Surgery. 2008;14:1-10.

27. Shereff MJ, Baumhauer JF. Current concepts review: hallux rigidus and osteoarthrosis of the first metatarsophalangeal joint. J Bone Joint Surg Am. 1998;80:898-908.

28. Bayomy AF, Aubin PM, Sangeorzan BJ, Ledoux WR. Arthrodesis of the First Metatarsophalangeal Joint: A Robotic Cadaver Study of the Dorsiflexion Angle. The Journal of Bone \& Joint Surgery. 2010;92:1754-1764.

29. van Doeselaar DJ, Heesterbeek PJ, Louwerens JWK, Swierstra BA. Foot function after fusion of the first metatarsophalangeal joint. Foot \& ankle international. 2010;31:670-675.

30. Fuhrmann RA, Wagner A, Anders JO. First metatarsophalangeal joint replacement: the method of choice for end-stage hallux rigidus? Foot and ankle clinics. 2003;8:711-721.

31. Haddad S, Coetzee J, Estok R, Fahrbach K, Banel D, Nalysnyk L. Intermediate and long-term outcomes of total ankle arthroplasty and ankle arthrodesis. J Bone Joint Surg Am. 2007;89:1899-1905.

32. Dayton $P$, Kauwe M, Kauwe JS, Feilmeier M, Hirschi J. Observed changes in first metatarsal and medial cuneiform positions after first metatarsophalangeal joint arthrodesis. The Journal of Foot and Ankle Surgery. 2014;53:32-35.

33. Brodsky JW, Baum BS, Pollo FE, Mehta H. Prospective gait analysis in patients with first metatarsophalangeal joint arthrodesis for hallux rigidus. Foot \& ankle international. 2007;28:162-165.

34. Galois L, Girard D, Martinet N, Delagoutte J, Mainard D. [Optoelectronic gait analysis after metatarsophalangeal arthrodesis of the hallux: fifteen cases]. Revue de chirurgie orthopedique et reparatrice de l'appareil moteur. 2006;92:52-59.

35. Davis III RB, Ounpuu S, Tyburski D, Gage JR. A gait analysis data collection and reduction technique. Human Movement Science. 1991;10:575-587. 


\section{General Discussion}

36. Wiewiorski M, Barg A, Valderrabano V. Chondral and osteochondral reconstruction of local ankle degeneration. Foot and ankle clinics. 2013;18:543-554.

37. Wesseling M, de Groote F, Meyer C, Corten K, Simon J-P, Desloovere K, Jonkers I. Gait alterations to effectively reduce hip contact forces. Journal of Orthopaedic Research. 2015;33:1094-1102.

38. Fregly BJ, Reinbolt JA, Rooney KL, Mitchell KH, Chmielewski TL. Design of patient-specific gait modifications for knee osteoarthritis rehabilitation. IEEE Transactions on Biomedical Engineering. 2007;54:1687-1695. 
Valorisation

VALORISATION 


\section{Valorisation}

This thesis describes the development, repeatability and sources of error of the GlasgowMaastricht foot model (GM-model). This model is the first kinematic foot model that simulates the motion of all 26 bones in the human foot. The simulation of all joints in the foot can be used to evaluate clinical treatment methods in the foot and ankle. Furthermore the GM-model has already been implemented in an inverse musculoskeletal foot model in the AnyBody Technology package. Finally by using this inverse dynamic model as an input for a forward dynamic foot model, the latter model can be used to predict the effect a foot orthosis, as was the goal of the European FP7 project A-Footprint. The A-footprint consortium existed of six SME partners (Baltic Orthoservice UAB Lithuania, Peacocks Medical Group Ltd - UK, Firefly Orthoses Limited - Ireland, RSscan INTERNATIONAL - Belgium, AnyBody Technology A/S - Denmark, Junquera y Diz S.L Spain), five academic partners (Glasgow Caledonian University - UK, University of Newcastle upon Tyne - UK, Thomas More Kempen VZW - Belgium, Academisch Ziekenhuis Maastricht - the Netherlands, Stichting Fontys - the Netherlands) and one industrial partner (Materialise NV - Belgium).

\section{The GM model to evaluate clinical treatment methods in the foot and ankle}

The use of solely the kinematic model might improve the knowledge of foot and ankle biomechanics. Prior to the introduction of the GM-model (Chapter 3), the kinematic model with the highest detail of the foot had eight segments in the foot ${ }^{1}$. The simulation of motion between all joints enables a deeper understanding of how the various structures of the foot contribute to foot function. In the future this might lead to insight in general motion patterns of the foot and pathology specific alterations of these patters. Better understanding of these patterns is of interest for brace developers and shoe manufacturers. For example ankle braces are designed to guide ankle motion, however these restriction in ankle motion might result in compensation of this motion in the mid foot as has been shown for taping of the ankle ${ }^{2}$.

This model creates the opportunity to study the motion in all joints in the foot (Chapter 5). For example, patients suffering on osteoarthritis on MTP 1 receive an arthrodesis on this joint. However, no consensus in literature can be found in which angle the joint should be fixed ${ }^{3-5}$. In addition recently first study showed compensation in hindfoot and forefoot kinematics for patients with a MTP 1 arthrodesis ${ }^{6}$. However, it is not yet clear what the effect of this fixation angle is on the compensation in other joints in the foot. Compensation of motion in other joints might lead to overload of these joints and therefore other complaints as is the case for patients with an ankle arthrodesis ${ }^{7}$. 


\section{Valorisation}

Prevention of these complaints by choosing the fixation angle with the lowest compensation in other joints is of great value for patients and society.

\section{The GM-model in the musculoskeletal model of the foot and ankle in AnyBody}

In the AnyBody Modelling System (AMS) the GM-model has been combined with an inverse dynamic model into a musculoskeletal model (see figure 7.1). The AMS is used by various companies in the sports (e.g. calculating optimal saddle height for bicycles), automotive (e.g. ergonomic design of the car interior) and orthopaedic sector (e.g. giving input for implant design). The embedding of GM-model in AMS has increased the modelled number of segments in the foot up to 26 . This increase in number of segments leads to the possibility to calculate the forces in the intrinsic foot muscles needed to perform a dynamic action.

By the implementation of the GM-model in AMS it is easy accessible for a large group of researchers and clinicians. It is thereby not necessary for each separate user of the model to translate the GM-model into their own algorithms. Furthermore, by increasing the accessibility of the model next steps required before clinical use of the model can be accelerated. For example further validation of the model can be simultaneously performed by multiple research groups.

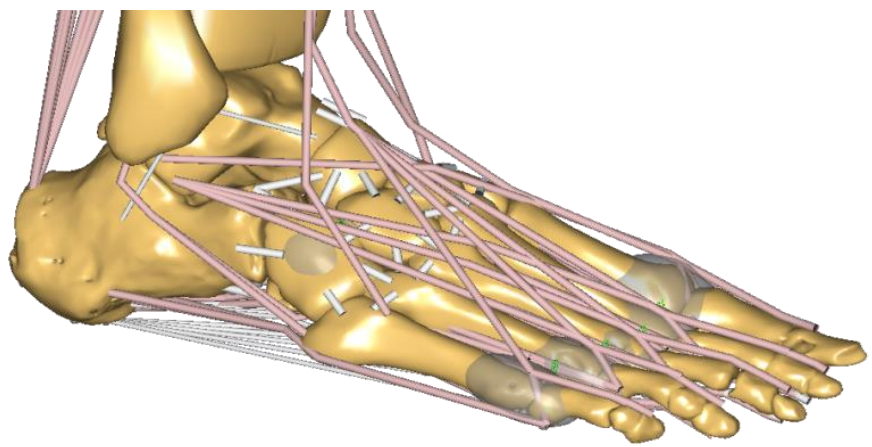

Figure 7.1 The GM-model as kinematic input of the musculoskeletal model of the foot and ankle in the AnyBody Modelling system

The musculoskeletal model recently has been used in scientific research. Al-Munajjed et al. ${ }^{8}$ used the musculoskeletal model to investigate the metatarsal loading during gait. They showed a loading on the tarsometatarsal joints of 0.75-1.5 times body weight during the early part of stance, indicating some pre-tension from the ligaments and muscles. This is of clinical interest since dorsal displacement of the metatarsal head is a common complication after MT 1 osteotomies ${ }^{9}$. Before the introduction of this model, these forces 


\section{Valorisation}

could not be measured without a highly invasive operation. The integration of the GMmodel to the AMS therefore leads to further insight in intrinsic foot muscle forces and the accessibility to the model for a large group of users.

\section{The GM-model in the production chain for rapid manufacturing of foot orthoses}

Up to 196 million Europeans suffer disabling foot and ankle pain and the prevalence is set to rise in an ageing society with increasing chronic long term conditions. A conservative treatment to reduce foot and ankle pain is the use of foot orthoses (FO's). Currently $70 \%$ of the FO's produced yearly are made using traditional techniques relying on impressions casts, templates and hand fabrication. Personalised devices provide more effective outcome in terms of symptom reduction, fit, comfort and aesthetics but are more costly and time consuming to manufacture ${ }^{10,11}$.

The study presented in this thesis has been performed in the A-footprint project (http://www.afootprint.eu/), a European project funded under the FP7 program. Afootprint has the objective to develop novel ankle/foot and foot orthoses for common disabling conditions which are cost effective, high-speed to market, and personalised for form and function. With the use of novel scanning methods and models, a foot orthosis is designed and with rapid manufacturing the orthosis is 3D printed (see Figure 7.2)

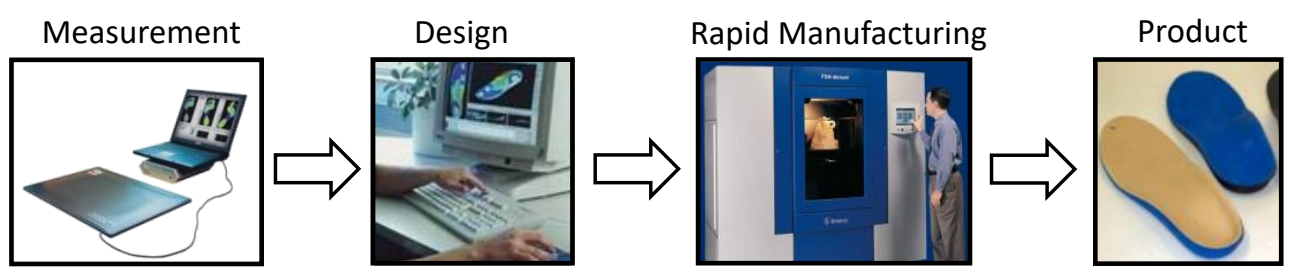

Figure 7.2 Visual representation of the novel production chain, as investigated in the Afootprint project. From dynamic measurements, via automatic design, the foot orthosis is rapid manufactured

The novel production chain starts with a dynamic plantar pressure measurement and a 3D surface scan of the foot and ankle. These measurements are used to scale (the 3D scan) the inverse dynamic musculoskeletal GM-model and dynamically drives this model with the dynamic plantar pressure scan. The inverse dynamic model can be used as an input in a forward dynamic model ${ }^{12}$, as described in Chapter 1 . The forward dynamic model is able to automatically design the shape and best material of a foot orthosis. Last step in this production chain is the rapid manufacturing of the designed FO. 


\section{Valorisation}

This production method creates the ability to create personalised FO's that are designed and produced by a controlled and standardised method. And therefore, in the future the novel method will produce FO's cheaper, more precise. Furthermore, The FO's can be reproduced exactly or first adapted on a computer and then reproduced.

\section{Conclusions}

The work described in this thesis has already shown its added value by the embedding in the AnyBody Modelling System. Added value of the direct application of the GM-model, requires further research towards validation of the GM-model as described in Chapter 6. In addition, before the GM-model will be used in the production chain of rapid manufactured FO's further development of the coupling of the inverse dynamic model and the forward dynamic model is required. 


\section{Valorisation}

\section{References}

1. MacWilliams BA, Cowley M, Nicholson DE. Foot kinematics and kinetics during adolescent gait. Gait \& Posture. 2003;17:214-224.

2. Deschamps K, Dingenen B, Pans F, Van Bavel I, Matricali GA, Staes F. Effect of taping on foot kinematics in persons with chronic ankle instability. Journal of Science and Medicine in Sport. 2016;19:541-546.

3. Shereff MJ, Baumhauer JF. Current concepts review: hallux rigidus and osteoarthrosis of the first metatarsophalangeal joint. J Bone Joint Surg Am. 1998;80:898-908.

4. Bayomy AF, Aubin PM, Sangeorzan BJ, Ledoux WR. Arthrodesis of the First Metatarsophalangeal Joint: A Robotic Cadaver Study of the Dorsiflexion Angle. The Journal of Bone \& Joint Surgery. 2010;92:1754-1764.

5. van Doeselaar DJ, Heesterbeek PJ, Louwerens JWK, Swierstra BA. Foot function after fusion of the first metatarsophalangeal joint. Foot \& ankle international. 2010;31:670-675.

6. Stevens J, Meijer K, Bijnens W, Fuchs T, Rhijn Lv, Hermus J, Hoeve Sv, Poeze M, Witlox A. Where does the foot compensate? Foot \& Ankle International in press.

7. Coester LM, Saltzman CL, Leupold J, Pontarelli W. Long-term results following ankle arthrodesis for post-traumatic arthritis. The Journal of Bone \& Joint Surgery. 2001;83:219219.

8. Al-Munajjed AA, Bischoff JE, Dharia MA, Telfer S, Woodburn J, Carbes S. Metatarsal Loading During Gait-A Musculoskeletal Analysis. Journal of Biomechanical Engineering. 2016;138:034503-034503.

9. Lehman DE. Salvage of complications of hallux valgus surgery. Foot and Ankle Clinics.8:15-35.

10. Powell M, Seid M, Szer IS. Efficacy of custom foot orthotics in improving pain and functional status in children with juvenile idiopathic arthritis: a randomized trial. The Journal of rheumatology. 2005;32:943-950.

11. Wrobel JS, Fleischer AE, Crews RT, Jarrett B, Najafi B. A Randomized Controlled Trial of Custom Foot Orthoses for the Treatment of Plantar Heel Pain. Journal of the American Podiatric Medical Association. 2015;105:281-294.

12. Ruimerman R, Oosterwaal M, Guldemond NA. Optimalisatie van inlegzoolontwerp door gebruik van computer simulaties. NOV2009. Rosmalen, the Netherlands 2009. 


\section{SUMMARY}




\section{Summary}

A quarter of the middle and old aged population suffers of foot and ankle pain on a daily basis. A conservative treatment to reduce foot and ankle pain is the use of foot orthoses (FO's). Finding the correct material and shape of FO's for a specific patient is not trivial. Lack of understanding the biomechanics behind FO's is impeding the standardisation in the prescription and design of FO's.

Computational models can be used to improve the knowledge of orthotic therapy. In previous decade models have been used to study the effect of FO's on altered gait with kinematic models. Finite element models have for example been used to predict the plantar pressure relieving effect of an FO on the foot in a static or 2D situation.

Preliminary steps using a forward dynamic model of the foot and ankle have shown that in principle it is possible to calculate an FO for a specific objective (e.g. pressure relief). However, this proof of concept approach did not simulate normal gait and focussed on an average healthy foot. Clinical use of this model is therefore not possible yet. Before the model could be effectively used to benefit daily clinical practice the model should be able to simulate the dynamics of gait. In addition, a patient specific configuration is required to account for subject specific differences in foot form and mobility. This can both be solved by using the predicted muscle forces from a subject specific, scalable, inverse dynamic model as an input in the forward dynamic model. The inverse dynamic model on its turn requires kinematics as an input. This can be measured with multi-segment kinematic foot models.

To date over 15 multi-segment foot models have been developed. The difference between these models is the location of the markers on the foot and in what way the foot is divided in the different segments. An important source of error of kinematic foot models is the effect of the assumptions made to calculate joint kinematics from the motion of markers on the skin, i.e. soft tissue artefacts (STA) and the rigid body assumption. STA are the artefacts arising from the relative movement of the skin with respect to the bones. The rigid body assumption is the assumption that two separate bones can be modelled as one single rigid segment. In addition to the aforementioned model errors, other imperfections can occur when performing repeated measurements.

This thesis describes the development of the Glasgow-Maastricht foot model (GM-model), a kinematic foot model that decreases the number of degrees of freedom using kinematic rhythms instead of using the rigid body assumption. This novel kinematic foot model simulates the motion of all 26 segments on a highly detailed level. This thesis starts with the description of the measurements (Chapter 2) required as an input to develop the model (Chapter 3). Validation of the model has been performed by comparison the output with existing literature (Chapter $\mathbf{3}$ ), testing the intra subject repeatability (Chapter 4 ) and 
the measuring the effect of STA (Chapter 5). This thesis ends with a general discussion of the GM-model (Chapter 6) on its strengths, weaknesses and future application.

Chapter $\mathbf{2}$ of this thesis describes the measurements performed to generate input for the development of the GM-model. To develop the model a subject specific dataset needed to be generated. The dataset was collected in two centres (Glasgow and Maastricht); participants were 10 healthy subjects and 15 patients requiring orthotic devices. Three groups of patients with ankle and foot problems were included: seven metatarsalgia, seven flexible flat foot and a stroke patient.

The protocol existed of four sections. 1) A clinical foot function assessment by a clinician, followed by two questionnaires to measure foot-related impairments. 2) A 3D surface scan to digitally measure foot shape in different loading positions. 3) Extended gait analysis was undertaken, including kinematics, kinetic, EMG and plantar pressure measurements. This analysis was for barefoot and shod trials. 4) The foot and ankle complex was imaged by CT and a subgroup was imaged by MRI. Four CT scans were undertaken in various loading positions, while the plantar pressure was measured by an instrumented insole.

Image data was segmented to derive the size of bones and orientation of the joint axis. Insertion and origins of muscles and ligaments were determined for extra input on biomechanical properties of the model. The measurements of Chapter 2 led to a unique dataset, which was used in Chapter 3 to develop the GM-model.

Chapter $\mathbf{3}$ is a description of the GM-model and an evaluation of the model by comparing the results of the GM-model with existing literature. Segmented CT data from one healthy subject was used to create a template GM-model. Following this, the template was scaled to produce subject-specific models for five additional healthy participants using a surface scan of the foot and ankle. Forty-three skin mounted markers, mainly positioned around the foot and ankle, were used to capture the stance phase of the right foot of the six healthy participants during walking. The GM-model was then applied to calculate the intrinsic foot kinematics.

Distinct motion patterns were found for all joints. The variability in outcome depended on the location of the joint, with reasonable results for sagittal plane motions and poor results for transverse plane motions.

The results of the GM-model were comparable with existing literature, including bone pin studies, with respect to the range of motion, motion pattern and timing of the motion in the studied joints. This novel model is the most complete kinematic foot model to date. 


\section{Summary}

Before using the model in a clinical setting, further validation is necessary, which is partly performed in Chapter 4 and Chapter 5.

The intra subject repeatability of the model was measured in Chapter 4. Gait analysis of the right foot of eight healthy participants was performed during two sessions with approximately four days ( $4.4 \pm 2.6$ days) in between. Kinematics were calculated using the GM-model. Subsequently, the range of motion of each degree of freedom was calculated. By comparing the two sessions the overall intraclass coefficient $(3, \mathrm{k})$ (ICC) of the model was calculated. Mean ICC and standard errors for the maximum and minimum joint angle and the range of motion for all degrees of freedom were calculated.

The ICC of the GM-model is 0.67 ( $95 \% \mathrm{Cl}-0.51$ to 0.95 ). ICC of the range of motion showed good to excellent agreement for most (57\%) of the degrees of freedom. Three degrees of freedom showed an unacceptable standard error of the measurement (SEM) for range of motion $\left(>5^{\circ}\right)$. The minimum angle showed unacceptable SEM for four degrees of freedom and for the maximum angle this was the case for eight degrees of freedom.

It was shown that the test-retest repeatability of the GM-model was moderate to good.

Chapter 5 investigated the effect of STA and described the relative motion caused by soft tissue motion of skin mounted markers of the GM-model, since increased complexity leads to greater risk of introducing STA errors. This chapter used a method to quantify the effect of soft tissue motion on marker positions based on imaging data, in order to gain better insight in the potential kinematic errors of the Glasgow-Maastricht foot model. In particular, a method is used to quantify soft tissue motion that is non-surgical, three dimensional and independent of the rigid body assumption. The approach was based on computed tomography measurements of the foot and ankle in a variety of poses and loading states and calculated the motion of a skin mounted radio opaque marker, with respect to its related bone.

The effect of soft tissue motion on marker positions of the GM- model ranged from 1.9 $6.7 \mathrm{~mm}$. Meaning that markers can move up to $6.7 \mathrm{~mm}$ with respect to the bone. Although a high accuracy of calculation was achieved, no specific cause for relative marker motion could be significantly defined. Application of the method on the hindfoot and midfoot showed a low correlation between the size of the bones, the soft tissue thickness and the marker motion.

This chapter quantified the effect of soft tissue motion on marker positions of the GMmodel, using a novel method based on four static CT-scans in varying loading positions. 
The last chapter of this thesis, Chapter 6, discussed the novel kinematic foot model, by describing its strengths, weaknesses, recommendations for future research and possible clinical applications

The GM-model is the first kinematic model that simulates motion between all 26 bones in the foot. By 3D surface scanning, the GM-model is scalable in all directions. Furthermore the GM-model is partly validated, by comparable output as existing literature, overall moderate to good test-retest repeatability and motion of the markers of $1.9 \mathrm{~mm}-6.7 \mathrm{~mm}$ caused by skin motion of the model.

Future development of the GM-model should focus on further validation. Firstly the effect of STA on kinematics of the GM-model should be studied in a dynamic situation. Furthermore intra and inter observer variability should be further studied. Intra observer repeatability was studied in Chapter 4 , however a large confidence interval was found. Inter observer and intra centre variability has not been studied yet. In addition, the sensitivity of the GM-model to small changes in e.g. marker positions has not been studied. First step in further development of the GM-model is the modelling of the swing phase; currently the GM-model only models the stance phase.

The GM-model can be used as a tool in the field foot kinematics. Modelling of 26 segments of the foot creates a unique opportunity to define the optimal segmentation of the foot in an in vivo situation. Furthermore, the GM-model has already been implemented in the AnyBody Modelling System as input for the inverse dynamic modelling. Future clinical application of the GM-model in combination with this inverse dynamic model can be in the prescription of foot orthoses, as has been suggested previously. Direct clinical application of the model might be the measurement of the effect of fixation of a foot joint on other foot joints.

In conclusion, this thesis described the development of the GM-model, a 26 segments kinematic foot model. This model has been partially validated by comparison with literature, test-retest repeatability and calculating the effect of soft tissue artefacts. The GM-model can be used by itself as a research tool to gather further insight in foot and ankle biomechanics and to investigate the effect on kinematics of clinical interventions. Furthermore the model can be used as an input in the chain of models to predict the effect of FO's. This latter step needs further development of this chain of models. 

Samenvatting

\section{SAMENVATTING}




\section{Samenvatting}

Een kwart van de mensen ouder dan 40 jaar heeft dagelijks last van pijn aan de voet of enkel. Een mogelijke conservatieve behandelmethode voor het verlagen van de pijn is het gebruik van steunzolen. Het kiezen van het juiste materiaal en het ontwerpen van de juiste vorm van de steunzool voor een patiënt is echter lastig. De complexiteit van de biomechanica achter het effect van de steunzool verhindert standaardisering in het voorschrijven en ontwerp van steunzolen.

Computermodellen kunnen gebruikt worden om meer te begrijpen van steunzooltherapie. Afgelopen decennia zijn er kinematische modellen gebruikt om het effect van steunzolen op de veranderde gang van patiënten te bestuderen. Ook zijn eindige elementen gebruikt om bijvoorbeeld de hoeveelheid plantaire drukverlaging door steunzoolgebruik te voorspellen. Dit is echter alleen mogelijk gebleken in 2D of statische modellen.

Eerste stappen naar het gebruik van een ander type model van de voet en enkel, een voorwaarts dynamisch model, hebben laten zien dat het in principe mogelijk is om automatisch een steunzool te berekenen met een specifiek doel (bijvoorbeeld plantaire drukverlaging). Deze methode simuleerde echter geen normale stap en maakte gebruik van een model van een gemiddelde gezonde voet. Klinisch gebruik van dit model is daardoor nog niet mogelijk. Hiervoor moet het model eerst een normale stap kunnen simuleren voor een specifieke patiënt, waarbij het rekening houdt met de specifieke eigenschappen van de voet van deze patiënt. Deze beide problemen kunnen worden opgelost door gebruik te maken van de berekeningen van een ander type model, een patiënt specifiek invers dynamisch model van de voet en enkel. Dit invers dynamisch model berekent de spierkracht die nodig is om de voet te laten bewegen. Deze beweging is de input van het model. Deze beweging of kinematica kan gemeten worden met behulp van een multi-segmenten kinematisch voetmodel.

Tot op heden zijn er 15 verschillende kinematische voetmodellen ontwikkeld. Zij verschillen in locatie van de markers op de voet en in de manier hoe zij de voet opdelen in meerdere segmenten. Een belangrijke bron van fouten van deze modellen ontstaat door de aannames die gedaan worden om de beweging van markers op de huid te vertalen naar gewrichtsuitslagen. Deze fouten kunnen worden gesplitst in de fouten die ontstaan door de beweging van de huid ten opzichte van de botten (STA) en de aanname dat sommige botten in de voet en enkel niet bewegen ten opzichte van elkaar en daarom als één segment kunnen worden gemodelleerd. Andere fouten in de metingen kunnen ontstaan doordat de meting gevoelig is voor kleine verschillen tussen herhalingen van de meting.

Dit proefschrift beschrijft de ontwikkeling van het Glasgow-Maastricht voet model (GMmodel), dit is een kinematisch voetmodel dat gebruik maakt van kinematische ritmes om de beweging van meerdere botten samen te voegen, in plaats van de aanname dat de 


\section{Samenvatting}

botten één segment zijn. Dit nieuwe model simuleert daardoor beweging in alle 26 botten van de voet. Dit proefschrift begint met een beschrijving van de metingen (hoofdstuk 2) die nodig waren om het GM-model te ontwikkelen (hoofdstuk 3). Het model is gevalideerd door de uitkomsten van het model te valideren met de literatuur (hoofdstuk 3), het testen van de intra proefpersoon herhaalbaarheid (hoofdstuk 4) en het meten van het effect van huidverschuiving (hoofdstuk 5). Het proefschrift wordt afgesloten met een algemene discussie (hoofdstuk 6) over de sterktes, zwaktes en mogelijke toepassingen van het GM-model.

Hoofdstuk 2 van dit proefschrift beschrijft de metingen die zijn uitgevoerd om het GMmodel te ontwikkelen. Hiervoor was een patiënt specifieke dataset nodig. Deze dataset is verzameld in twee centra (Glasgow en Maastricht). Deelnemers waren 10 gezonde personen en 15 patiënten die steunzolen of een enkel voet orthese nodig hadden. De patiënten bestonden uit drie groepen: zeven patiënten met metatarsalgie, zeven met een flexibele platvoet en één CVA patiënt.

Het gebruikte meetprotocol bestond uit vier gedeelten. 1) Een klinische voet functie anamnese door een arts, gevolgd door twee vragenlijsten over pijn aan de voet. 2) Een 3D oppervlakte scan waarmee de vorm van de voet werd gemeten onder verschillende belastingen. 3) Een uitgebreide gangbeeldanalyse die bestond uit het meten van kinematica, kinetica, EMG en plantaire druk metingen. Deze analyse werd zowel blootvoets als geschoeid uitgevoerd. 4) Vier CT scans van de voet en enkel onder verschillende belastingen, terwijl de plantaire druk werd gemeten met behulp van een meetzool. Van een gedeelte van de proefpersonen is een MRI van de voet en enkel gemaakt.

De data van CT en MRI werd gesegmenteerd om het formaat van de botten en de positie van de gewrichten te bepalen. Start en einde van spieren en ligamenten werd bepaald om meer informatie te krijgen over de biomechanische eigenschappen van de gemeten voet. De metingen uit hoofdstuk 2 hebben een unieke dataset opgeleverd, welke gebruikt is in hoofdstuk 3 om het GM-model te ontwikkelen.

Hoofdstuk 3 beschrijft het GM-model en evalueert het model door de resultaten van het model te vergelijken met bestaande literatuur. Gesegmenteerde CT-data van één gezonde proefpersoon is gebruikt als basis voor het GM-model. Dit basismodel werd geschaald met behulp van de 3D oppervlakte scan om patiënt specifieke modellen te maken voor vijf andere gezonde personen. Met 43 huidmarkers, voornamelijk gepositioneerd op de voet en enkel, werd de standsfase van de rechtervoet van zes gezonde proefpersonen gemeten 


\section{Samenvatting}

tijdens het lopen. Het GM-model werd vervolgens gebruikt om de kinematica van de voet van de proefpersonen te berekenen.

De bewegingsuitslagen van de gewrichten tussen de 26 botten in de voet werden gemeten. De variabiliteit in de resultaten was afhankelijk van de oriëntatie van de gemeten bewegingsuitslag. In het sagitale vlak waren de resultaten beter dan in het transversale vlak.

De resultaten van het GM-model waren vergelijkbaar op de grootte van de bewegingsuitslag en het bewegingspatroon met bestaande literatuur, waaronder studies met botpinnen en experimenten op kadavervoeten. Dit nieuwe model is op dit moment het compleetste kinematische voetmodel. Voordat dit model gebruikt kan worden in de kliniek is echter verdere validatie nodig, Hiermee is een start gemaakt in hoofdstuk 4 en hoofdstuk 5.

De intra proefpersoon herhaalbaarheid van het model is gemeten in hoofdstuk 4. Gangbeeld analyse van de rechtervoet van acht gezonde proefpersonen werd gemeten gedurende twee sessies waartussen vier dagen $(4.4 \pm 2.6$ dagen) zat. Kinematica werd berekend met het GM-model. Vervolgens werd de bewegingsuitslag berekend voor elke vrijheidsgraad van het model. De resultaten van de twee sessies werden vergeleken en gebruikt om de intra klasse coëfficiënt $(3, k)$ (ICC) van het model te berekenen. Gemiddelde ICC en standaardmeetfout (SEM) voor de maximale en minimale hoeken en de totale bewegingsuitslag voor elke vrijheidsgraad werden berekend.

De ICC van het GM-model was 0.67 (95\% $\mathrm{BI}-0.51$ tot 0.95 ). ICC van de bewegingsuitslag liet goede tot excellente herhaalbaarheid voor $57 \%$ van de gewrichten zien. Drie gewrichten hadden een onacceptabele SEM van meer dan vijf graden. De minimale hoeken hadden een onacceptabele SEM voor vier vrijheidsgraden en voor de maximale hoeken was dit het geval voor acht vrijheidsgraden.

Met deze experimenten werd aangetoond dat de test-hertestbetrouwbaarheid van het GM-model gemiddeld tot goed was.

Hoofdstuk 5 onderzocht het effect van STA en beschrijft de relatieve beweging tussen bot en markers van het GM-model. Dit is onderzocht, omdat de complexiteit van het GMmodel gepaard gaat met een groter risico op de introductie van meetfouten door STA. In het hoofdstuk is gebruikgemaakt van een methode om de beweging tussen bot en marker door het zachte weefsel tussen het bot en de marker te kwantificeren met behulp van CT-data. Door deze nieuwe methode was het mogelijk om STA te meten zonder chirurgische ingreep op een drie dimensionale manier en zonder aannames over het 


\section{Samenvatting}

clusteren van meerdere botten in één segment. Door meerdere CT metingen van de voet en enkel uit te voeren was het mogelijk om de beweging van de markers te meten.

De beweging ten gevolge van het zachte weefsel van het GM-model varieerde van 1.9-6.7 $\mathrm{mm}$. Ondanks het feit dat er een hoge nauwkeurigheid bereikt is in de metingen, was het niet mogelijk een specifieke oorzaak te vinden voor de grootte van de beweging van de markers. De grootte van de beweging was niet afhankelijk van het formaat van de botten of de dikte van het zachte weefsel.

Het hoofdstuk heeft het effect van beweging van de markers van het GM-model gekwantificeerd met behulp van een nieuwe methode.

Het laatste hoofdstuk van dit proefschrift, hoofdstuk 6, bediscussieert het nieuwe kinematische model aan de hand van de sterktes, zwaktes, aanbevelingen voor de toekomst en mogelijke klinische applicaties.

Het GM-model is het eerste kinematische model dat de beweging van alle 26 botten in de voet simuleert. Door middel van een 3D oppervlakte scan is het GM-model schaalbaar in alle richtingen. Het GM-model is gedeeltelijk gevarieerd, doordat de resultaten vergelijkbaar zijn met bestaande literatuur, gemiddelde tot goede test-hertest herhaalbaarheid en beweging van de markers van $1.9 \mathrm{~mm}-6.7 \mathrm{~mm}$ ten opzichte van de botten.

Om het model in de kliniek te gebruiken is verdere validatie noodzakelijk. Ten eerste is het noodzakelijk om het effect van de beweging van de markers door STA op de kinematica in een dynamische situatie te onderzoeken. Verdere intra en inter onderzoeker variabiliteit moet worden onderzocht. De intra onderzoeker herhaalbaarheid uit hoofdstuk 4 liet een groot betrouwbaarheidsinterval zien. Verder onderzoek is daarom nodig. De variabiliteit tussen onderzoekers en tussen onderzoekscentra is nog niet onderzocht. Ook is de gevoeligheid van het GM-model voor kleine veranderingen in bijvoorbeeld het positioneren van de markers nog niet onderzocht. Een eerste stap in de uitbreiding van het GM-model is modelleren van de zwaaifase. Op dit moment modelleert het GM-model namelijk alleen de standsfase.

$\mathrm{Na}$ verdere validatie kan het GM-model gebruikt worden in het onderzoeksveld van de voet kinematica. Het modelleren van de beweging van de 26 botten van de voet creëert de mogelijkheid om deze botten op een optimale manier samen te voegen in andere modellen. Een andere toepassing van het model heeft al plaatsgevonden: het GM-model is geïmplementeerd in het AnyBody Modelling System. In dit systeem is GM-model samen met een invers dynamisch model gecombineerd tot een spier skelet model van de voet en enkel. In de kliniek heeft het model toegevoegde waarde, omdat het bijvoorbeeld kan 


\section{Samenvatting}

meten wat het effect is van het fixeren van een gewricht in de voet op andere gewrichten in de voet.

Concluderend: Dit proefschrift beschrijft de ontwikkeling van het GM-model, een 26 segmenten kinematisch voetmodel. Dit model is gedeeltelijk gevalideerd door het vergelijken met bestaande literatuur door te kijken naar test-hertest betrouwbaarheid en door de beweging van markers door onderliggend zacht weefsel in kaart te brengen. Het GM-model kan zelf gebruikt worden in het onderzoek om meer inzicht te krijgen in de voet en enkel biomechanica en tevens om veranderingen van kinematica na klinische ingrepen te onderzoeken. Tenslotte kan het model gebruikt worden als eerste stap in de keten van modellen om het effect van steunzolen te berekenen. Om deze keten sluitend te maken is echter verder onderzoek noodzakelijk. 
Dankwoord

DANKWOORD 


\section{Dankwoord}

Graag wil ik iedereen bedanken die mij tijdens mijn promotie heeft geholpen, heeft gesteund en heeft bijgedragen in mijn ontwikkeling.

Mijn promotieteam wil ik hartelijk bedanken voor de begeleiding in mijn promotietraject. Lodewijk, je hebt ervoor gezorgd dat ik niet alleen bezig was met interessante technische oplossingen, maar juist met het verder helpen van de klinische praktijk. Ik heb veel respect voor hoe je jouw vele taken combineert: het begeleiden van promovendi in uiteenlopende onderwerpen, het behandelen van jouw patiënten, het leidinggeven aan een grote afdeling in het ziekenhuis, maar vooral het profileren van orthopedie als belangrijke vakgroep. Adhiambo, gedurende mijn promotietraject kwam jij bij het team. De week in Venetië heeft zeker gezorgd voor meer wederzijds begrip tussen die twee nerds aan de ene kant en de artsen aan de andere kant. Dank voor je snelle en grondige feedback tijdens de laatste fase van mijn proefschrift, hierdoor is het proefschrift veel beter geworden. Kenneth, oude Amsterdammert. Toen ik bij jou aanklopte om mij te begeleiden in mijn gefinancierd onderzoek, had ik het avontuur dat we hebben doorlopen om deze promotie af te ronden niet kunnen voorspellen. De trips die we hebben gemaakt voor de vergaderingen van A-footprint en de congressen waren altijd een perfecte balans tussen werk en ontspanning. De brainstormsessies in jouw kamer waren niet alleen goed in het verder brengen van mijn onderzoek, maar ook zeker van mijzelf als mens. Heel veel succes in het nog groter maken van de biomechanica in Maastricht.

De beoordelingscommissie, Prof. dr. Hans Savelberg, Dr. Rosemary Dubbeldam, Dr. Martijn Poeze, Prof. dr. Nicolaas Schaper en Prof. dr. ir. Nico Verdonschot wil ik hartelijk bedanken voor het lezen en beoordelen van mijn proefschrift. Ook de corona wil ik bedanken voor het lezen van mijn proefschrift, jullie aanwezigheid tijdens mijn verdediging en jullie kritische vragen.

Mijn onderzoek was niet mogelijk geweest zonder de metingen aan de proefpersonen. Dank aan de collega's en vrienden voor de trip naar het zuiden en de vele uren die ik aan jullie voeten mocht zitten. Maar zeker ook dank voor de patiënten voor wie het meedoen aan wetenschappelijk onderzoek vaak meer impact heeft dan voor de gezonde proefpersonen. Tijdens elke meting lieten deze patiënten mij inzien wat het nut is van het voetenonderzoek.

Tijdens mijn promotietraject hebben veel studenten geholpen. Jan-Jurre, Paul, Marloes, Robberto, Jorik, Pien en Meike dank voor jullie enthousiaste bijdrage aan het onderzoek. Joost, dank voor al jouw werk aan hoofdstuk 4, ook nadat je project al lang was afgerond was je altijd bereikbaar en bereid om mee te helpen.

Dear colleagues from the A-footprint project. It was great to be part of this project. After each six-month meeting (on great locations, with great food), you gave me an energy boost to continue the research. Jim, Scott, Søren, Amir, Sylvain, thanks for your 
contribution to the research and the papers. Good luck with all your research. I hope that when the moment comes, I need a foot orthosis, it will be designed automatically and 3D printed.

Tijdens mijn werk bij TNO Health and Sports ben ik voor het in eerst in aanraking gekomen met de voet en enkel biomechanica. Ronald, dankjewel voor jouw geduld tijdens mijn introductie in dit vakgebied, en vooral dank voor al jouw werk aan het binnen halen van Afootprint en het werk aan het forward model. Andy, John, Joëlle, Marc, Mark, Merijn, Pamela, Par en Sytze, dank voor jullie introductie in het werkende leven. Helaas is het niet zo met de afdeling gegaan als wij allen hadden gehoopt, maar ik vind het heel fijn om te zien hoe goed iedereen terecht is gekomen.

Mijn eerste collega's in Maastricht van het Medical Field Lab wil ik hartelijk bedanken voor het mij thuis laten voelen in het ziekenhuis. Rianne, dank voor alle goede gesprekken in de trein en je eeuwige rust en je positieve inbreng. Luc, fijn om te zien dat het weer goed met je gaat, heel veel succes met al je spannende avonturen. Jody, tijdens onze tijd bij het MFL heb ik altijd veel opgestoken van jouw ervaring binnen het azM. Ilske, eigenlijk geen onderdeel van het MFL maar de koffiemomentjes zorgden voor een erg welkome afwisseling. Het blijft leuk om jou zo gelukkig te zien samen met Bob. Nick, jammer hoe het zo gelopen is. Maar één ding is zeker, zonder jou was ik nooit gestart met het schrijven van dit boekwerk.

$\mathrm{Na}$ de overgang van het Medical Field Lab naar bewegingswetenschappen kwam ik in een grote onderzoeksgroep terecht. De kritische vragen tijdens de lab-meetings hebben bijgedragen aan het aanscherpen van het onderzoek en ook aan het helder leren uitleggen van mijn soms technische onderzoek. Tom, Herman, Tamar, Hans, Maarten, Marieke, Harry en Desiree, dank voor de fijne samenwerking en de gezelligheid tijdens de ALBAS en andere momenten. Paul dank voor je hulp bij de metingen en het afstellen en installeren van de apparatuur. Alessio, ik vond het altijd erg prettig om op technisch gebied met jou te sparren.

Het grootste gedeelte van mijn tijd bij BW heb ik doorgebracht in kamer 2.2222222220, daar waar de BW-gezellig groep zat. Het was echt een geweldige tijd, waarbij ik de vele vlaaien en taarten zal missen, maar de kilo's die daarbij horen iets minder. De gezellige avonden op stap in Maastricht of Eindhoven, de borrels in onze kamer, het gezamenlijk klagen over onze begeleiders. Ik mis het nu al. Jullie afscheidscadeau, een eigen gemaakt muziekboek, zie ik nog dagelijks met plezier. Brendje, de moeder van onze kamer, dankjewel voor jouw eeuwige vrolijkheid. De taarten op maandagochtend als ik een deadline haalde werden steeds bijzonderder, maar waren bijna altijd "jammie". Waiyan, het rustpunt in de kamer, heel veel succes met het afronden van jouw thesis. Hanzl, je begon met het helpen met mijn experimenten en nog vervelender het segmenteren van 


\section{Dankwoord}

de $\mathrm{CT}$, maar nu ben je bezig met je eigen onderzoek, succes daarmee. Berend, als staande Belg in onze kamer was het soms wennen voor je, maar jouw enthousiasme voor het onderzoek werkte aanstekelijk. Ruudje, zonder dat je het zelf weet heb je iets moois achtergelaten in onze kamer: Ruudje-dag. Deze dag draaide om eten (appelflappen, donuts, chocomel, yoghurt, kip) en bankdrukken. Mijn $40 \mathrm{~kg}$ heb ik nog heel lang moeten aanhoren. En tenslotte, Pietertje, we hebben veel gedeeld: de congressen samen, de frustratie van het uitleggen van biomechanica aan artsen. Alleen de taarten deelden we niet, daarvan pakten we altijd een extra stuk (of drie).

Mijn onderzoek vond niet alleen plaats onder de vlag van BW, maar ook onder die van Orthopedie. Tijdens de ORM en de pizzameetings waren alle cel-praatjes voor mij af en toe lastig te volgen. Maar juist doordat daar verschillende onderzoeksvelden samenkomen, ontstonden de creatieve ideeën. De cake van de week zorgde voor een goed moment van pauze op donderdag. En ook de lab-uitjes waren altijd erg leuk. Alex, Andy, Bernhard, Chris, Don, Eva, Ilona, Jim, Joris, Maarten, Marjolein, Marloes en Tim, dank voor de goede tijd bij orthopedie. Jerney, dankjewel voor je hulp bij het regelen van alle administratie voor het afronden van dit proefschrift.

Mijn huidige collega's bij Gupta wil ik heel erg bedanken voor het geduld dat jullie hebben gehad met het afronden van dit proefschrift. Maar vooral voor het geven van de ruimte die ik heb ervaren om het af te kunnen ronden. Ik ben erg blij met jullie als collega's, en vooral de energie die ik elke dag krijg van het werken met jullie.

Frans Brooijmans, je hebt er niet alleen voor gezorgd dat ik weer pijnvrij door het leven kan, maar je was zeker ook een ongelofelijke motivator om dit onderzoek af te ronden. Ik gun het je van harte dat je prachtige werk bij patiënten ook zal leiden tot een proefschrift. Uiteraard wil ik ook al jouw collega's danken voor hun behandelingen en enthousiasme. Mijn hockeyteams van de afgelopen jaren wil ik erg bedanken voor het zorgen voor afleiding en momenten om het werk van mij af te zetten. $H X, D 2$, en nu ook het team in Utrecht dank!

Bestuur: Gijs, Marnix, Bram, Mariska en Kitty, 13 jaar geleden kwamen we voor het eerst samen in de keuken van mijn studentenhuis. Het blijft bijzonder hoe zes verschillende mensen toch een hechte groep kunnen zijn. Ik geniet nog altijd van de momenten dat we elkaar zien.

Lieve Tackelaars, tijdens mijn eerste jaren in Eindhoven hebben jullie ervoor gezorgd dat mijn ouders toch nog goede nachtrust hebben gehad, ondanks het feit dat hun 17 -jarige zoon in zijn eentje op kamers zat. Maar niet alleen hun hebben jullie een goede tijd bezorgd, ook mijn studententijd is daardoor een geweldige periode geweest. De bata, hart van Brabant, weekendjes weg, bezoekjes op elkaars stageadres, ik denk er met veel plezier aan terug. Ik zie niet iedereen van jullie meer even vaak, maar gelukkig is het jaarlijkse 
tackelweekend ondertussen een traditie geworden, en ook in de sneeuw is het erg goed vertoeven met jullie. Het verbreken van mijn afspraak met Mariko heeft me $€ 100$ gekost, maar die $€ 100$ is dit proefschrift zeker waard.

Lieve vrienden van de eetclub, door mijn verhuizing naar Utrecht komt het eten en koken er de laatste tijd niet veel meer van. Duncan, (dikke) Els, Jappie, Judith, Joepie en Marloes, dank jullie wel voor het aanhoren van mijn verhalen over mijn promotie en het advies dat jullie altijd gaven tijdens de gezellige avonden samen.

Lieve krentenbroodjes, ik vind het geweldig dat we ook na onze middelbare schooltijd elkaar nog af en toe zien. Heel mooi om te zien hoe iedereen zijn eigen weg op is gegaan. Theo, Ans, Ronald, Maaike, Bloem, Lente, Matthijs, Afke en June, dank voor het warme welkom in jullie familie. Ondanks het feit dat we net iets verder wonen dan jullie zouden willen, genieten we van elk moment met jullie. Jullie belangstelling voor en het vragen naar de status van mijn proefschrift werkte als goede stok achter de deur.

Pap, Mam, Ann, Frank, Naud en Jasmijn, jullie wil ik bedanken voor jullie bijdrage aan wie ik ben. Pap en mam, super fijn dat jullie altijd achter me staan ongeacht welke keuze ik maak. Ik vind het een prachtig uitgangspunt van jullie dat de hersenen die je hebt gekregen een gegeven zijn, maar wat je ermee doet aan je zelf ligt. Frank \& Ann, dankjewel voor al jullie hulp, ondersteuning en motivatie. Naud en Jasmijn, jullie vrolijkheid en openheid werkt aanstekelijk.

Bram en Annemarije, dank jullie wel voor jullie steun tijdens deze periode. Ik vind het heel bijzonder dat jullie mijn paranimfen willen zijn. De oplettende lezer heeft jullie namen hierboven ook al een aantal keer voorbij zien komen. Brammetje, studievriend, bestuursgenoot, teamgenoot, je blijft een bijzondere vriend. Heerlijk hoe jij in het leven staat. Annemarije, zusje, collega, maar vooral vriendin, dank voor de fijne gesprekken die ik met je kan hebben.

En tot slot, Elske. Je maakt het leven zoveel mooier. Dankjewel voor al jouw geduld. Toen ik je leerde kennen was ik mijn proefschrift aan het afronden en nu, ruim 2 jaar later, is het dan ook daadwerkelijk gelukt. Jouw steun en liefde hebben ervoor gezorgd dat ik nu kan zeggen dat ik het proefschrift ook daadwerkelijk heb afgerond. Ik kijk ernaar uit om de tijd die ik nu over houd aan leuke dingen met jou te besteden. 

About the author

ABOUT THE AUTHOR 


\section{About the author}

Michiel Oosterwaal was born in Rozenburg on March 14th 1983. He attended secondary school at GSG Helinium in Hellevoetsluis and graduated in 2000. He studied biomedical engineering at Eindhoven University of Technology and received his master degree in 2007 with a thesis in the field of cardiovascular biomechanics.

After graduation Michiel worked at TNO, Netherlands Organisation for Applied Scientific Research, at the department of Health and Sports. At TNO he started his research in the field of foot and ankle biomechanics. In 2009 and 2010 he worked at the Medical Field Lab in Maastricht as innovation case manager, where he worked on valorisation of scientific research and partly on the scientific research as presented in this thesis.

In January 2011 he started his PhD trajectory at the department of Human Movement Sciences and the department of Orthopaedics of the Maastricht University Medical Centre. Michiel has conducted his PhD research in NUTRIM school for Nutrition, Toxicology and Metabolism and CAPHRI school for Public Health and Primary Care. This PhD trajectory was part of the A-Footprint project, a FP7 European project to automate processes to speed up the manufacturing, delivery and supply of personalised devices exploiting digital scanning, computer-aided design and rapid manufacturing.

Michiel currently lives in Utrecht and works as a strategist at Gupta Strategists, a strategy consultancy firm focused on healthcare. 